\author{
Aus dem Institut für Humangenetik \\ kommissarische Leitung Prof. Dr. Bernd Wollnik \\ im Zentrum Hygiene und Humangenetik \\ der Medizinischen Fakultät der Universität Göttingen
}

\title{
Zur Charakterisierung von Stra8 - Cre - transgenen Mäusen
}

\author{
INAUGURAL - DISSERTATION \\ zur Erlangen des Doktorgrades \\ der Medizinischen Fakultät der \\ Georg - August - Universität zu Göttingen
}

vorgelegt von

Romy Graner

aus Heilbronn

Göttingen 2015 
Dekan:

I. Berichterstatter: Prof. Dr. med. Dr. h.c. W. Engel

II. Berichterstatter/in:

II. Berichterstatter/in:

Tag der mündlichen Prüfung:
Prof. Dr. rer.nat. H. K. Kroemer 


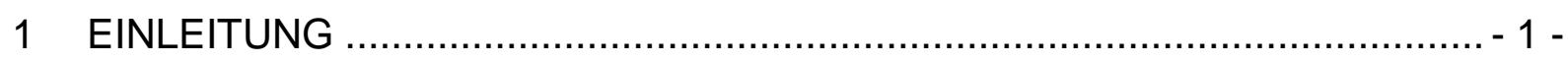

1.1 Stammzellen und Regeneration ....................................................... - 1 -

1.2 Adulte residente Stammzellen .......................................................... - 1 -

1.3 Wanderung von Zellen und Stammzellen ............................................. - 2 -

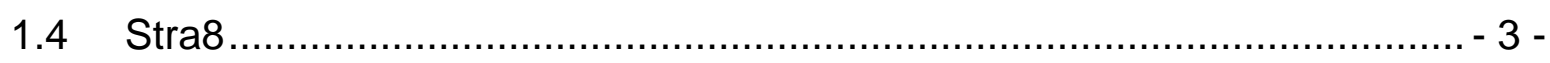

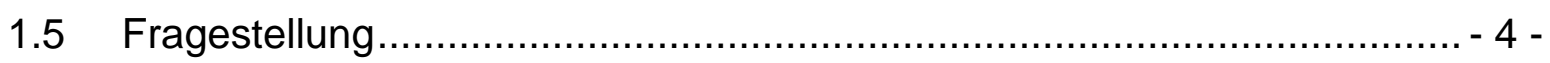

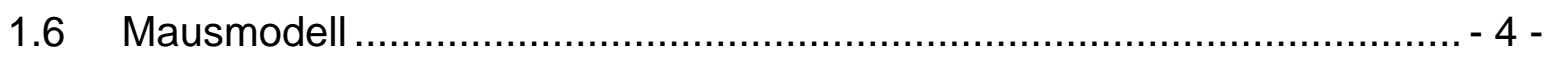

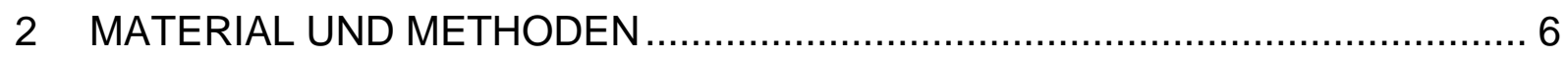

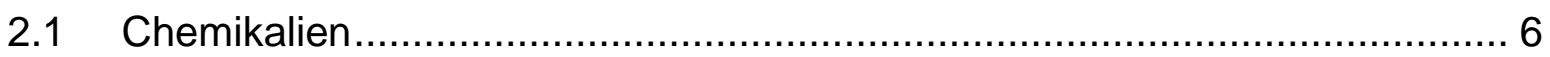

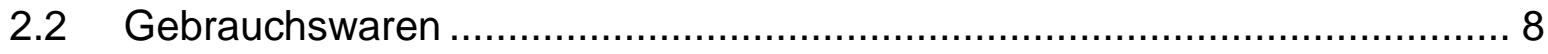

2.2.1 Gebrauchswaren für die Zellkultur .............................................. 8

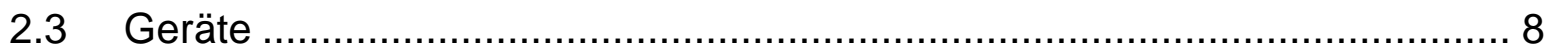

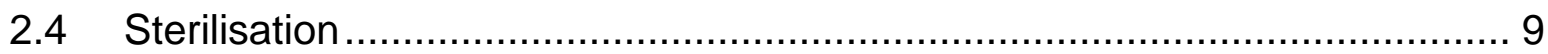

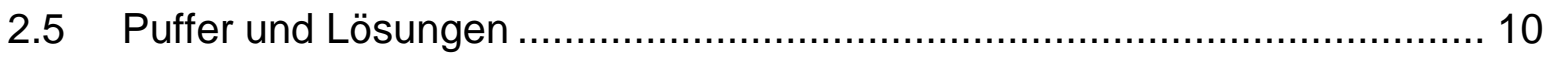

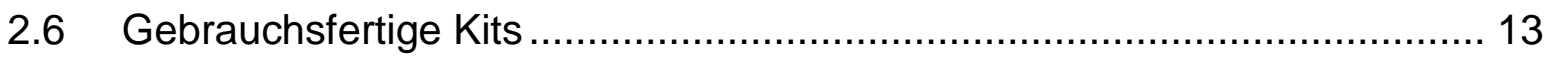

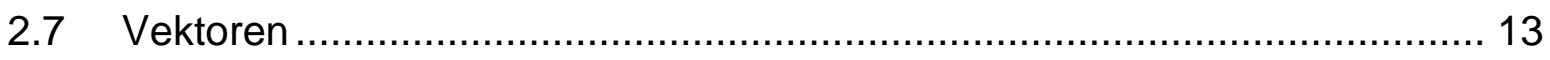

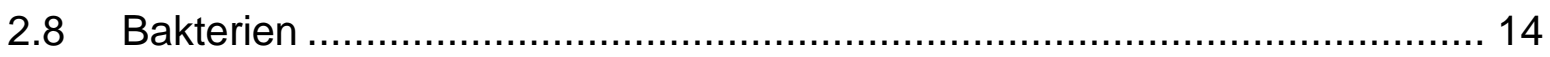

2.8.1 Medien für die Bakterienkultur .......................................................... 14

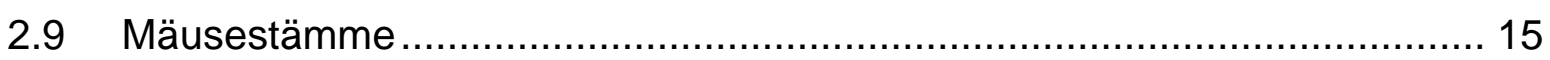

2.10 Eukaryotische Zelllinien .............................................................. 15

2.10.1 Medien für die Zellkultur ......................................................... 15

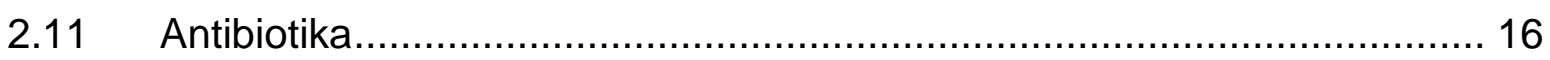

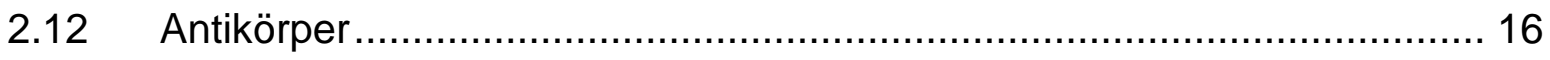

2.13 Oligonukleotide ........................................................................ 17

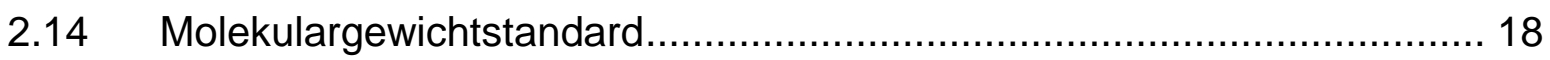

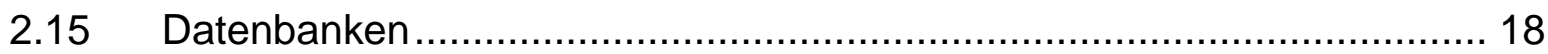




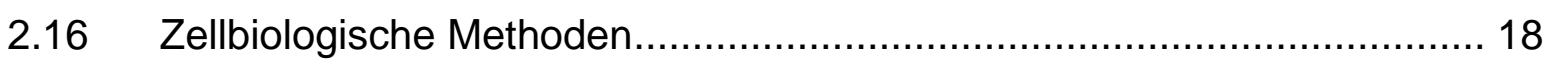

2.16.1 Kultivierung von murinen embryonalen Stammzellen (ES-Zellen)..... 18

2.16.2 Gewinnung und Kultivierung von murinen embryonalen Fibroblasten 18

2.16.3 Auftauen und Einfrieren von eukaryotischen Zellen......................... 19

2.16.4 Passagieren von eukaryotischen Zellen ........................................ 19

2.16.5 MitomycinC-Behandlung von embryonalen Fibroblasten................... 20

2.16.6 Transfektion mit Lipofectamin ................................................... 20

2.17 Isolierung und Aufreinigung von Nukleinsäuren ................................... 21

2.17.1 Isolierung von RNA aus Geweben............................................. 21

2.17.2 Herstellung von komplementärer DNA durch Reverse Transkription. 21

2.17.3 Isolierung von genomischer DNA aus Mäuseschwänzen und Gewebe

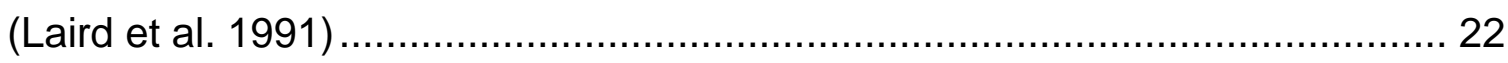

2.17.4 Minipräparation von Plasmid-DNA aus Bakterien ............................. 22

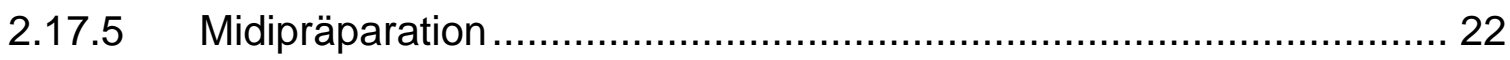

2.17.6 Isolierung von DNA- Fragmenten aus Agarosegelen........................ 23

2.18 Konzentrationsbestimmungen von Nukleinsäuren ................................ 23

2.19 Enzymatische Modifikation von DNA.................................................. 23

2.19.1 Restriktionsspaltung von Plasmid-DNA ...................................... 23

2.20 Polymerasekettenreaktion ............................................................ 24

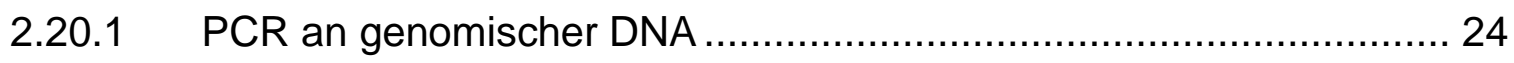

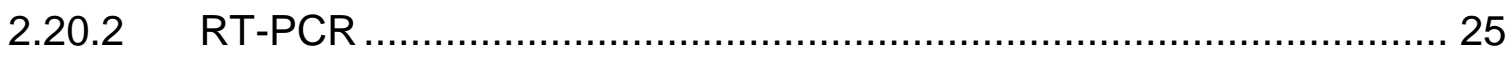

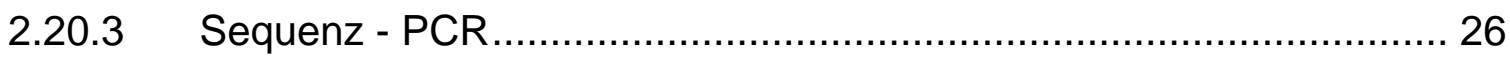

$2.21 \quad$ Klonierung von DNA - Fragmenten .................................................. 27

2.21.1 Ligation von PCR-amplifizierten DNA-Fragmenten......................... 27

2.21.2 Transformation, modifiziert nach Hanahan 1983 ............................. 27

$2.22 \quad$ Horizontale Gelelektrophorese ................................................... 27

2.23 Histologische Methoden ............................................................... 28 


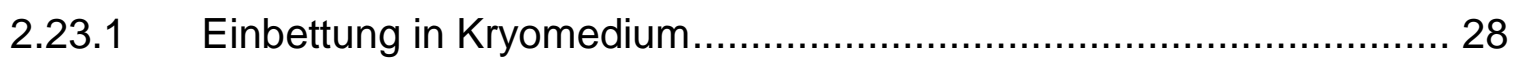

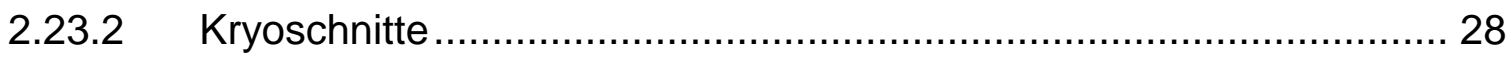

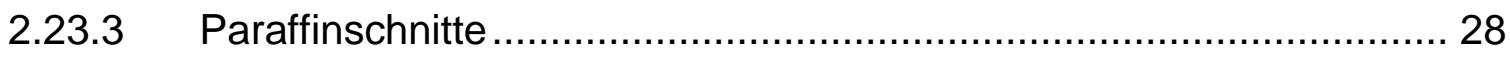

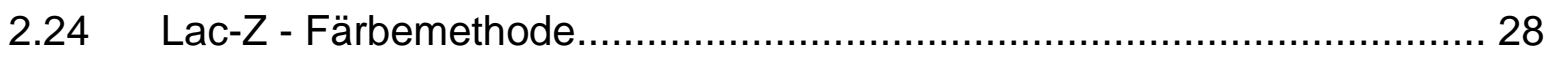

2.24.1 Protokoll 1 (für ganze Organe und Schnittfärbungen)..................... 28

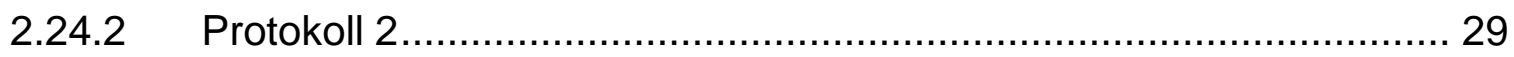

2.24.3 Lac Z Kit der Firma InvivoGen ........................................... 29

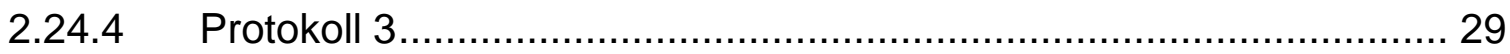

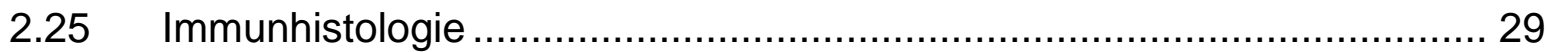

2.26 HE-Färbung (Hämatoxylin-Eosin-Färbung) ..................................... 30

2.27 Messung der Luziferaseaktivität ..................................................... 30

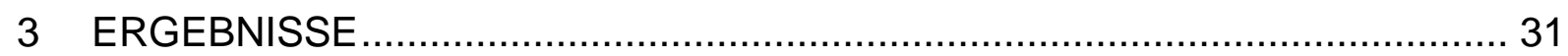

3.1 Untersuchung und Genotypisierung der Stra8-Cre/R26R - Mäusen........... 31

3.1.1 Genotypisierung von Stra8-Cre/R26R - Mäusen durch Rückkreuzung. 31

3.2 Nachweis von LacZ - Expression durch X - Gal - Färbung ...................... 34

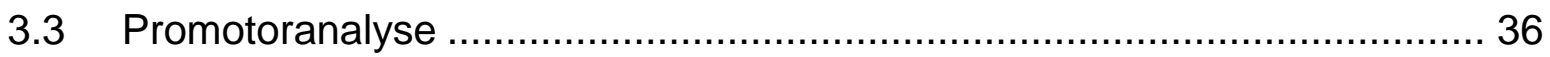

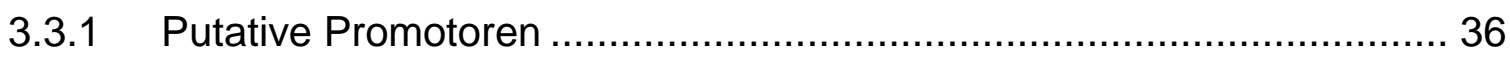

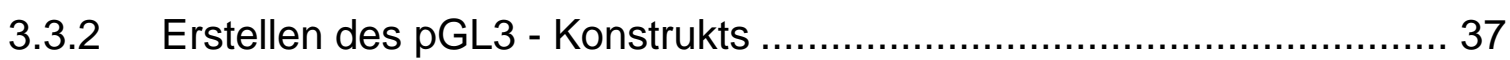

3.4 Expressionsanalysen von LacZ in doppelt transgenen Mäusen................ 43

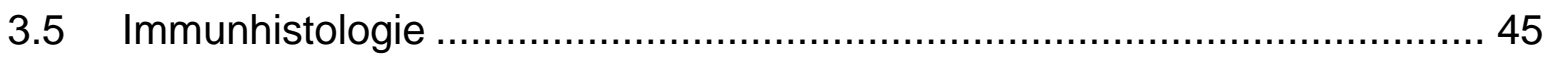

3.5.1 Testes in verschiedenen Entwicklungsstufen............................... 45

3.5.2 Nachweis von LacZ in den verschiedenen Organen........................ 49

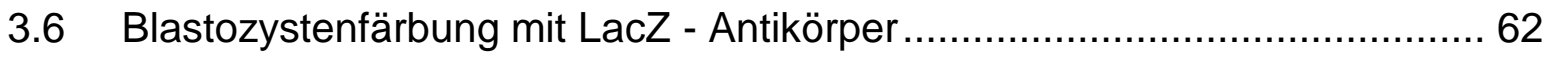

3.7 Geschlüpfte Blastozysten mit LacZ - Antikörperfärbung .......................... 63

3.8 Färbung von Embryonen 13,5 dpc mit X - Gal ................................... 64

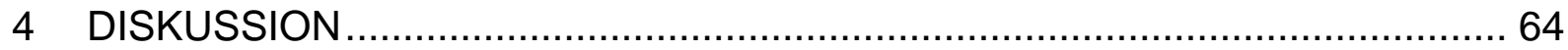

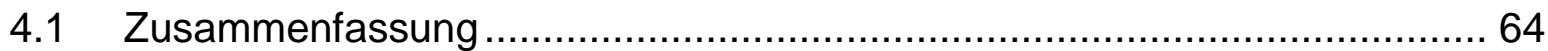




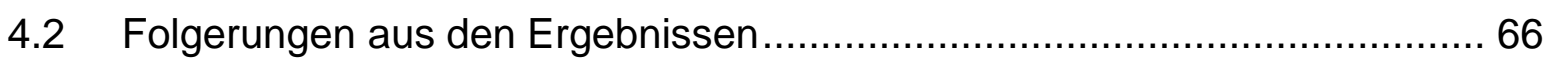

4.3 Begründung des Verwerfens der ursprünglichen Hypothese ..................... 69

4.4 Lösungsmöglichkeit der Fragestellung .................................................. 73

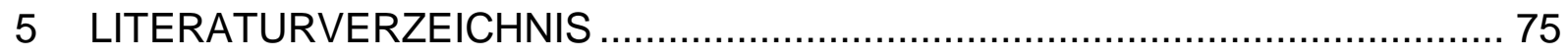

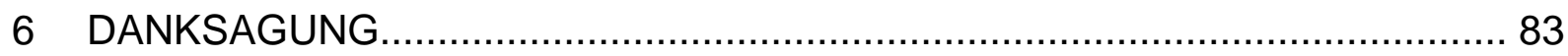




\section{ABBILDUNGS - UND TABELLENVERZEICHNIS}

Abb. 1:

Abb. 2:

Abb. 3:

Abb. 4:

Abb. 5:

Abb. 6:

Abb. 7:

Abb. 8:

Abb. 9:

Abb. 10:

Abb. 11:

Abb. 12:

Abb. 13:

Abb. 14:

Abb. 15:

Abb. 16:

Abb. 17:

Abb. 18:

Abb. 19:
Konstruktion der Stra8 - Cre/R26R - transgenen Maus

PCR - Analyse zur Genotypisierung des Gewebes der Stra8Cre/R26R - Mäuse mithilfe ihrer Nachkommen

PCR - Analyse derselben Proben wie in Abbildung 2

Genotypisierung des Gewebes einer homozygoten männlichen Stra8 - Cre/R26R - Maus

Genotypisierung des Gewebes einer heterozygoten weiblichen Stra8 - Cre/R26R - Maus

Histologie des Gewebes einer Stra8 - Cre/R26R - Maus nach XGal Färbung

Putative Promotorbereiche von Stra8

Basic Vektor

Enhancer Vektor

Promotor Vektor

Control Vektor

Testverdau pGL3 - Basic - Vektor

Testverdau pGL3 - Control - Vektor

Testverdau pGL3 - Enhancer nach Ligation

Testverdau der einzelnen Konstrukte in pGL3 - Enhancer

Luziferasemessung

Reverse Transkriptase PCR

HPRT - PCR

Immunhistologie in der Testesentwicklung der heterozygoten Stra8 - Cre/R26R - Maus von Tag 0 bis Tag 20 
Abb. 20: Immunhistologie in der Testesentwicklung der homozygoten Stra8 - Cre/R26R - Maus von Tag 0 bis Tag 20

Abb. 21: Immunhistologie in der Testesentwicklung der Stra8 - Cre/R26R Maus nur mit 2. Antikörper (negativ Kontrolle)

Abb. 22: Immunhistologie des Gewebes der heterozygoten Stra8 Cre/R26R - Maus

Abb. 23: Immunhistologie des Gewebes der heterozygoten Stra8 Cre/R26R - Maus

Abb. 24: $\quad$ Immunhistologie des Gewebes der homozygoten Stra8 Cre/R26R - Maus

Abb. 25: Immunhistologie des Gewebes der homozygoten Stra8 Cre/R26R - Maus

Abb. 26: Immunhistologie des Gewebes der Rosa26 - LacZ - Maus als Positivkontrolle

Abb. 27: Immunhistologie des Gewebes der Rosa26 - LacZ - Maus als Positivkontrolle

Abb. 28: Immunhistologie des Gewebes des Gewebes der Stra8 - Cre Maus als Negativkontrolle

Abb. 29: Immunhistologie des Gewebes der Stra8 - Cre - Maus als Negativkontrolle

Abb. 30: Immunhistologie des Gewebes der R26R - Maus als Negativkontrolle

Abb. 31: Immunhistologie des Gewebes der R26R - Maus als Negativkontrolle

Abb. 32: Immunhistologie des Gewebes der WT Maus als Negativkontrolle

Abb. 33: $\quad$ Immunhistologie des Gewebes der WT Maus als Negativkontrolle

Abb. 34: $\quad$ Blastozystenfärbung

Abb. 35: $\quad$ Geschlüpfte Blastozysten der Stra8 - Cre/R26R - Maus 
Abb. 36: $\quad X$ - Gal - Färbung von Embryonen 13,5 dpc der Stra8 - Cre/R26R - Maus und einer WT - Maus als Negativkontrolle

Abb. 37: $\quad$ Struktur des Stra8 - Proteins

Tab. 1:

Auswahl keimzellspezifischer Gene, die in pluripotenten Zellen exprimiert werden 


\section{ABKÜRZUNGSVERZEICHNIS}

\begin{tabular}{|c|c|}
\hline AK & Antikörper \\
\hline AMP & Adenosinmonophoaphat \\
\hline ATP & Adenosintriphospat \\
\hline bp & Basenpaare \\
\hline BSA & Rinderserumalbumin \\
\hline${ }^{\circ} \mathrm{C}$ & Grad Celsius \\
\hline cDNA & komplementäre DNA \\
\hline CTP & Cytidin-5‘-triphosphat \\
\hline$d$ & Tag \\
\hline DAPI & 4‘,6'- Diamidino-2-Phenylindolhydrochlorid \\
\hline dATP & Desoxyadenosintriphosphat \\
\hline $\mathrm{dCTP}$ & Desoxycytidintriphosphat \\
\hline dest. & destilliert \\
\hline dGTP & Desoxyguanosintriphosphat \\
\hline DMEM & Dulbecco's Modifiziertes Eagle Medium \\
\hline DMSO & Dimethylsulfoxid \\
\hline DNA & Desoxyribonukleinsäure \\
\hline DNase & Desoxyribonuklease \\
\hline dNTPs & Desoxynukleotidtriphosphate \\
\hline$d p c$ & days post coitum \\
\hline$d p p$ & days post partum \\
\hline dsDNA & doppelstrang DNA \\
\hline DTT & Dithiothreitol \\
\hline dTTP & Desoxytymidintriphosphat \\
\hline
\end{tabular}




$\begin{array}{ll}\text { E.Coli } & \text { Escherichia Coli } \\ \text { E-Cup } & \text { Eppendorf - Cup } \\ \text { EDTA } & \text { Ethylendiamintetraessigsäure } \\ \text { EGC } & \text { embryonic germ cells } \\ \text { EGFP } & \text { enhanced green fluoruescent protein } \\ \text { EM } & \text { Elektronenmikroskop }\end{array}$

ES-Zellen embryonale Stammzellen

ESC embryonic stem cell

et al. et alii

$\mathrm{EtOH} \quad$ Ethanol

FKS fötales Kälberserum

g Gramm

$x \mathrm{~g} \quad$ Erdbeschleunigung $\left(9,81 \mathrm{~m} / \mathrm{s}^{2}\right)$

h Stunde

HE Hämatoxylin-Eosin

HPRT Hypoxanthin-Phosphoribosyl-Transferase

Hrs Herausgeber

ICM inner cell mass

IU international unit

$\mathrm{kb} \quad$ Kilobasenpaare

I Liter

LB Luria-Bertani

LIF Leukämi inhibierender Faktor

Lsg. Lösung

M Molar ( $\mathrm{mol} / \mathrm{l})$

maGSC multipotent adult germline stem cell

MEF mouse embryonic fibroblast 


\begin{tabular}{ll} 
min & Minute \\
MPI & Max - Planck - Institut \\
mRNA & messenger - Ribonukleinsäure \\
$\mu$ & mikro \\
n & nano \\
PBS & phosphatgepufferte Salzlösung \\
PCR & Polymerase-Kettenreaktion \\
PFA & Paraformaldehyd \\
PGC & primordial germ cell \\
pH & pH - Wert \\
PPi & Pyrophosphat \\
RNA & Ribonukleinsäure \\
RNase & Ribonuklease \\
Rpm & Rotationen pro Minute \\
RT & Raumtemperatur \\
RT-PCR & Reverse Transkriptase PCR \\
SDS & Natriumdodecylsulfat \\
SSC & spermatogonial stem cell \\
Std. & Stunde \\
SV 40 & Simian - Virus 40 \\
TBE & Tris-Borat-EDTA (-Puffer) \\
TE & Tris-EDTA (-Puffer) \\
Tris & Tris-hydroxymethyl-aminomethan \\
U & unit \\
UMG & Universitätsmedizin Göttingen \\
UV & ultraviolett \\
V & Volt \\
\hline
\end{tabular}


WT Wildtyp

X - Gal 5-Brom-4-Cholr-3-indolyl- $\beta$-Galactopyranosid

\section{Code der Nukleinsäuren}

$\begin{array}{ll}\text { A } & \text { Adenosin } \\ T & \text { Thymin } \\ \mathrm{G} & \text { Guanin } \\ \mathrm{C} & \text { Cytosin } \\ \mathrm{U} & \text { Uracil }\end{array}$




\section{EINLEITUNG}

\subsection{Stammzellen und Regeneration}

Wir leben in einer ständig älter werdenden Gesellschaft. Folgen dieses erhöhten Lebensalters sind unter anderem eine Verschiebung der Erkrankungen hin zu degenerativen Veränderung im Körper. So ist zum Beispiel die ischämische Herzkrankheit die führende Todesursache in der Welt (Murray und Lopez 1997). Allein in Europa machen Herz-Kreislauferkrankungen 40\% aller Todesfälle der unter 75-Jährigen aus (Sans et al. 1997). Trotz Verbesserung der Akutversorgung und der daraus resultierenden Minderung der Spätfolgen sind die ischämisch bedingten Schäden im Herzgewebe bisher nicht reparabel. Die Idee der regenerativen Medizin ist es nun, gezielt körpereigene Regenerationsprozesse anzusprechen und somit dem Körper mit eigenen Mitteln zur Heilung zu verhelfen und funktionsgestörte Zellen, Gewebe und Organe wieder zu reparieren. In der physiologischen Regeneration spielen Stammzellen eine wichtige Rolle. So sind beispielsweise hämatopoetische Stammzellen dafür verantwortlich, dass wir ein Leben lang unsere Blutzellen und Immunzellen erneuern können. Aber auch während der Embryonalzeit dienen Stammzellen als Ursprung aller weiteren Zelltypen, aus denen sich der neue Organismus aufbaut. Es ist daher eine innovative Idee, Stammzellen als körpereigene Ressourcen gezielt bei degenerativen Veränderungen im Körper zu nutzen und hierfür neue klinische Verfahren zu entwickeln.

\subsection{Adulte residente Stammzellen}

Unter all den verschiedenen Stammzelltypen sind die adulten Stammzellen für die körpereigene Regeneration am interessantesten. Obwohl diese im Gegensatz zu embryonalen Stammzellen (ESCs embryonic stem cells) nur noch in festgelegtes Gewebe ausdifferenzieren können, bilden sie eine unerschöpfliche körpereigene Quelle, die in den einzelnen Organen bereits vorliegt (z.B. hämatopoetische Stammzellen) und nicht wie bei ESCs erst generiert werden müssen. Da in Deutschland humane Embryonen unter das Embryonenschutzgesetz fallen, ist die Generierung und das Arbeiten mit pluripotenten Zellen streng gesetzlich geregelt. So ist die Gewinnung von humanen ESCs in Deutschland generell verboten. Es dürfen auch nur humane ESCs aus dem Ausland zu Forschungszwecken eingeführt werden, die vor dem 01.05.2007 generiert wurden. Ein weiteres Problem der ESCs 
ist, dass sie sich gegenüber dem Empfänger der Zellen immunologisch unterscheiden. Dies kann bei Transplantationen zu erheblichen immunologischen Abwehrreaktionen führen, die bis hin zur Tumorbildung reichen können. Aufgrund dieser technischen und moralischen Aspekte eignen sich ESCS derzeit kaum bei regenerativen Einätzen. Adulte Stammzellen hingegen sind körpereigen, stimmen immunologisch mit dem Empfängerorganismus überein und führen bei autologen Transplantationen zu keinen immunologischen Fremdreaktionen. Die gewonnenen Zellen und die Empfänger sind immunologisch identisch. Hämatopoetische Stammzellen sind adulte Stammzellen, die bereits sehr ausführlich erforscht sind. Sie sind im Knochenmark angesiedelt, dienen als Ursprungszellen aller Blut - und Abwehrzellen und sorgen für die regelmäßige Erneuerung der hämatopoetischen Subpopulationen. Therapeutisch werden sie bereits bei Leukämien eingesetzt. Hierbei werden vor einer Strahlen - oder Chemotherapie dem Patienten gesunde Stammzellen entnommen und diese nach Therapie, wenn das blutbildende System stark minimiert ist, wieder zugefügt. Dieses Verfahren, das bereits vor 40 Jahren eingeführt wurde, machte eine Hochdosis Chemotherapie erst möglich.

In anderen Organen gibt es ebenfalls adulte Stammzellen. So wurden bereits Stammzellen in Haut, Leber, Gehirn und Bauchspeicheldrüse beschrieben (Gage 2000; Crosby und Strain 2001; Joannides et al. 2004; Kruse et al. 2006). Residente Stammzellen im Herzen sind ebenfalls bekannt (Beltrami et al. 2003). Jedoch werden diese Zellen bei pathologischen Zuständen, wie z.B. Myokardinfarkt, nicht ausreichend stimuliert und tragen daher kaum zur Regeneration nach Insult bei. Daher reicht ihr Potential für Reparaturmaßnahmen nicht aus. Grundlage der Überlegung dieser Arbeit ist, ob man auf andere Stammzellpopulationen des Körpers zurückgreifen kann. Dabei wären adulte Stammzellen, die wie ESCs Pluripotentz aufweisen, die ideale Lösung für einen therapeutischen Ansatz.

\subsection{Wanderung von Zellen und Stammzellen}

Zellwanderung spielt in der Embryonalentwicklung eine entscheidende Rolle. Nach der Verschmelzung der beiden Vorkerne bildet sich zunächst eine zweiblättrige Keimscheibe, bestehend aus Hypoblast und Epiblast. Zwischen Tag 6 und 7,5 der Embryonalentwicklung der Maus findet die Gastrulation statt. Dabei bildet die bis dahin zweiblättrige Keimscheibe eine zusätzliche räumliche Orientierung aus und der Epiblast differenziert sich in die drei Keimblätter: Ektoderm, Mesoderm und 
Endoderm. Für die Trennung in die verschiedenen Keimblätter lösen sich Zellen aus dem epithelialen Zellverband des Epiblasten und wandern auf die Primitivrinne zu, stülpen sich nach innen und bilden zwischen Epiblast und Hypoblast eine neue Zellschicht, das Mesoderm. Am Ende der Primitivrinne befindet sich der Primitivknoten. Von dort lösen sich ebenfalls Zellen aus inrem Verband, wandern nach kranial ab, drängen dabei den Hypoblasten nach lateral ab und bilden so das innerste Keimblatt, das Endoderm. Die verbleibende oberste (dorsale) Schicht bildet das Ektoderm. Bei der Gastrulation kommt es gleichzeitig zur irreversiblen Trennung von Keimbahnzellen und somatischen Zellen. Der Embryo hat nun eine räumliche Orientierung in alle drei Achsen und differenziert zwischen Keimbahnzellen, die die volle Erbinformation an die nächste Generation weitergeben, und zwischen somatischen Zellen, aus denen sich Zellverbände ausdifferenzieren. Im adulten Organismus tritt dieses Phänomen in abgeschwächter Form noch immer auf. So wandern zum Beispiel Immun - und Abwehrzellen an den Ort der Entzündung. Aber auch Keimbahnzellen können wandern. Derzeit ist es noch vorherrschende Lehrbuchmeinung, dass Oozyten embryologisch angelegt werden und als primäre Oozyten einen Mitosearrest in der Prophase der ersten Reifeteilung machen. Erst mit der Pubertät unter hormoneller Einwirkung reifen einzelne Oozyten heran und vollenden die erste Reifeteilung. Durch den Eisprung kommt es zur Einleitung der zweiten Reifeteilung, die mit der Befruchtung abgeschlossen wird. So sind alle Oozyten bereits embryonal angelegt und können nicht nachgebildet werden. (Green und Zuckerman 1951; Borum 1961; Peters 1970; McLaren 1984; Anderson und Hirshfield 1992) Diese Auffassung wird zur Zeit unter Fachleuten kontrovers diskutiert. Neuste Forschungsergebnisse deuten nämlich auch auf Stammzellen im Ovar hin (Johnson et al. 2004). So konnte diese Arbeitsgruppe um Johnson ein Jahr später zeigen, dass sich auch Oozyten regenerieren können. Sie konnten an einem Mausmodell Keimbahnzellen nachweisen, die aus dem Knochenmark einwandern und sich im Ovar niederlassen, um dort die Oozytenproduktion wieder aufzunehmen (Johnson et al. 2005). Auf diesen Aspekt soll später in der Diskussion noch einmal näher eingegangen werden.

\subsection{Stra8}

Stra8 (stimulated by retinoic acid gene 8) ist ein bekannter Keimbahnzellmarker, der ausschließlich in prämeiotischen Spermatogonien von adulten männlichen Mäusen und in prämeiotischen Folikeln von weiblichen Mäusen exprimiert wird. Unsere 
Arbeitsgruppe konnte aus dem Hoden adulter Mäuse spermatogoniale Stammzellen (SSCS) gewinnen, die nach Kultur und Reprogrammierung in vitro ähnliche Eigenschaften wie ESCs aufweisen und als, multipotent adult germ - line stem cells (maGSC) bezeichnet werden. Für die Isolierung der SSCs - enthaltenden Keimbahnpopulationen existieren in unserer Arbeitsgruppe bereits zwei transgene Mauslinien, Stra8 - EGFP sowie Stra8 - EGFP/Rosa26, die mit dem keimzellspezifischen Promotor $(1,4 \mathrm{~kb})$ ausgestattet sind. Die daraus gewonnenen maGSCs können in vitro in alle drei Keimblätter differenzieren und in immundefizienten Mäusen Teratome bilden (Guan et al. 2006). Die daraus differenzierten Kardiomyozyten exprimieren myozytäre Marker, generieren Aktionspontentiale und setzten spontan Calcium aus dem noch unreifen sarkoplasmatischen Retikulum frei, was eine Eigenschaft unreifer Kardiomyozyten ist. Auch weisen die differenzierten Gefäßmuskelzellen SM - a - Aktin und SM Myosin heavy chain auf und die Endothelzellen CD31, VEGF - Rezeptoren und Von Willebrand - Faktor. Dies sind jeweils gewebsspezifische Marker (Streckfuss Bomeke et al. 2009). Ungeklärt ist, ob maGSCs auch in vivo in Herzmuskelzellen und vaskuläre Zellen differenzieren können (Guan und Hasenfuss 2007; Cheng et al. 2012)

\subsection{Fragestellung}

Aus diesem Kontext heraus ergab sich nun die Fragestellung der vorliegenden Arbeit: Ist es möglich, dass Stammzellen aus dem Hoden auswandern, sich in geschädigtem Gewebe ansiedeln, ausdifferenzieren und in den Zellverband wieder integrieren können?

\subsection{Mausmodell}

Um die oben genannte Fragestellung zu bearbeiten, wurde eine doppelt transgene Mauslinie Stra8/R26R generiert, die durch die Kreuzung zweier transgener Linien erzeugt worden war, und zwar die Stra8 - Cre - Linie und die R26R - Linie. Die beiden Linien werden im Folgenden näher beschrieben (siehe auch Abb.1). In der R26R - Linie (Soriano 1999) wird die Expression des eingebrachten beta Galactosidase - Gens von dem ROSA26 - Promotor reguliert und im Normalfall durch die vorangeschaltete Stoppsequenz blockiert und nicht abgelesen. Diese Stoppsequenz wird von zwei loxP - Sequenzen eingeschlossen. Diese von loxP flankierte Stoppsequenz kann mit einer Cre - Rekombinase herausgeschnitten 
werden, so dass es zu einer Expression von LacZ kommt. Die Stra8 - Cre - Linie exprimiert eine solche Cre - Rekombinase unter der Kontrolle des 1,4 kb Stra8 Promotors. Werden nun die beiden transgenen Linien miteinander verpaart, so wird die Stoppsequenz überall dort herausgeschnitten, wo der Stra8 - Promotor entweder gerade aktiv ist oder in Vorläuferzellen aktiv war, da die Excision nicht reversibel ist. Dieses kann dann durch den Nachweis der LacZ - Expression sichtbar gemacht werden. Als Positivkontrolle wurde eine ROSA26 - LacZ - Linie verwendet, die ein der R26R - Linie identisches LacZ - Insert hat, welches jedoch über kein LoxP flankiertes Stoppkodon verfügt und daher LacZ ubiquitär exprimiert (Friedrich und Soriano 1991; Zambrowicz et al. 1997).

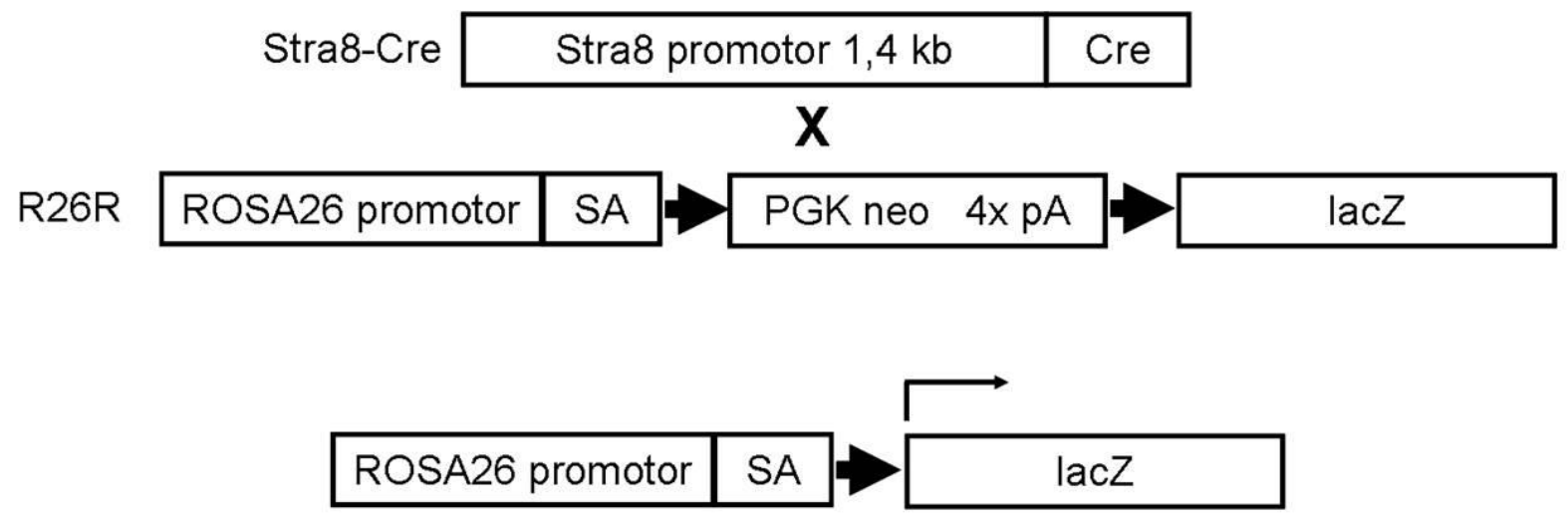

Abb. 1: Konstrukt der Stra8 - Cre / R26R - transgenen Maus.

Das in die R26R - transgenen Mauslinien eingebrachte LacZ - Gen wird von dem ROSA26 - Promotor reguliert und durch die vorgeschaltene Stoppsequenz blockiert. Um diese Stoppsequenz sind zwei LoxP - Sequenzen lokalisiert, die durch eine Cre - Rekombinase herausgeschnitten werden können.

Die Stra8 - Cre - Maus hat eine solche Cre - Rekombinase, die unter der Kontrolle des 1,4 kb Promotors von Stra8 steht. Werden die Tiere nun verpaart, schneidet die Cre - Rekombinase, sobald der Promotor von Stra8 aktiv ist, die LoxP - Sequenz der R26R - Maus heraus. In der Folge kommt es zu einer Expression von LacZ. 


\section{MATERIAL UND METHODEN}

\subsection{Chemikalien}

1kb-DNA-Leiter

Agar

Agarose

Ampicillin

Ampuwa

BSA

Collagenase

DH5a-kompetente Zellen

DMEM

DMSO

dNTPs

EDTA

Eosin

Ethanol

Ethidiumbromid

Eukitt

FKS

Gelatine

Geneticin G418

Glutaraldehyd

Hämatoxilin

Hefeextrakt

IPTG

Isopropanol
Invitrogen, Groningen, Niederlande

Roth, Karlsruhe

Invitrogen, Groningen, Niederlande

Roth, Karlsruhe

Fresenius AG, Bad Homburg

Sigma, Deisenhofen

Sigma, Deisenhofen

Invitrogen, Groningen, Niederlande

PAN, Aidenbach

Sigma, Deisenhofen

BioBudget, Krefeld

Roth, Karlsruhe

Sigma, Deisenhofen

T.J. Baker, Deventer, Niederlande

Eurobio, Frankreich

Fluka, Neu-Ulm

PAN, Aidenbach

Sigma, Deisendorf

Gibco/BRL, Eggenstein

Sigma, Deisenhofen

Merck, Darmstadt

Roth, Karlsruhe

Applichem, Darmstadt

Merck, Darmstadt 


\begin{tabular}{|c|c|}
\hline L-Glutamin & Gibco/BRL, Eggenstein \\
\hline LIF & Chemicon, Temecula, USA \\
\hline M2-Medium & Sigma, Deisenhofen \\
\hline McCoy's 5A & Invitrogen, Groningen, Niederlande \\
\hline Mitomycin C & Sigma, Deisenhofen \\
\hline $\mathrm{NaCl}$ & Roth, Karlsruhe \\
\hline Nicht-essentielle Aminsosäuren & Gibco/BRL, Eggenstein \\
\hline Paraformaldehyd & Sigma, Deisendorf \\
\hline PBS & PAN, Aidenbach \\
\hline Penicillin/Streptomycin & Gibco/BRL, Eggenstein \\
\hline Platinum-Taq Polymerase & Invitrogen, Groningen, Niederlande \\
\hline Proteinase $\mathrm{K}$ & Roth, Karlsruhe \\
\hline Restriktionsenzyme & Invitrogen, Groningen, Niederlande \\
\hline Reverse Transkriptase & Invitrogen, Groningen, Niederlande \\
\hline RNAseA & Sigma, Deisendorf \\
\hline Saccharose & Sigma, Deisendorf \\
\hline SDS & Roth, Karlsruhe \\
\hline SOC-Medium & Invitrogen, Groningen, Niederlande \\
\hline Sodium-Pyruvat & Gibco/BRL, Eggenstein \\
\hline B-Mercaptoethanol & Gibco/BRL, Eggenstein \\
\hline TriReagent & MRC, Cincinnati, USA \\
\hline Trypsin/EDTA & Invitrogen, Groningen, Niederlande \\
\hline Tween20 & Roth, Karlsruhe \\
\hline Vector Shield with DAPI & Vector Labratories, USA \\
\hline X - Gal & Applichem, Darmstadt \\
\hline Xylol & Roth, Karlsruhe \\
\hline
\end{tabular}




\subsection{Gebrauchswaren}

Blottingpapier GB 003

Elektroporationsküvette Gene Pulser

Cuvette, 0,4 cm, gap 50

Filterpapier 0850

Kühlzentrifugenbecher

Nitrocellulose-Membran Hybond ${ }^{\mathrm{TM}} \mathrm{-C}$

Objektrräger/Deckgläser

Petrischalen

Pipettierspitzen

Reaktionsgefäße

Röntgenfilme Hyperfilm ${ }^{\mathrm{TM}}$ MP

Sterilfilter
Schleicher \& Schüll, Dassel

BioRad, München

Schleicher \& Schüll, Dassel

Nalge, Rochester, USA

Amersham Pharmacia Biotech, Freiburg

Schütt, Göttingen

Greiner, Nürtingen

Eppendorf, Hamburg

Eppendorf, Hamburg

Amersham Pharmacia Biotech, Freiburg

Sartorius, Göttingen

\subsubsection{Gebrauchswaren für die Zellkultur}

$\begin{array}{ll}\text { Auslaufspipetten } & \text { Sarstedt, Sarstedt } \\ \text { Kryocups } & \text { Greiner, Nürtingen } \\ \text { Kulturflaschen } & \text { Sarstedt oder Nunc } \\ \text { Kulturschalen }(10+5 \mathrm{~cm}) & \text { Nunc, Wiesbaden } \\ \text { 6-Loch-Platten } & \text { Nunc, Wiesbaden } \\ \text { 24-Loch-Platten } & \text { Nunc, Wiesbaden } \\ \text { 96-Loch-Platten } & \text { Nunc, Wiesbaden } \\ \text { 14ml Zentrifugenröhrchen } & \text { Corning, NY, USA } \\ \text { Pasteurpipetten } & \text { Brand, Wiesbaden } \\ \text { Zellschaber } & \text { Greiner, Nürtingen }\end{array}$

\subsection{Geräte}


Automated DNA-Sequencer ABI 377

Brutschrank IR Autoflow

$\mathrm{CO}_{2}$ Water-Jacketed-Incubator

Cryothom

Fotomikroskop BX60

Konvokalmikroskop LSM 510

Lichtmikroskop

Luminometer

Photometer

Primus Cycler

PTC-100 ${ }^{\text {TM }}$ Peltier Thermal Cycler

Sterilbank HERAsafe

Thermomixer 5436

Turboblotter ${ }^{\mathrm{TM}}$

Zentrifuge Biofuge 13

Zentrifuge Hettich Universal

Zentrifuge Megafuge 1.OR

Zentrifuge J2-21

Zentrifuge5415 D
Applied Biosystems, Foster City, USA

Nuaire Nice, Plymouth, GB

Leica, Wetzlar

Olympus, Planegg

Olympus, Planegg

Zeiss, Göttingen

BioTek, Bad Friedrichshall

Eppendorf, Hamburg

MWG-Biotech, Ebersberg

MJ Research, BioRad

Heraeus, Hamburg

Eppendorf, Hamburg

Schleicher \& Schüll, Dassel

Heraeus, Osterode

Hettich, Tuttlingen

Heraeus, Osterode

Beckmann, München

Eppendorf, Hamburg

\subsection{Sterilisation}

Die Sterilisation von Lösungen erfolgte für $20 \mathrm{~min}$. bei $121^{\circ} \mathrm{C}$ und $10^{5} \mathrm{~Pa}$ im Dampfdruckautoklaven (Webco, Bad Schwartau). Bei hitzeempfindlichen Lösungen erfolgte die Sterilisation durch Sterilfiltration (Sterilfilter, 0.2-0.45 $\mu \mathrm{m}$ Porengröße). Gebrauchswaren wurden entweder autoklaviert oder für $8-12 \mathrm{~h}$ bei $180^{\circ} \mathrm{C}$ hitzesterilisiert. 


\subsection{Puffer und Lösungen}

Die Lösungen für den alltäglichen Laborbetrieb wurden nach Sambrook et al. (1989) angesetzt. Die Chemikalien wurden je nach Bedarf in deionisiertem $\left(\mathrm{dH}_{2} \mathrm{O}\right)$, in vollentsalztem Wasser (Millipore), in bidestillertem Wasser $\left(\mathrm{ddH}_{2} \mathrm{O}\right)$ oder Ampuwa gelöst. Den Erfordernissen entsprechend wurden die Lösungen dampfdrucksterilisiert, sterilfiltriert, frisch angesetzt, aliquotiert und bei $-20^{\circ} \mathrm{C}$ oder bei $4^{\circ} \mathrm{C}$ aufbewahrt.

Die Puffer für Enzyme und für gebrauchsfertige Kits wurden, wie vom Hersteller geliefert, nach Beipackzettel benutzt. Ebenso ist ihre Zusammensetzung aus dem entsprechenden Beipackzettel ersichtlich und daher hier nicht weiter aufgeführt.

dNTP-Lösung (25 mM)

$$
\begin{aligned}
& 100 \mathrm{mM} \text { dATP } \\
& 100 \mathrm{mM} \text { dCTP } \\
& 100 \mathrm{mM} \text { dGTP } \\
& 100 \mathrm{mM} \text { dTTP }
\end{aligned}
$$

Fix A1

$$
\begin{aligned}
& \text { 1,35 ml Formaldehyd } \\
& 0,4 \mathrm{ml} \text { Glutaraldehyd } \\
& 0,1 \mathrm{ml} \mathrm{10 \%} \mathrm{Nonidet} \mathrm{P40} \\
& 5 \mathrm{ml} \text { 10xPBS }
\end{aligned}
$$

Fix A2

$1 \%$ Formaldehyd

$02 \%$ Glutaraldehyd

$0,02 \% \mathrm{NP}-40$

In PBS 
Fix B1

Fix B2

Färbelösung 1

Färbelösung 2
1,35 ml Fomaldehyd

0,4 ml Glutaraldehyd

$1 \mathrm{ml} 10 \%$ Nonidet P40

$5 \mathrm{ml}$ 10xPBS

$5 \mathrm{ml} 1 \% \mathrm{NaDOC}$

$1 \%$ Formaldehyd

$0,2 \%$ Glutaraldehyd

$0,2 \% N P-40$

$0,1 \%$ Sodium deoxycholate in PBS

$2,5 \mathrm{ml} x$ - Gal (20mg/ml)

$0,023 \mathrm{~g}$ in $1 \mathrm{ml} 250 \mathrm{mM}$ $\mathrm{K}_{3} \mathrm{Fe}(\mathrm{CN})_{6}$

$0,1056 \mathrm{~g}$ in $1 \mathrm{ml} 250 \mathrm{mM}$ $\mathrm{K}_{4} \mathrm{Fe}(\mathrm{CN})_{6}$

$1 \mathrm{ml} 100 \mathrm{mM} \mathrm{MgCl} 2$

$100 \mathrm{ml}$ Phosphatpuffer $(72 \mathrm{ml}$ $A+28 \mathrm{ml} \mathrm{B}$ )

102

$\mathrm{mg}$

$\mathrm{C}_{6} \mathrm{~N}_{6} \mathrm{FeK}_{3}$

Kaliumhexcyanoferrat III

$130 \mathrm{mg} \quad \mathrm{K}_{4} \mathrm{Fe}(\mathrm{CN})_{6} \quad 3 \mathrm{H}_{2} \mathrm{O}$

gelbes Blutlaugensalz

$100 \mu \mathrm{l} \mathrm{M} \mathrm{MgCl}_{2}$

0,01\% Sodium Deoxycholate 
0,02 \% Igepal Ca 630

Färbelösung 3

Lysis Puffer

M/15 Phosphatpuffer

PBS-Puffer (10x)
$1 \mathrm{mg} / \mathrm{ml} \mathrm{X-gl}$

5 mM Potassium Ferricyanide

5 mM Potassium Ferrocyanide

$2 \mathrm{mM} \mathrm{MgCl} 2$

in PBS

$0.2 \mathrm{M} \mathrm{NaOH}$

$1 \%(w / v)$ SDS

A: 9,465 $\mathrm{g} \mathrm{Na}_{2} \mathrm{HPO}_{4}$ ad $1 \mathrm{I} \mathrm{H}_{2} \mathrm{O}$

B: $9,07 \mathrm{~g} \mathrm{KH}_{2} \mathrm{PO}_{4}$ ad 1 I $\mathrm{H}_{2} \mathrm{O}$

$90 \mathrm{ml} \mathrm{A}+10 \mathrm{ml} \mathrm{B}=\mathrm{M} / 15$

Phosphatpuffer

$130 \mathrm{mM} \mathrm{NaCl}$

$7 \mathrm{mM} \mathrm{Na}_{2} \mathrm{HPO}_{4}$

$3 \mathrm{mM} \mathrm{NaH}_{2} \mathrm{PO}_{4}$

$\mathrm{pH} 7.5$

$15 \%$ Ficoll 400

200 mM EDTA, pH 7.4

$0.1 \%$ Orange G 
TBE (5x)

\subsection{Gebrauchsfertige Kits}

DirektPCR $\AA^{\circ}$ Lysis Reagent (Tail)

Dual-Luciferase $\AA$ Reporter Assay System

DYEnamic ET-Terminator Mix

IMMOLASE ${ }^{\text {MM }}$ DNA Polymerase

LacZ Tissue Staining Kit

Montage ${ }^{\mathrm{TM}}$ PCR Centrifugal Filter Device-System

pGEM®T-Easy Vector System I

PLATINUM®Taq DNA Polymerase-System

PureLink $^{\mathrm{TM}}$ HiPure Plasmid DNA Purification Kits

QIAEX II®Gel Extraktion Kit

QIAquick®Gel Extraktion Kit

Kryomedium

\subsection{Vektoren}

pGEM-T easy

pGL3- Basic
$0.45 \mathrm{M}$ Tris- $\mathrm{HCl}$

$0.45 \mathrm{M}$ Borsäure

10 mM EDTA; pH 8.5
PeqLab, Erlangen

Promega, Wisconsin, USA

CLONTECH

Laboratories, Palo Alto, USA

Bioline, Luckenwalde

InvivoGen, San Diego, USA

Milipore Corporation, Bedford, USA

Promega, Wisconsin, USA

Gibco, BRL, Eggenstein

Invitrogen, Groningen,

Niederlande

Qiagen, Hilden

Qiagen, Hilden

Leica Microsystems, Nussloch

Promega, Wisconsin, USA

Promega, Wisconsin, USA 
pGL3-Control

pGL3-Enhancer

pGL3-Promoter

pRL-SV40

\subsection{Bakterien}

Escherichia coli DH5a(Hanahan 1983)
Promega, Wisconsin, USA

Promega, Wisconsin, USA

Promega, Wisconsin, USA

A.Craig, Freiburg

Invitrogen, Groningen, Niederlande

\subsubsection{Medien für die Bakterienkultur}

LB (Luria-Bertani)-Medium (pH 7,5)

1\% (w/v) Trypton

$0,5 \%(w / v)$ Hefeextrakt

$1 \%(\mathrm{w} / \mathrm{v}) \mathrm{NaCl}$

Ampicillin $(0,1 \mathrm{mg} / \mathrm{ml})$

Zusätze zur Selektion

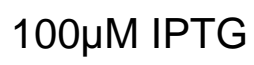

$0.4 \% X-$ Gal

Agarplatten enthielten1,5\% (w/v) Agar

Die Medien wurden mit einfach destilliertem Wasser angesetzt und autoklaviert.

Stammlösung:

$100 \mathrm{mg} / \mathrm{ml}$ Ampicillin in $\mathrm{H}_{2} \mathrm{O}$

$0.2 \mathrm{~g} / \mathrm{ml} \mathrm{IPTG}$ in $\mathrm{H}_{2} \mathrm{O}$

$8 \% \times-$ Gal in Dimethylformamid 
Die Lösung wurde sterilfiltriert und gebrauchsfertig bei $-20^{\circ} \mathrm{C}$ gelagert. Antibiotika, IPTG und X - Gal wurden nach dem Autoklavieren den abgekühlten Medien (ca. $50^{\circ} \mathrm{C}$ ) hinzugefügt. Platten und Flüssigmedium wurden bei $4^{\circ} \mathrm{C}$ gelagert.

\subsection{Mäusestämme}

Die Mäuse stammen aus institutseigenen Beständen, dem Max - Planck - Institut für Experimentelle Medizin Göttingen oder wurden von der Firma Charles River in Sulzfeld bezogen. Die Tiere wurden bei einem zwölfstündigen Hell-Dunkel-Rhythmus bei $22^{\circ} \mathrm{C}$ und $55 \%$ relativer Luftfeuchtigkeit gehalten. Gefüttert wurde mit dem Tierfutter der Firma ssniff-Spezialdiäten (Soest).

\subsection{Eukaryotische Zelllinien}

$\begin{array}{lll}\text { Zellinie } & \text { Isoliert aus } & \text { Referenz } \\ \text { ES-RI } & \text { embryonalen Stammzellen } & \text { (Nagy et al. 1993) } \\ \text { MEF } & \text { embryonalen Fibroblasten } & \text { (Adham et al. 1997) }\end{array}$

\subsubsection{Medien für die Zellkultur}

Medien und Zusätze zur Anzucht eukaryotischer Zellen wurde als sterile Lösung zugekauft (Pan, Aidenbach; Gibco BRL, Eggenstein)

ES-Kulturmedium

DMEM

0,1 $\mathrm{mM}$ nicht essentielle

Aminosäuren

1 mM Natrium-Pyruvat

$1 \mu \mathrm{M}$ B-Mercaptoethanol

2 mM L-Glutamin

$1 \mathrm{mM}$ Penicillin/Streptomycin

$20 \%$ FKS 
(1 $000 \mathrm{U} / \mathrm{ml} \mathrm{LIF)}$

MEF-Kulturmedium

DMEM

2 mM L-Glutamin

$1 \mathrm{mM}$ Penecillin/Streptomycin

$10 \%$ FKS

Zur Lagerung der Zellen in flüssigem Stickstoff wurden folgende Einfriermedien verwendet:

ES-Zellen

MEF-Zellen

\subsection{Antibiotika}

Zur Selektion von immunkompetenten Zellen wurde Ampicillin als Antibiotikum verwendet, angesetzt in einer $50 \mathrm{mg} / \mathrm{ml}$ Stammlösung in bidest. Wasser in einer Endkonzentration $50 \mu \mathrm{g} / \mathrm{ml}$. Diese wurde anschließend steril filtriert und bei $-20^{\circ} \mathrm{C}$ aufbewahrt. Je nach Bedarf wurde die Lösung dem LB-Medium bzw. dem LB-Agar erst nach Autoklavierung und nach dem Abkühlen auf ca. $55^{\circ} \mathrm{C}$ zugesetzt.

\subsection{Antikörper}

Für die Immunhistochemie wurde als erster Antikörper anti-ß-Galactosidase (Kaninchen) der Firma Abcam verwendet. Dieser wird durch den zweiten Antikörper anti-Kaninchen IgG Cy3 der Firma Sigma detektiert und konnte über Fluoreszenz sichtbar gemacht werden. 


\subsection{Oligonukleotide}

Alle eingesetzten Primer wurden von der Firma MWG/Operon bezogen. Mit Ampuwa wurde eine Konzentration von $100 \mu \mathrm{M}(100 \mathrm{pmol} / \mu \mathrm{l})$ eingestellt und als Stock bei $20^{\circ} \mathrm{C}$ gelagert. Die Primer wurden mit einer Konzentration von $10 \mathrm{pmol} / \mu \mathrm{l}$ eingesetzt.

- Le F

- R 523

- Wong 2

- Stra8-F

- Cre-R

- TPF

- TPR

- $\mathrm{gK} 1$

- Luziferase R1.1

- Luziferase-F1

- Luziferase-F2

- Luziferase-R2

- Stra8pr350Xhol

- Stra8pr350Hindlll

- Stra8pr289Xhol

- Stra8pr289HindIII

- Stra8pr1,4Xhol

- Stra8pr1,4HindIII

- 273-F1-Xhol

- 1,4-F2-Xhol

- 922-F2-Bgl|I

- 273-R1-HindIII

- 1,4-R1-HindIII

- 922-R1-HindIII

- HPRT1

- HPRT2

- LacZ RT-1
5' AAAGTCGCTCTGAGTTGTTAT 3،

5' GGAGCGgGAGAAATGGATATG 3"

5' GCGAAGAGTTTGTCCTCAACC 3“

5 ' GCGCTCCTAGTGTGCCAGTTTGAT 3،

5' AGTGAAACAGCATtGCTGTCA 3“

5' AACCAGTGCAATCAGTGCACC 3"

5' ATGGACACAGGAACTCCTGG 3“

5' TCTGAGCCCAGAAAGCGAAGg 3“

5' CGACTCTAGAATTACACGGCG 3"

5' GTAAAGCCACCATGGAAGACGCC 3"

5' GAGGAGCCTTCAGGATTACAAG 3“

5“ GAATTACACGGCGATCTTTCC 3“

5" GACTCGAGCCACAATCTACCAAACCATTTGA 3“

5' CTAAGCTTCCACATCAGTTTGGCACACTACG 3"

5“ GACTCGAGCACCTTACTCATCCACCACC 3“

5" CTAAGCTTCAAAAACAAACCAACAACCCAAAA 3"

5“ GACTCGAGGATGCAGGCCCGGGACCACC 3“

5' CTAAGCTTGTCAGTCACTCACGGACTGCCC 3“

5" GACTCGAGGGAACCCCTTCTCTTTGTCC 3"

5' GACTCGAGCAAGGACAAGGCTCTCCAAG 3“

5' GAAGATCTCAGCATTTGTGGGTCACTTG 3“

5' CTAAGCTTCGAGGCATCAGTGTTAGCAA 3“

5' CTAAGCTTTCTGGGAGTTACGGCGATAC 3،

5' CTAAGCTTTGCTCTAGGAATCCCTGCTC 3“

5 ' CGTCGTGATTAGCGATGATG 3“

5' TATGTCCCCCGTTGACTGAT 3“

5' CTAATCCGAGCCAGTTTACC 3، 
- LacZ RT-2 5'GgCAgATACACTTGCTGATGC 3“

\subsection{Molekulargewichtstandard}

DNA Längenstandard $(1 \mu \mathrm{g} / \mu \mathrm{l}): \quad$ 1kb-Leiter $(0.12-12.2 \mathrm{~kb})$

Der DNA -Längenstandard wurde nach Herstellerangaben verdünnt und mit StopMix versehen.

\subsection{Datenbanken}

Nukleotidsequenzen wurden mit Hilfe der Sequenzdatenbank GenBank (http://www.ncbi.nlm.nih.gov) und mit dem BLAST-Programm (Altschul et al. 1990) analysiert.

\subsection{Zellbiologische Methoden}

Für die Zellkultur wurden ausschließlich adhärent wachsende Zellen in beschichteten Gewebekulturschalen im entsprechenden Medium bei $37^{\circ} \mathrm{C}$ verwendet. Zur Einstellung eines günstigen $\mathrm{pH}$-Wertes (alle Medien enthielten $\mathrm{NaHCO}_{3}$ ) wurden die Zellen unter einer Begasung mit 5\% $\mathrm{CO}_{2}$ kultiviert. Bevor sie eine $100 \%$ Konfluenz erreichten, wurden die Zellen passagiert.

\subsubsection{Kultivierung von murinen embryonalen Stammzellen (ES-Zellen)}

Um die ES-Zellen in undifferenziertem Zustand zu halten, ist es wichtig, dass die Zellen auf Mitose-inhibierten Maus-Fibroblasten (Feederzellen) ausplattiert werden. Zusätzlich wird das ES-Medium mit dem Cytokin LIF (Leukemia Inhibitory Factor) versetzt (Smith et al. 1988).

\subsubsection{Gewinnung und Kultivierung von murinen embryonalen Fibroblasten}

Für die Routinekultur sind Feederzellen unentbehrlich. Diese bestehen aus mitotisch inaktivierten Fibroblasten und werden in einer gleichmäßig verteilten Zellschicht plattiert, auf die die ES-Zellen ausgesät werden. Geeignete Feederzellen für die ESZellen sind STO-Fibroblasten (Ware und Axelrad 1972) und embryonale Fibroblasten (MEF). Diese werden hergestellt, indem man aus einer schwangeren Maus 13,5-15,5 Tage alte Embryonen isoliert. Die Bauchorgane der Embryonen werden entfernt, die Köpfe abgetrennt und der restliche Rumpf wird zerkleinert. Die daraus resultierende 
Suspension wird mit $20 \mathrm{ml}$ Trypsin/EDTA und $1 \mathrm{ml}$ DNAse versetzt und unter Rühren $30 \mathrm{~min}$. bei $37 \mathrm{C}$ inkubiert. Anschließend wird die Zellsuspension bei $270 \mathrm{x} \mathrm{g}$ für 10 min. abzentrifugiert und der Überstand verworfen. Das Pellet wird in MEFKulturmedium erneut gelöst und in ein geeignetes Kulturgefäß transferiert. Nach etwa 24h werden nicht adhärente Zellen durch einen Wechsel des Kulturmediums ausgespült. Nach ca. 3 Tagen werden die MEFs im Verhältnis 1:3 geteilt und nach weiteren 3-5 Tagen in Passage 1 kryokonserviert. Durch die Behandlung mit dem Spindelgift Mitomycin C erfolgt die mitotische Inaktivierung der Zellen (Martin und Evans 1975), somit sind die Zellen nicht mehr teilungsfähig.

\subsubsection{Auftauen und Einfrieren von eukaryotischen Zellen}

Für die Kryokonservierung wurde eine bewachsene Platte mit PBS gewaschen und trypsiniert. Durch das im Kulturmedium enthaltene FKS wurde das Trypsin inaktiviert und die Zellen bei $270 \times \mathrm{g}$ für $5 \mathrm{~min}$. zentrifugiert. Der Überstand wurde abgenommen und das Pellet zuerst in $500 \mu \mathrm{l}$ Kulturmedium resuspendiert und dann mit $500 \mu \mathrm{l}$ des jeweiligen Gefriermediums gut gemischt. Die zuvor beschrifteten Gefrierröhrchen wurden sofort auf Eis gestellt. Das Einfrieren von Zellen sollte möglichst langsam verlaufen. Daher wurden die Gefrierröhrchen in einer vorgekühlten Styroporbox bei $-80^{\circ} \mathrm{C}$ (nicht schneller als $1^{\circ} \mathrm{C} / \mathrm{min}$.) über Nacht eingefroren. Nun konnten die Röhrchen bis zu weiteren Verwendung in flüssigem Stickstoff gelagert werden.

Im Gegensatz dazu hat das Auftauen von gefrorenen Zellen rasch zu erfolgen. Die Zellen wurden im $37^{\circ} \mathrm{C}$ warmen Wasserbad aufgetaut und schnellstmöglich in einer großen Menge des jeweiligen Kulturmediums aufgenommen, um das DMSO entsprechend zu verdünnen. Nach Zentrifugation konnte der Überstand abgenommen und das Zellpellet zum Ausplattieren in Kulturmedium aufgenommen werden.

\subsubsection{Passagieren von eukaryotischen Zellen}

Abhängig von der Zelllinie und der Zelldichte sind die Zellen bereits nach zwei- bis viertägiger Inkubation konfluent und können bereits nach zwei bis viertägiger Inkubation auf mehrere Kulturgefäße aufgeteilt werden. Hierfür wurden die Zellen mit PBS gewaschen und abhängig von der Kulturgefäßgröße wurden 1-5 ml Trypsin/EDTA zugegeben. Nach 5 min. Inkubation bei $37^{\circ} \mathrm{C}$ konnte das Ablösen der 
Zellen unter dem Lichtmikroskop beurteilt werden. Hatten sich die Zellen vollständig gelöst, wurde dieselbe Menge Kulturmedium zugegeben und resuspendiert. Dabei wird das Trypsin durch das im Kultumedium enthaltene FKS inhibiert, so dass dieses keinen negativen Einfluss haben kann. Die Zellen wurden für 5 min. bei $270 \times \mathrm{g}$ zentrifugiert, der Überstand abgenommen, das Pellet in entsprechender Menge Kulturmedium aufgenommen und wiederum in Kulturgefäßen ausplattiert. Beim nächsten Mediumwechsel (ca. $24 \mathrm{~h}$ später) wurden die bis dahin nicht adhärenten Zellen ausgewaschen.

\subsubsection{MitomycinC-Behandlung von embryonalen Fibroblasten}

Das Antibiotikum Mytomycin C wurde in MEF-Medium mit einer Endkonzentration von $10 \mu \mathrm{g} / \mathrm{ml}$ aus einer 50x Stock - Lösung gelöst und auf die Fibroblasten gegeben. Nach einer Einwirkzeit von $2 \mathrm{~h}$ bei $37^{\circ} \mathrm{C}$ wurden die Fibroblasten zweimal mit PBS gewaschen und trypsiniert. Mitomycin - behandelte Fibroblasten können nicht mehr anwachsen, daher werden sie nun auf Gelatine - beschichteten Platten ausplattiert, wodurch sie durch die Gelatine am Boden des Kulturgefäßes fixiert werden. Die Kulturgefäße wurden mit $0,1 \%$ iger steriler Gelatinelösung beschichtet und bei $37^{\circ} \mathrm{C}$ für mindestens $2 \mathrm{~h}$ inkubiert.

\subsubsection{Transfektion mit Lipofectamin}

Lipofectamin TM 2000 ist ein kationisches Lipid, das eine liposomenvermittelte Transfektion von eukaryontischen Zellen ermöglicht. Zur Transfektion auf 24 - Well Platten wurden pro Well 0,4 $\mu \mathrm{g}$ der aufgereinigten Konstrukt - DNA, 0,4 $\mu \mathrm{g}$ Renilla Firefly und $50 \mu \mathrm{l}$ OptiMEM gemischt und $10 \mathrm{~min}$. bei RT inkubiert. Gleichzeitig wurden $2 \mu \mathrm{l}$ Lipofectamin ${ }^{\text {TM }} 2000$ und $50 \mu$ OptiMEM gemischt und ebenfalls $10 \mathrm{~min}$. bei RT inkubiert. Anschließend wurden beide Ansätze zusammengegeben und 30 min. bei RT inkubiert und mit $400 \mu \mathrm{l}$ OptiMEM versehen. Das Gemisch wurde auf die zuvor mit PBS gewaschenen Zellen aufgetragen und $3 \mathrm{~h}$ bei $37^{\circ} \mathrm{C}$ und $5 \% \mathrm{CO}_{2}$ inkubiert. Anschließend wurden pro Well $400 \mu$ I OptiMEM mit $20 \%$ FKS zugegeben und dann weiter $3 \mathrm{~h}$ bei $37^{\circ} \mathrm{C}$ und $5 \% \mathrm{CO}_{2}$ inkubiert. Nun war die Transfektion erfolgt und die Zellen konnten nach zweimaligem Waschen in PBS in normales Kulturmedium aufgenommen werden. 


\subsection{Isolierung und Aufreinigung von Nukleinsäuren}

Standardprotokolle für molekularbiologische Methoden wurden nach Sambrook et al. 1989 ausgeführt.

\subsubsection{Isolierung von RNA aus Geweben}

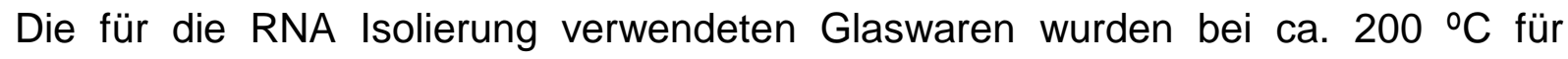
mehrere Stunden sterilisiert, um sie vollständig von RNasen zu befreien. Des Weiteren wurde stets mit Handschuhen gearbeitet und alle folgenden Arbeitsschritte auf Eis durchgeführt. Zu $100 \mathrm{mg}$ frischem Gewebe wurde $1 \mathrm{ml}$ Lysispuffer (TriReagent von Sigma) gegeben, homogenisiert und $5 \mathrm{~min}$. bei RT inkubiert. Nach Zugabe von $200 \mu$ l Chloroform wurde der Ansatz gut durchmischt, $15 \mathrm{~min}$. bei RT inkubiert und anschließend $15 \mathrm{~min}$. bei $15.000 \times \mathrm{g}$ nochmals bei $4^{\circ} \mathrm{C}$ zentrifugiert. Die obere Phase, die die RNA enthält, wurde abgenommen, in ein neues Reaktionsgefäß überführt und mit 0,7 Volumen Isopropanol $10 \mathrm{~min}$. bei RT gefällt. Anschließend wurde die Suspension $10 \mathrm{~min}$. lang bei $4{ }^{\circ} \mathrm{C}$ und $15.000 \times \mathrm{g}$ zentrifugiert und mit $70 \% \mathrm{EtOH}$ gewaschen. Das so entstandene Pellet wurde bei RT getrocknet, in $\mathrm{H}_{2} \mathrm{O}$ aufgenommen und 10 min. bei $55^{\circ} \mathrm{C}$ inkubiert.

\subsubsection{Herstellung von komplementärer DNA durch Reverse Transkription}

Zur Untersuchung der Genexpression wurde die Reverse-Transkriptase PCR (RTPCR) eingesetzt. Diese Methode benötigt eine DNA-Matrize als Substrat, damit die isolierte RNA zunächst mittels Reverser Transkription in komplementäre DNA (cDNA) umgeschrieben werden kann. Die dafür benötigte Ansatzstelle für die SuperScript-II-Reverse Transkriptase wird durch den Oligo-dT-Primer und die PolyASequenz der mRNA gebildet. Für diesen Schritt wurden $5 \mu \mathrm{g}$ RNA, $1 \mu \mathrm{d}$ dNTP-Mix und $1 \mu$ l Oligo-dT-Primer mit sterilem $\mathrm{H}_{2} \mathrm{O}$ auf $13 \mu$ laufgefüllt und $5 \mathrm{~min}$. bei $65^{\circ} \mathrm{C}$ denaturiert. Anschließend wurden $4 \mu \mathrm{l} 5 \mathrm{x}$ First-Strand-Puffer und $2 \mu \mathrm{l}$ 0,1 M DTT hinzugefügt, für $2 \mathrm{~min}$. bei $42{ }^{\circ} \mathrm{C}$ inkubiert und mit $1 \mu \mathrm{l}$ SuperScript-II-ReverseTranskriptase versehen. Auf diese Weise wurde die cDNA-Synthese gestartet und nach 50 min. durch eine 15 - minütige Inkubation bei $70^{\circ} \mathrm{C}$ gestoppt. 


\subsubsection{Isolierung von genomischer DNA aus Mäuseschwänzen und Gewebe (Laird et al. 1991)}

Zur Genotypisierung von Mäusen wurden 1-2 cm lange Schwanzspitzen von 5 Wochen alten Mäusen mit $150 \mu \mathrm{l}$ DirektPCR® Lysis Reagent (Tail) versetzt und $5 \mu \mathrm{l}$ Proteinase K (10 mg/ml) zugegeben. Dieser Ansatz wurde über Nacht bei $55^{\circ} \mathrm{C}$ im Thermomixer inkubiert und am nächsten Morgen für weitere $50 \mathrm{~min}$. bei $95{ }^{\circ} \mathrm{C}$ auf dem Thermomixer belassen und anschließend bei $4{ }^{\circ} \mathrm{C}$ gelagert.

Für die Isolation von DNA aus Gewebe wurden $700 \mu$ Lysispuffer mit $35 \mu$ l Proteinase $\mathrm{K}$ versetzt und über Nacht bei $55^{\circ} \mathrm{C}$ auf dem Thermomixer inkubiert. Am nächsten Morgen wurde zur Präzipitierung die Zellsuspension zentrifugiert, der Überstand in ein neues E-Cup pipettiert und mit $500 \mu$ I Isopropanol gefällt. Um die DNA aufzureinigen, wurde sie mit 70 \% Ethanol gewaschen und in $100 \mu$ Ampuwa gelöst. Bis zur weiteren Analyse konnte sie nun bei $4^{\circ} \mathrm{C}$ gelagert werden.

\subsubsection{Minipräparation von Plasmid-DNA aus Bakterien}

Die Isolierung von Plasmid-DNA im analytischen Maßstab wurde mit den Lösungen E1, E2 und E3 der Firma Quiagen mittels einer modifizierten Methode der alkalischen Lyse (Birnboim und Doly 1979) aus $5 \mathrm{ml}$ LB-Übernachtkulturen mit Ampicilin durchgeführt. Die Qualität der isolierten DNA reicht für PCR-Analysen, Restriktionen und Sequenzierungen aus. Glycerinkulturen wurden aus den Übernachtkulturen für die Plasmid-Minipräparation durch Zugabe von $300 \mu$ l sterilem Glycerin zu $700 \mu \mathrm{l}$ der Bakteriensuspension gewonnen. So konnte die Suspension nach guter Durchmischung als Stock bei $-80^{\circ} \mathrm{C}$ gelagert werden.

\subsubsection{Midipräparation}

Für die Transfektion von DNA in eukaryontische Zellen wurde das Plasmid mit dem PureLink $^{\mathrm{TM}}$ HiPure Plasmid DNA Purification Kit präpariert. Dazu wurden $25 \mathrm{ml}$ einer LB-Übernachtkultur mit entsprechendem Antibiotikum abzentrifugiert und mittels Lysis Puffer aufgeschlossen. Zelltrümmer, Proteine und Salzkomplexe wurde durch Filtration abgetrennt, das Lysat über eine äquilibrierte Säule gegeben, die gebundene DNA gewaschen und in einem Falcon eluiert. Nach der Präzipitation mit 
$10,5 \mathrm{ml}$ Isopropanol wurde das Pellet mit $70 \%$ EtOH gewaschen, luftgetrocknet und in $200 \mu \mathrm{l}$ TE Buffer aufgenommen.

\subsubsection{Isolierung von DNA- Fragmenten aus Agarosegelen}

Diese Methode wurde benutzt, um DNA-Fragmente für die Sequenzierungen und die Klonierungsexperimente zu isolieren. Hierbei kamen das QIAEXII® Gel Extraktion Kit und das QIAquick® Gel Extraktion Kit zum Einsatz. Die gewünschte DNA - Bande wurde nach gelelektrophoretischer Auftrennung auf einem Transilluminator unter UVLicht $(354 \mathrm{~nm})$ mit einem sterilen Skalpell herausgeschnitten, in ein steriles E-Cup überführt, gewogen und mit der jeweiligen Menge des entsprechenden Puffers versetzt. Die weitere Isolierung erfolgte nach dem jeweiligen Protokoll des Herstellers. Die DNA wurde in 20-50 $\mu$ l Ampuwa aufgenommen, und zur Konzentrationsbestimmung wurde ein Aliquot auf ein Agarosegel aufgetragen.

\subsection{Konzentrationsbestimmungen von Nukleinsäuren}

Die Ausbeute isolierter DNA aus Geweben wurde im Vergleich mit Proben von bereits bekannten Konzentrationen auf dem Agarosegel abgeschätzt. Nach Plasmidpräparationen wurde die Konzentration mit einem Photometer (Eppendorf) bestimmt. Unter Annahme einer $\mathrm{OD}_{260}$ von 1 einer dsDNA Lösung von $50 \mathrm{ng} / \mu \mathrm{l}$ können die Konzentrationen nach Abzug des Hintergrundes des Lösungsmittels $\left(\mathrm{H}_{2} \mathrm{O}\right)$ berechnet werden. Die Protein- bzw. Salzkonzentrationen werden dabei im Quotienten $\mathrm{OD}_{260280}$ und $\mathrm{OD}_{260230}$ widergespiegelt und sollten >1,8 bzw. 2,0 sein.

Bei dem verwendeten Photometer kann man bereits vor der Messung sowohl die Art der Nukleinsäure als auch den Verdünnungsfaktor angeben und erhält dann unmittelbar die endgültigen Konzentrationen in $\mu \mathrm{g} / \mu \mathrm{l}$, so dass keine weitere Berechnung notwendig ist.

\subsection{Enzymatische Modifikation von DNA}

\subsubsection{Restriktionsspaltung von Plasmid-DNA}

Plasmid - DNA wurde durch Restriktionsenzyme verschiedener Hersteller gespalten. Gewöhnlich wurden 10U Enzym pro $1 \mu \mathrm{g}$ DNA über 1-2 $\mathrm{h}$ bei dem jeweiligen Temperaturoptimum des benutzten Enzyms eingesetzt. Zur Insert-Isolierung wurden dementsprechend $10 \mu \mathrm{g}$ Plasmid-DNA mit $100 \mathrm{U}$ Enzym $(10 \mathrm{U} / \mu \mathrm{l})$ in Reaktionsansätzen von 100-200 $\mu \mathrm{l}$ verwendet. Für die gleichzeitige 
restriktionsenzymatische Spaltung mit zwei unterschiedlichen Enzymen wurde ein mit beiden Enzymen kompatibler Puffer eingesetzt. Wenn dies nicht möglich war, wurde die DNA zwischen den beiden Reaktionen präzipitiert, um einen Pufferwechsel zu ermöglichen. Um unspezifische Reaktionen zu vermeiden, wurde dem Reaktionsansatz bei Bedarf $1 \mu \mathrm{g}$ BSA (10 mg/ml) zugegeben. Anschließend wurde ein Aliquot auf ein Agarosegel aufgetragen, um den Verdau auf Vollständigkeit zu überprüfen.

\subsection{Polymerasekettenreaktion}

\subsubsection{PCR an genomischer DNA}

Die Polymerasekettenreaktion (PCR) wird benutzt, um DNA-Fragmente zu amplifizieren. Dabei handelt es sich um eine enzymatische in vitro - Methode (Saiki et al. 1988). Die Spezifität dieser Amplifikation beruht auf zwei Oligonukleotidprimern, die das gewünschte DNA-Fragment flankieren und nach einer Hitzedenaturierung an den jeweiligen Strang binden. Nun synthetisiert die hitzestabile DNA-Polymerase (Taq-Polymerase oder Immolase) des Archebakteriums Thermus aquaticus (Chien et al. 1976) bei ihrer optimalen Temperatur $\left(72^{\circ} \mathrm{C}\right)$ die DNA entlang der Region zwischen den Primern. So entsteht eine sich wiederholende Abfolge von Denaturierungen der DNA-Stränge, Anlagerung der Primer (Annealing) und DNA Synthese (Elongation), bei der eine exponentielle Vermehrung des jeweiligen DNA Fragments stattfindet. Die meist verwendete Immolase Taq und Platinum Taq DNA Polymerase verfügen über einen hitzestabilen Inhibitor, der während der Denaturierung inaktiviert wird und damit die Durchführung einer hot start - PCR möglich macht, wodurch die Entstehung unspezifischer Amplifikate während der ersten Zyklen vermieden wird. 
Für die PCR wurde ein Ansatz aus $24 \mu$ Reagenzien der Firma Invitrogen Platinum ${ }^{\circledR}$ Taq DNA Polymerase oder der Firma bioline IMMOLASE DNA Polymerase verwendet und $1 \mu \mathrm{I}$ DNA nach folgendem Schema pipettiert :

$1 \mu \mathrm{l} \quad$ Primer 1

$1 \mu \mathrm{l} \quad$ Primer 2

$0,5 \mu \mathrm{l} \mathrm{Taq}$

$1,5 \mu \mathrm{MgCl}$

$0,5 \mu \mathrm{l}$ dNTP's

$2,5 \mu \mathrm{l}$ Puffer

$18 \mu \mathrm{l} \mathrm{H}_{2} \mathrm{O}$

Die Ansätze wurden in einem PCR Thermocycler der Firma Applied Biosystems mit folgendem Programm inkubiert:

5 min. $\quad 94^{\circ} \mathrm{C} \quad$ Vordenaturierung

$\left.\begin{array}{lll}20 \text { sec. } & 94{ }^{\circ} \mathrm{C} & \text { Denaturierung } \\ 30 \text { sec. } & 55-68{ }^{\circ} \mathrm{C} & \text { Annealing } \\ 1-2 \mathrm{~min} . & 72{ }^{\circ} \mathrm{C} & \text { Elongation }\end{array}\right\}$ 30-35 Zyklen

5min. $\quad 72^{\circ} \mathrm{C} \quad$ Auffüllreaktion

Die Annealing - Temperatur war primerspezifisch und wurde für das jeweilige Primerpaar angepasst. Für die Spezifität des Produkts wurde die Fragmentlänge des Produkts in der horizontalen Agarosegelelektrophorese ermittelt. Dabei werden 12,5 $\mu \mathrm{l}$ des fertigen Ansatzes plus 2,5 $\mu \mathrm{l}$ Stop-Mix aufgetragen.

\subsubsection{RT-PCR}

Um kleinste Transkriptmengen von bestimmten Genen in Zellen und Organen nachzuweisen, benutzt man die RT-PCR (Reverse Transkriptions-PCR). Hierbei wird isolierte RNA mit Hilfe von SUPERSCRIPT II RNaseH, dem Reverse TranskriptaseSystem von Invitrogen in cDNA umgeschrieben (Erststrangynthese der komplementären DNA). Danach wird, wie unter 2.20.1 dargestellt, weiter verfahren. 


\subsubsection{Sequenz - PCR}

Die Sequenz-PCR wurde nach dem Kettenabbruchverfahren von Sanger et al. (1977) in einer modifizierten Form durchgeführt. Die Methode beruht auf dem Prinzip der statistisch unterbrochenen DNA-Neusynthese durch den Einbau von Didesoxynukleotiden (ddNTP). Dabei wurde mit dem DYEnamic ET-Terminator-Mix der Firma Amersham Pharmacia gearbeitet. Dieser Mix enthält dNTP's, mit vier unterschiedlichen Fluroeszenzfarbstoffen markierte ddNTPs, DNA-Taq Polymerase sowie Reaktionspuffer. Bei der gelelektrophoretischen Auswertung werden Fluroeszenzfarbstoffe über Laserabtastung automatisch detektiert und können hierüber analysiert werden.

Zuerst wird eine PCR zur Amplifikation des zu sequenzierenden Fragments durchgeführt, anschließend das PCR Produkt mit einem gebrauchsfertigen MonatgePCR Centrifugal Filter Device-System der Firma Milipore Corporation aufgereinigt und ein Aliquot auf ein Testgel aufgetragen. Damit soll die einzusetzende Menge des ursprünglichen PCR Produkts für die anschließende Sequenz-PCR abgeschätzt werden.

Folgender Ansatz wurde in einem dünnwandigen 0,2 ml PCR-Reaktionsgefäß zusammenpipettiert:

\section{0,5-1 $\mu$ l PCR-Produkt $(1-1,5 \mu \mathrm{g})$}

$1 \quad \mu$ Primer

$4 \quad \mu$ I DYEnamic ET-Mix

Auf $10 \mu \mathrm{l}$ mit Ampuwa auffüllen

Die Kettenabbruchreaktion wurde als PCR in einem automatischen Thermocycler standardmäßig mit folgendem Programm durchgeführt:

$\left.\begin{array}{lll}40 \mathrm{sec} . & 95^{\circ} \mathrm{C} & \text { Vordenaturierung } \\ 20 \mathrm{sec} . & 95^{\circ} \mathrm{C} & \text { Denaturierung } \\ 25 \mathrm{sec} . & 55-68^{\circ} \mathrm{C} & \text { Annealing }\end{array}\right\} 25$ Zyklen

1 min. $\quad 72^{\circ} \mathrm{C} \quad$ Elongation 
Nach der PCR wurde die Probe mit Wasser auf $20 \mu \mathrm{l}$ aufgefüllt und dem Sequenzierungsservice im Institut übergeben.

\subsection{Klonierung von DNA - Fragmenten}

\subsubsection{Ligation von PCR-amplifizierten DNA-Fragmenten}

Zur Klonierung von PCR-Produkten wurde das pGEM-Teasy Vektorsystem der Firma Amersham benutzt. Das System enthält einen linearisierten Vektor mit 3'-T Überhängen, die kompatibel zu den 3'-A-Überhängen des PCR - Produkts sind, die von den meisten DNA-Polymerasen erzeugt werden (Clark 1988). Die aus dem Agarosegel isolierten PCR-Produkte wurden laut Protokoll über Nacht bei $4^{\circ} \mathrm{C}$ mit dem Vektor ligiert.

\subsubsection{Transformation, modifiziert nach Hanahan 1983}

Für die Transformation eines Ligationsansatzes wurden $50 \mu \mathrm{l}$ kompetente E.coli DH5a-Zellen vorsichtig auf Eis aufgetaut, mit $2 \mu$ Ligationsansatz vermischt und 30 min. auf Eis inkubiert. Der Ansatz wurde bei $42^{\circ} \mathrm{C}$ für 1 min. einem Hitzeschock auf dem Thermomixer ausgesetzt und nach 5 min. Abkühlung auf Eis mit $950 \mu \mathrm{l}$ SOCMedium versetzt. Die transformierten Bakterien wurden für $1,5 \mathrm{~h}$ bei $37^{\circ} \mathrm{C}$ auf dem Thermomixer inkubiert und anschließend in verschiedenen Verdünnungsstufen (wichtig, um die Einzelklone zu erhalten) auf Selektionsplatten ausplattiert und über Nacht bei $37^{\circ} \mathrm{C}$ inkubiert. Konnte man am nächsten Tag Einzelkolonien erkennen, wurden diese mit einem sterilen Zahnstocher gepickt und damit $5 \mathrm{ml}$ LBÜbernachtkulturen für die Minipräparation angeimpft.

\subsection{Horizontale Gelelektrophorese}

Die horizontale Gelelektrophorese wurde zur Auswertung von PCRs, Restriktionskartierungen und Insertisolierungen benutzt. Je nach Größe der zu trennenden Fragmente wurden 0,8-2 \%ige Agarose - Gele in 0,5 \% TBE-Puffer hergestellt und Ethidiumbromid in einer Endkonzentration von 0,1 $\mu \mathrm{g} / \mathrm{ml}$ zugegeben. Damit sollen die aufgetragenen Produkte später unter UV-Licht sichtbar gemacht werden. Die mit Stop-Mix versehene DNA wurde aufgetragen, elektrophoretisch aufgetrennt und danach fotografisch dokumentiert. Zur Größenbestimmung wurden die DNA-Fragmente mit der 1kb-DNA-Leiter verglichen, die Initial mit auf das Gel aufgetragen wurde. 


\subsection{Histologische Methoden}

Die Analysen erfolgten an einem (Fluoreszenz-) Fotomikroskop (BX60, Olympus) sowie mit einem Konfokalmikroskop (LSM 510, Olympus). Durch das Konfokalmikroskop war es möglich, verschiedene Schichten einer Zellkolonie zu scannen.

\subsubsection{Einbettung in Kryomedium}

Diese Methode wurde genutzt, um Gewebe einzubetten, zu schneiden und erst anschließend zu färben. Hierfür wurden die Organe $2 \mathrm{~h}$ bei $4{ }^{\circ} \mathrm{C}$ in $4 \%$ PFA fixiert und über Nacht bei $4{ }^{\circ} \mathrm{C}$ in $25 \%$ Sucroselösung äquilibriert. Um das Gewebe möglichst schonend abzukühlen, wurde Isopentan in flüssigem Stickstoff solange heruntergekühlt bis es zähflüssig wurde. Darin wurde das Gewebe nun für $30 \mathrm{sec}$. eingefroren. Anschließend wurde es direkt in einen vorgekühlten Block mit Tissue Freezing Medium der Firma Jung senkrecht eingebettet und bei $-80^{\circ} \mathrm{C}$ tiefgefroren. $24 \mathrm{~h}$ später war der Block fertig zum Schneiden.

\subsubsection{Kryoschnitte}

Der Block wurde im Kryotom der Firma Leica in Schnitte mit einer Dicke von $5 \mu \mathrm{m}$ geschnitten und diese wurden auf Objektträger gezogen. Nach dreimaligem Waschen in PBS konnten die Schnitte nun gefärbt werden.

\subsubsection{Paraffinschnitte}

Das frische Gewebe wurde drei Tage in $4 \%$ PFA bei $4{ }^{\circ} \mathrm{C}$ fixiert und über mehrere Tage in eine Wasser-Alkohol Reihe mit steigendem Ethanolgehalt (40 \%-100\%) entwässert. Zur weiteren Entfettung und Aushärtung folgte eine Xylol-Isopropanol Reihe mit ebenso steigendem Xylolgehalt. Anschließend wurden die Gewebeproben in flüssigem Paraffin eingebettet, am Mikrotom geschnitten und auf Objektträger aufgezogen. Nun konnten sie gefärbt werden.

\subsection{Lac-Z - Färbemethode}

\subsubsection{Protokoll 1 (für ganze Organe und Schnittfärbungen)}

Um das Gewebe zu fixieren, wurden entnommene Organe zuerst $20 \mathrm{~min}$. bei $4{ }^{\circ} \mathrm{C}$ in Fix A.1 und anschließend weitere $20 \mathrm{~min}$. in Fix B.1 gegeben. Danach wurden sie 
zweimal $20 \mathrm{~min}$. in PBS gewaschen und über Nacht bei RT in Färbelösung 1 inkubiert. Nach zwei weiteren Waschschritten mit jeweils 20 min. in PBS wurden die Organe direkt in Kryomedium eingebettet und geschnitten. Diese Fixierungsmethode wurde sowohl für ganze Organe als auch bei Kryoschnitten direkt auf den Objektträgern angewendet.

\subsubsection{Protokoll 2}

Die bei diesem Protokoll verwendete Färbemethode wurde sowohl für Organe als auch für Objektträger bei Kryoschnitten verwendet. Das Gewebe bzw. der Objektträger wurden in einem Gemisch aus $7,5 \mathrm{~g}$ Sucrose, $10 \mathrm{ml}$ Formalin ad $100 \mathrm{ml}$ $\mathrm{M} / 15$ Phosphatpuffer (siehe S.11) für $20 \mathrm{~min}$. bei $4{ }^{\circ} \mathrm{C}$ fixiert. Nach der Fixierung wurde das Gewebe zweimal $10 \mathrm{~min}$. in PBS gewaschen und anschließend lichtgeschützt bei $37^{\circ} \mathrm{C}$ in $50 \mathrm{ml}$ Färbelösung 2 mit $1 \mathrm{ml} \mathrm{x}$ - Gal $(40 \mathrm{mg} / \mathrm{ml}$ in N,N Dimethyl Formamid) gefärbt.

\subsubsection{Lac Z Kit der Firma InvivoGen}

Dieses Kit wurde für ganze Organe verwendet. Dabei wurden die entnommenen Organe zuerst auf Eis in PBS/ $\mathrm{MgCl}_{2}$ - Lösung gewaschen und anschließend $30 \mathrm{~min}$. auf Eis in Fixierlösung fixiert. Nach zweimaligem Waschen in PBS konnten sie nun bei $37^{\circ} \mathrm{C}$ für 2-4 $\mathrm{h}$ in Färbelösung gefärbt werden. Zum Schluss wurden die Organe noch fünfmal in PBS gewaschen.

\subsubsection{Protokoll 3}

Das entnommene Gewebe wurde in PBS gewaschen und 30 min. in Fix A 2 bei $4^{\circ} \mathrm{C}$ unter Schütteln inkubiert. Nach erneutem Waschen wurde es ebenfalls unter Schütteln $1 \mathrm{~h}$ bei $4^{\circ} \mathrm{C}$ in Fix B 2 inkubiert. Vor der Färbung wurde das Gewebe erneut gewaschen und bei $30^{\circ} \mathrm{C}$ lichtgeschützt über Nacht in Färbelösung 2 gefärbt. Die gefärbten Organe wurden nun in Paraffinblöcke eingebettet.

\subsection{Immunhistologie}

Hierfür wurden die Paraffinschnitte zunächst gewässert und dann $1 \mathrm{~h}$ in Blockinglösung gegeben. So wurde eine höhere Antikörperspezifität erreicht. Der erste Antikörper wurde mit einer Verdünnung 1:200 bei $4{ }^{\circ} \mathrm{C}$ über Nacht in einer feuchten Kammer im Dunkeln inkubiert und am nächsten Morgen durch dreimaliges 
Waschen in PBS wieder entfernt. Anschließend wurde der zweite Antikörper mit einer Verdünnung von 1:500 für 1,5 $\mathrm{h}$ bei $\mathrm{RT}$ in der feuchten Kammer inkubiert und danach ebenfalls durch dreimaliges Waschen entfernt. Als Orientierungshilfe beim Mikroskopieren wurden die Zellkerne zusätzlich mit DAPI angefärbt und die Schnitte zum Schluss eingedeckelt und mit Nagellack versiegelt.

\subsection{HE-Färbung (Hämatoxylin-Eosin-Färbung)}

Zur besseren Orientierung bei LacZ - Färbungen auf Kryoschnitten wurde eine Schnittfolge erstellt, wobei der erste Schnitt mit LacZ und der zweite, unmittelbar nachfolgende Schnitt mit Hämatoxylin-Eosin gefärbt wurde. Mit dieser Methode färben sich die Zellkerne blau und das Zytoplasma rot bis blassrosa an.

Das in Kryomedium eingebettete und geschnittene Gewebe wurde nach dem Spülen in PBS für 10-15 min. in Hämatoxylin inkubiert. Darauf folgte ein 10-15 minütiges Bläuen der Zellen unter Leitungswasser, worauf sich eine Färbung mit Eosin für 1060 sec. anschloss. Nach drei weiteren Waschschritten in PBS und einer aufsteigenden Reihe EtOH konnten die Objektträger mit Eukit (Fluka) eingedeckelt werden.

\subsection{Messung der Luziferaseaktivität}

Für die sensitive und quantitative Messung der Aktivität des Reporterenzyms fireflyLuziferase (Photinus pyralis) in kultivierten Zellen wurde das dual-glow Luciferase Assay System der Firma Promega verwendet. Die Luziferase katalysiert folgende luminizierende Redoxreaktion:

Luzifersesubstrat (Luciferin) + ATP $+\mathrm{O}_{2} \rightarrow$ Oxyluciferin + Licht (560nm) + AMP + PPi $+\mathrm{CO}_{2}$

Für die Messung wurden die Zellkulturplatten (24 Well) zweimal mit PBS gewaschen und die Zellen mit $500 \mu \mathrm{l}$ Passiv-Lysis - Puffer lysiert. Die Flüssigkeit wurde in ein ECup überführt und 5 min. bei 13.000 rpm zentrifugiert. Bevor die Probe gemessen wurde, wurden $10 \mu$ l Probenlysat, $50 \mu \mathrm{l}$ Luziferase Assay Reagenz II und $50 \mu$ Stop \& Glo-Reagenz vorsichtig geschüttelt. Die zugegebene Luziferase katalysiert die oben beschriebene Reaktion, die dann über ein Luminometer gemessen werden kann. 


\section{ERGEBNISSE}

\subsection{Untersuchung und Genotypisierung der Stra8-Cre/R26R - Mäusen}

Im Folgenden wurden unsere doppelttransgenen Mäuse untersucht. Sie exprimieren Stra8 unter der Kontrolle eines 1,4 kb Promotors. Dies wird über einen Nachweis einer LacZ - Expression kontrollierbar.

\subsubsection{Genotypisierung von Stra8-Cre/R26R - Mäusen durch Rückkreuzung}

Da der Integrationsort des Stra8-Cre - Transgens nicht bekannt ist, muss durch Rückkreuzung der transgenen Tiere bestimmt werden, ob diese für das Konstrukt homozygot oder heterozygot sind. Dazu wurden die zu untersuchenden Tiere mit Wildtyp-Mäusen verpaart und deren Nachkommen genotypisiert. Waren alle Nachkommen positiv, so konnte davon ausgegangen werden, dass die verwendete Stra8-Cre - Maus homozygot ist.

Die Nachkommen der Stra8-Cre/R26R - Maus mit einer FVB-Wildtyp- Maus wurden mittels PCR genotypisiert. Die PCR-Primersequenz wurde komplementär zu den Sequenzabschnitten des gesuchten Inserts gewählt, dem Stra8 Promotor und dem Cre-Rekombinase-Gen, so dass eine Amplifikation nur bei Vorhandensein des Konstrukts stattfinden konnte (Abb. 2).

Um falsch negative Ergebnisse zu verhindern, wurde mit denselben Proben nochmals eine PCR durchgeführt. Es sollte geprüft werden, ob sich amplifizierbare DNA in der Probe befand (Abb. 3). Die Primer hierfür amplifizierten einen DNA Abschnitt, der unabhängig von dem Stra8-Cre/R26R Konstrukt in jeder Maus vorhanden ist.

Auf diese Weise wurden mindestens 15 Nachkommen untersucht, bevor über das Elterntier eine Aussage über den Integrationsort getroffen wurde. 


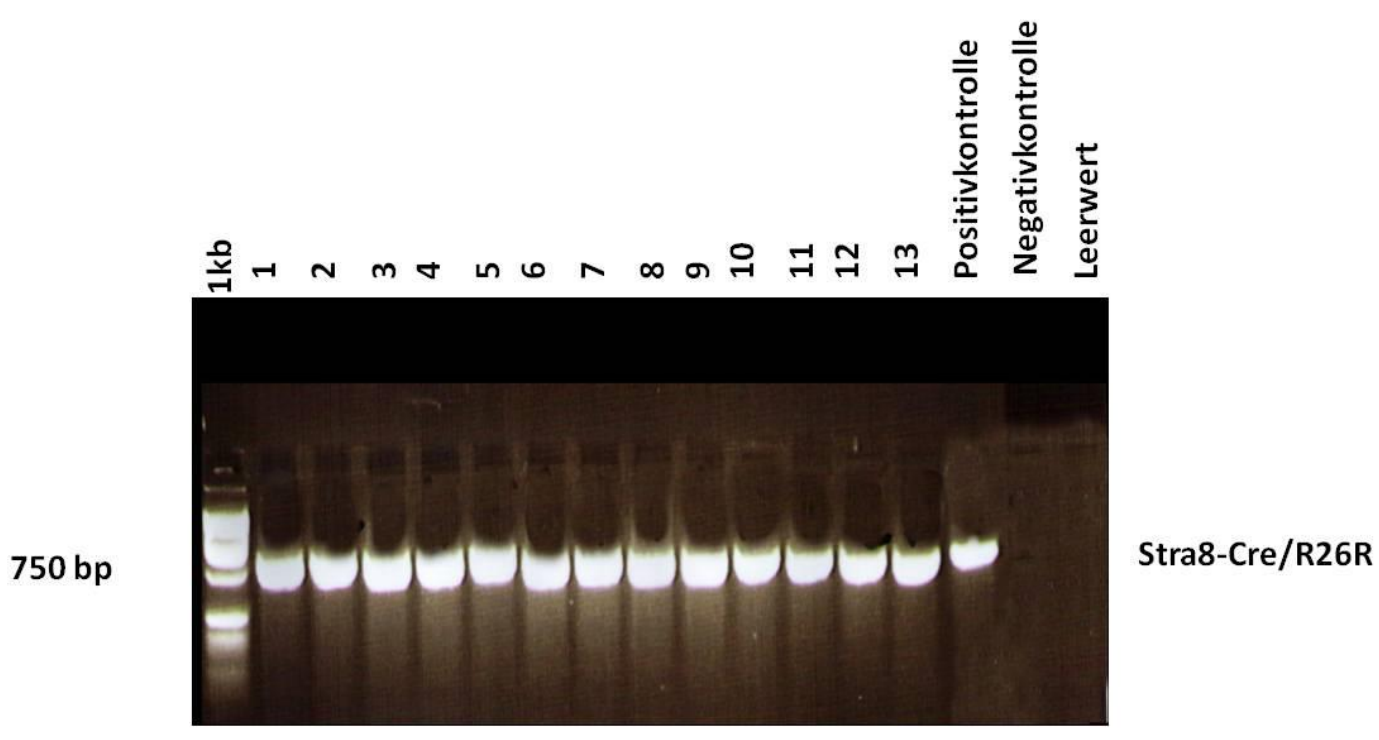

Abb.2: PCR-Analyse zur Genotypisierung des Gewebes der Stra8 - Cre / R26R Mäuse mithilfe ihrer Nachkommen

Zur Genotypisierung wurden Stra8 - Cre / R26R Mäuse mit FVB - Wildtypmäusen verpaart. Von diesen Nachkommen wurde eine DNA - Probe aus der Schwanzspitze gewonnen und mit Stra8 -Cre / R26R spezifischen Primern einer PCR - Analyse unterzogen. War das Konstrukt enthalten, erhielt man eine spezifische Bande von 750 bp. So wurden mindestens 15 Nachkommen untersucht, um über eine Rückkreuzung über das Elterntier eine Aussage zu treffen.

1-13: DNA aus den untersuchten Nachkommen.

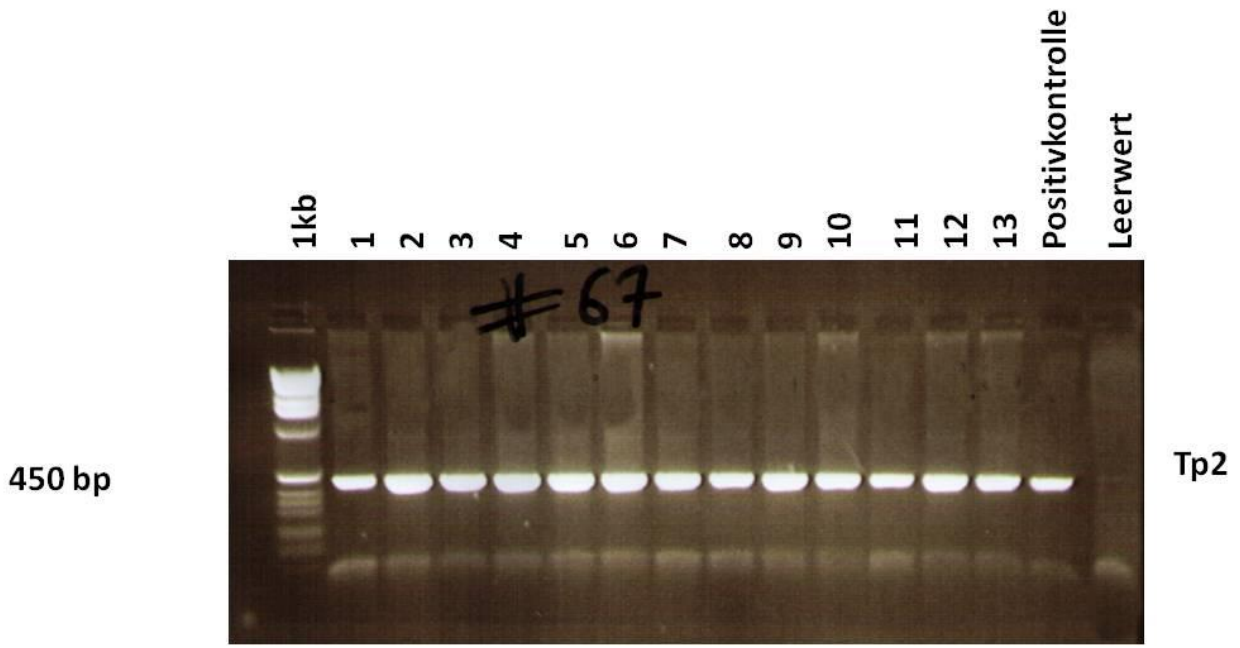

Abb. 3: PCR - Analyse derselben Gewebeproben wie in Abbildung 2

Um falsch negative Ergebnisse zu verhindern, wurde mit denselben DNA - Proben aus Abbildung 2 eine weitere PCR - Analyse durchgeführt. Es sollte sichergestellt werden, dass sich überhaupt amplifizierbare DNA in den Proben befindet. Die gewählten Primer amplifizieren einen DNA Abschnitt (Tp2), der unabhängig von dem Stra8 - Cre / R26R Konstrukt vorhanden ist.

1-13: DNA aus den untersuchten Nachkommen 
Nachdem nun der Genotyp der vorhandenen Mäuse für das erste Transgen, nämlich Stra8-Cre, bekannt war, sollte nun auch der Genotyp für das zweite Transgen (R26R) bestimmt werden. Dies ist wesentlich einfacher, da es sich um eine sehr gut charakterisierte Maus handelt, bei der der Integrationsort des Konstruktes bekannt ist. Die Genotypisierung wurde anhand des vom ,Jackson Laboratories' angegebenen Genotypisierungsprotokolls durchgeführt. Mithilfe der durch die gelelektrophoretisch Auftrennung entstandenen Banden konnte bestimmt werden, ob es sich um ein Wildtyp-, heterozygotes oder homozygotes Tier handelt. Homozygote Tiere wiesen eine Bande von 325bp auf, Wildtyp- Tiere eine Bande von 600bp und heterozygote Tiere wiesen beide Banden (Abb. 4 und 5).

Für diese PCR wurden Testes/Ovar, Leber, Milz, Niere, Herz, Gehirn, Haut, Muskel aus der Stra8-Cre/R26R - Maus präpariert. Ebenso wurde Knochenmark aus dem Femurknochen mit PBS ausgespült und Spermien direkt unter dem Mikroskop aus dem Epididymis mit IVF Medium ausgespült. Aus all diesen Gewebeproben wurde DNA extrahiert und untersucht.

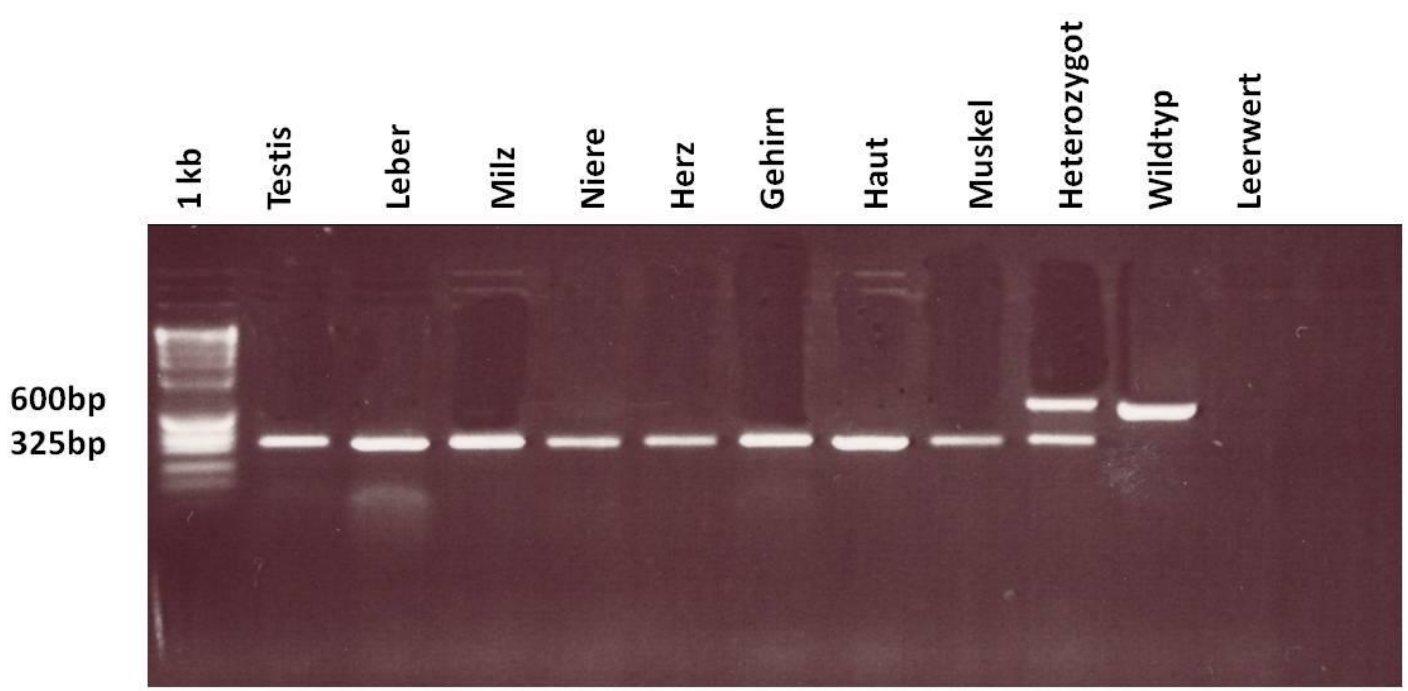

Abb. 4: Genotypisierung des Gewebes einer homozygoten männlichen Stra8 - Cre / R26R - Maus Für die Genotypisierung der Elterntiere wurde DNA aus deren Testes, Leber, Milz, Niere, Herz, Gehirn, Haut und Muskel extrahiert und mit konstruktspezifischen Primern eine PCR - Analyse durchgeführt. Dabei zeigten homozygote Tiere eine 325 bp - Bande. Die als Kontrolle mitgeführten Mäuse vom Wildtyp zeigten eine $600 \mathrm{bp}$ - Bande und die heterozygoten Tiere sowohl eine $600 \mathrm{bp}$ - als auch eine $325 \mathrm{bp}$ - Bande. 


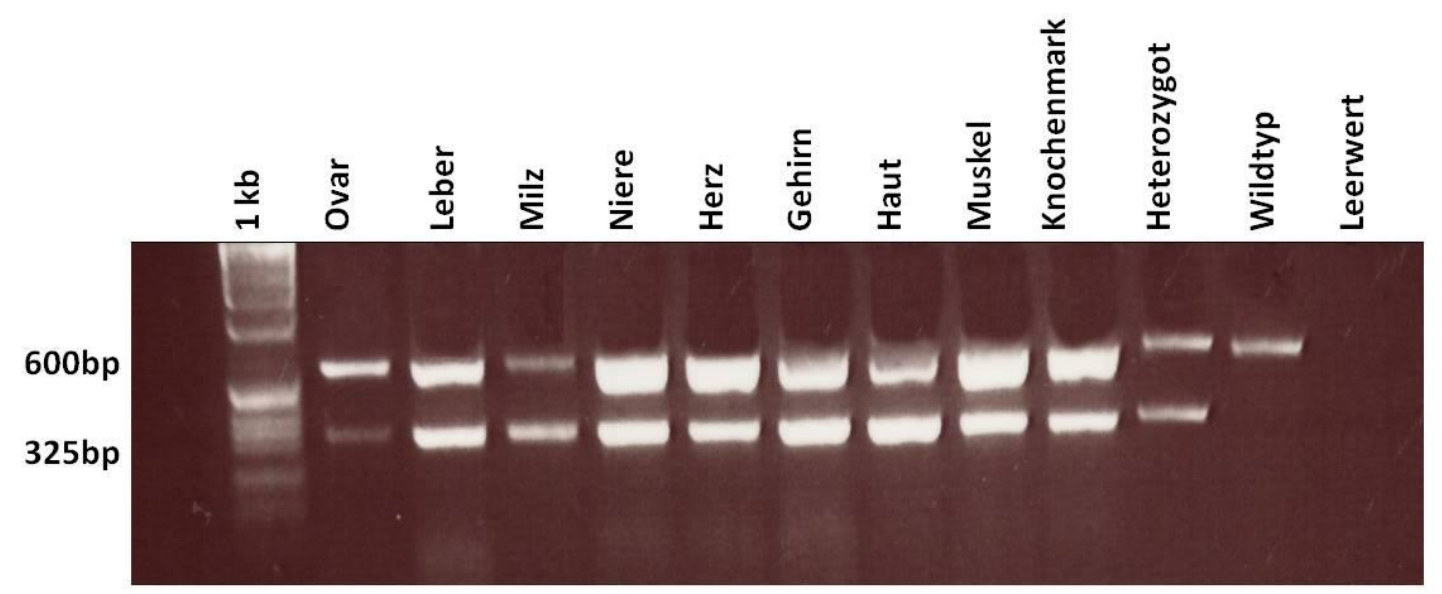

Abb. 5: Genotypisierung des Gewebes einer heterozygoten weiblichen Stra8 - Cre / R26R - Maus Für die Genotypisierung der Elterntiere wurde DNA aus deren Ovarien, Leber, Milz, Niere, Herz, Gehirn, Haut, Muskel und Knochenmark extrahiert und mit LacZ - spezifischen Primern eine PCR Analyse durchgeführt. Dabei zeigten homozygote Tiere eine 325 bp - Bande. Die als Kontrolle mitgeführten Mäuse vom Wildtyp zeigten eine 600 bp - Bande und die vom heterozygoten Typ sowohl eine $600 \mathrm{bp}$ - Bande als auch eine 325bp - Bande .

\subsection{Nachweis von LacZ - Expression durch X - Gal - Färbung}

Durch eine X - Gal - Färbung kann man LacZ - Expression nachweisen. Diese Färbung basiert auf einer Oxidation und resultiert in einer Blaufärbung des Gewebes.

Für die histologische Untersuchung wurden Testes/Ovar, Leber, Milz, Niere, Herz, Gehirn, Haut, Muskel aus einerStra8-Cre/R26R - Maus präpariert und fixiert. Knochenmark wurde aus dem Femurknochen mit PBS ausgespült, in einem E-Cup aufgefangen und fixiert. Spermien wurden direkt aus der Epididymis isoliert und ebenfalls fixiert.

Die Proben wurden als ganze Organe gefärbt. Dabei wurde die Färbezeit variiert, aber selbst nach einer Inkubationszeit von 10 Tagen in X - Gal war nur die äußere Schicht angefärbt. Das X - Gal drang nicht in tiefere Gewebsschichten vor, auch wenn diese zuvor durch eine Kanüle perforiert worden waren. Um auch die inneren Organschichten zu erreichen, wurden die Proben in Kryoblöcke eingebettet, geschnitten und anschließend gefärbt. Aus früheren Veröffentlichungen (OuladAbdelghani et al. 1996) war bekannt, dass der Stra8- Promotor in den prämeiotischen Stadien aktiv sein muss. Daher war eine durchgehende Blaufärbung der Keimzellen zu erwarten. Es konnten jedoch entgegen den Erwartungen, trotz 
Verwendung verschiedener Protokolle und einem speziellen Kit für LacZ Färbungen, keine verlässlichen und reproduzierbaren Ergebnisse erzielt werden. So waren die Testes doppelt homozygoter Mäuse nicht immer blau, sondern glichen von Zeit zu Zeit dem einer negativen Kontrolle oder wiesen nur vereinzelt blaue Punkte auf. Selbst beim Färben einer Testesprobe derselben Maus mit demselben Chemikalienstock ließen sich keine reproduzierbaren Ergebnisse generieren. Zur Kontrolle, ob der Färbevorgang an sich funktioniert hat, wurde eine Testesprobe einer ROSA26 - LacZ - Maus als positive Kontrolle mitgefärbt.

Bei den verschiedenen Färbeprotokollen war der Testis das einzige Organ, welches zeitweise durchgehend blau wurde. Niere und Gehirn hatten nur vereinzelt feine blaue Punkte, die restlichen Organe waren gar nicht gefärbt.

Da bei der Cyroschnitttechnik die Morphologie nur noch sehr schwer zuzuordnen ist, wurde eine Schnittserie erstellt, von der der erste Schnitt mit X - Gal gefärbt wurde und der unmittelbar darauf folgende Schnitte mit einer HE - Färbung. So konnte man sich auch auf kaum angefärbten Schnitten anhand der HE - Färbung orientieren. 

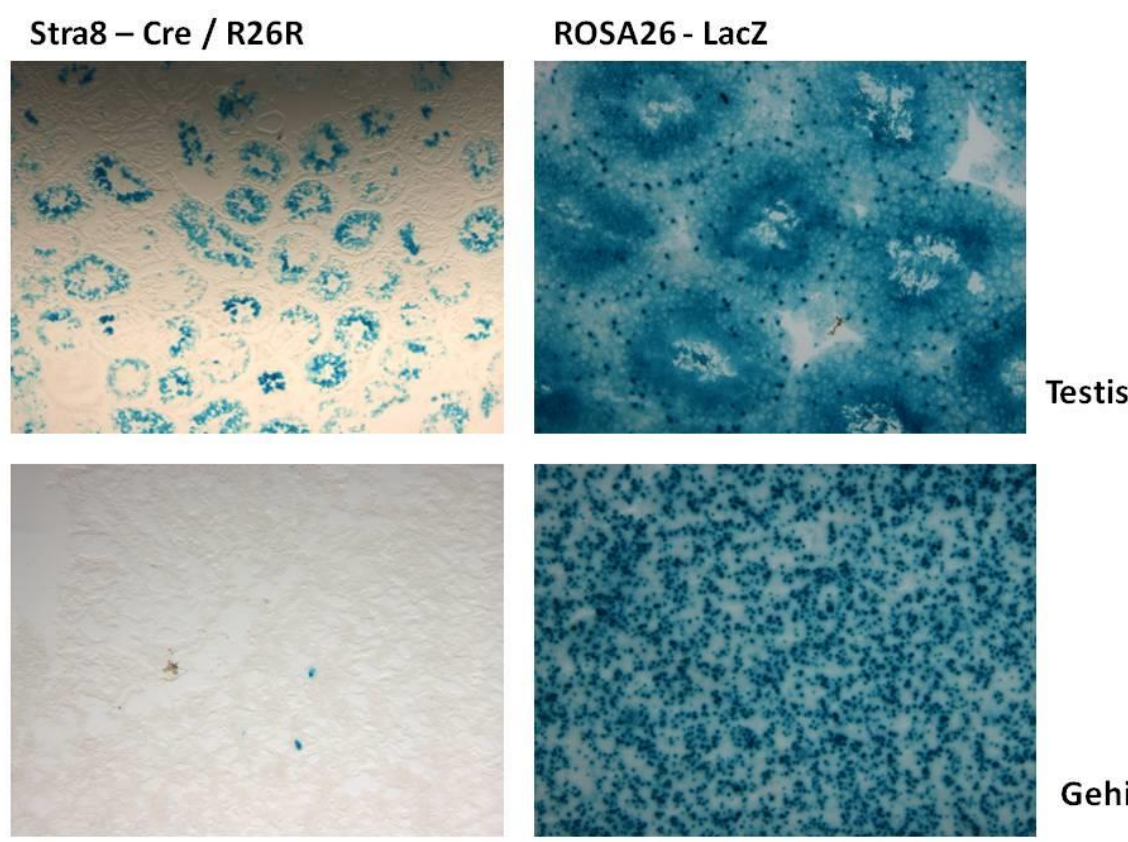

Gehirn
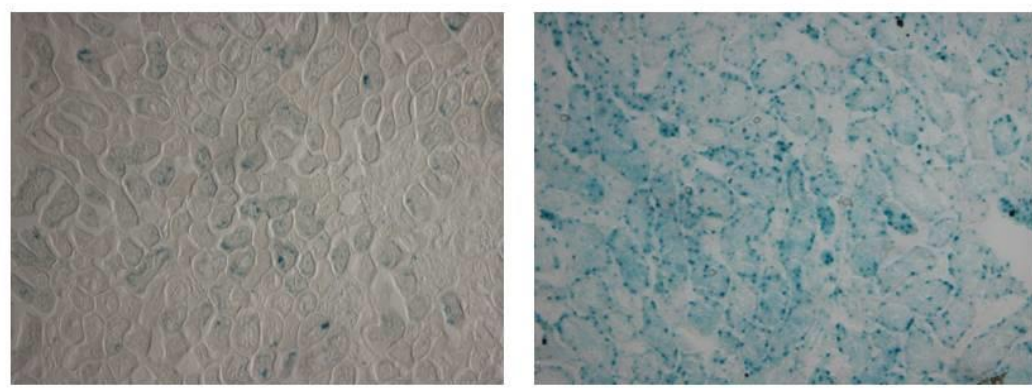

Niere
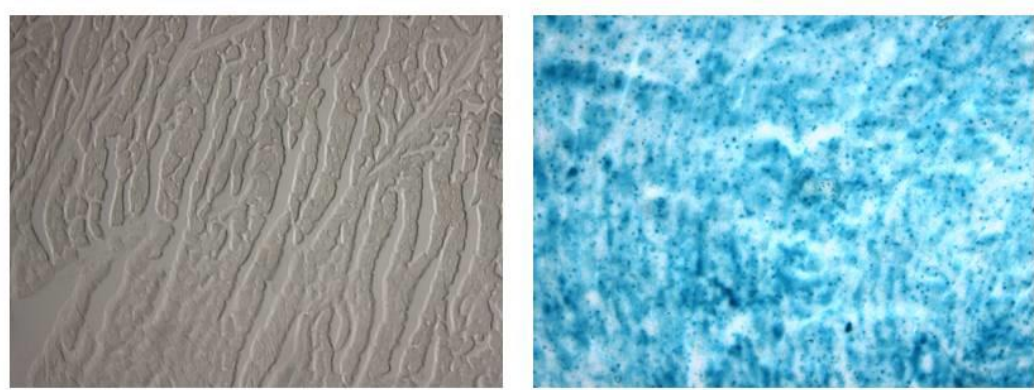

Herz

Abb. 6: Histologie des Gewebes einer Stra8 - Cre / R26R - Maus mit X - Gal - Färbung

Zur Überprüfung der LacZ - Expression in den einzelnen Geweben wurden histologische Schnitte angefertigt und mit X-Gal gefärbt. Dabei wird LacZ durch einen blauen Farbumschlag nachgewiesen. Als Positivkontrolle diente dasselbe Gewebe aus einer ROSA26 - Maus, die LacZ ubiquitär exprimiert. Hierbei stellte sich heraus, dass sich keine reproduzierbaren Ergebnisse generieren liessen.

\subsection{Promotoranalyse}

\subsubsection{Putative Promotoren}

Bisher wurde die Expression von Stra8 unter einem putativen 400bp Promotor (Giuili et al. 2002) und unter einem putativen $1,4 \mathrm{~kb}$ Promotor (Nayernia et al. 2004) untersucht. Dabei liegt der putative 400 bp Promotor innerhalb des 1,4 kb großen putativen Promotors. Beide Promotoren wurden im Zusammenhang mit 
spermatogonialen Stammzellen (SSCs) beschrieben. Laut Hypothese ließ sich mit der X - Gal - Färbung eine Blaufärbung erwarten. Es zeigte sich jedoch, dass keine verlässlichen Ergebnisse generiert werden konnten. Daher entschied ich, die Aktivität verschiedener putativer Promotorbereiche genauer $\mathrm{zu}$ untersuchen, um $\mathrm{zu}$ überprüfen, ob es einen aktiveren Promotor als den hierbei verwendeten 1,4kb Promotor gibt.

Für Stra8 kamen anhand der Gendatenbank von cisview (http://Igsun.grc.nia.nih.gov/cisview/) vier putative Promotoren in der 5'- Region des Stra8-Gens in Frage. Die Benennung der Promotoren richtet sich nach deren Größe.

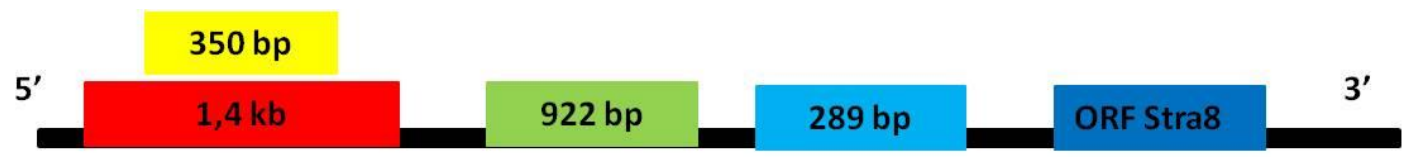

Abb. 7: Putative Promotorbereiche von Stra8:

Anhand der Gendatenbank cisview kommen vier mögliche Promotorbereiche vor dem Open Reading Frame (ORF) für Stra8 in Frage. Die Promotoren werden ihrer Größe nach benannt. Promotor 350bp liegt innerhalb des Promotors 1,4 kb.

\subsubsection{Erstellen des pGL3 - Konstrukts}

Für die Promotoranalysen wurden das pGL3 Luciferase Reporter System der Firma Promega verwendet. Dieses besteht aus vier verschiedenen Vektoren mit deren Hilfe die Promotoraktivität bestimmt werden kann. Einer dieser Vektoren (Enhancer Vektor Abb.9) enthält das jeweilig zu untersuchende Promotorstück, die restlichen Vektoren dienen als Positiv - bzw. Negativkontrolle. Die putativen Promotorregionen wurden zuerst über eine PCR auf Wildtyp - DNA amplifiziert und nach einer Gelextraktion in pGemTeasy kloniert. Die so erhaltenen Promotorfragmente wurden durch eine Sequenz-PCR auf Mutationen untersucht. Anschließend wurde ein geeigneter Klon für die weiteren Experimente ausgewählt.

Für die Messungen der Luziferaseaktivität wurden vier Vektoren verwendet, die in ihrem Aufbau untereinander gering variieren. Der pGL3 - Basic - Vektor (4818bp) (Abb.8) hat weder Promotor noch Enhancer und diente als Negativkontrolle. Der pGL3 - Enhancer - Vektor (5064bp) (Abb.9) besitzt dagegen keinen Promotor, aber einen Enhancer. In diesen Vektor wurden die zu untersuchenden putativen 
Promotoren eingefügt. In der unbearbeiteten Form diente auch er als Negativkontrolle. Der pGL3 - Promotor - Vektor (5010bp) (Abb.10) verfügt über einen Promotor, aber über keinen Enhancer und dient somit ebenfalls als Negativkontrolle. Als Positivkontrolle wurde der pGL3 - Control - Vektor benutzt (5256bp) (Abb. 11), der sowohl Promotor als auch Enhancer hat.

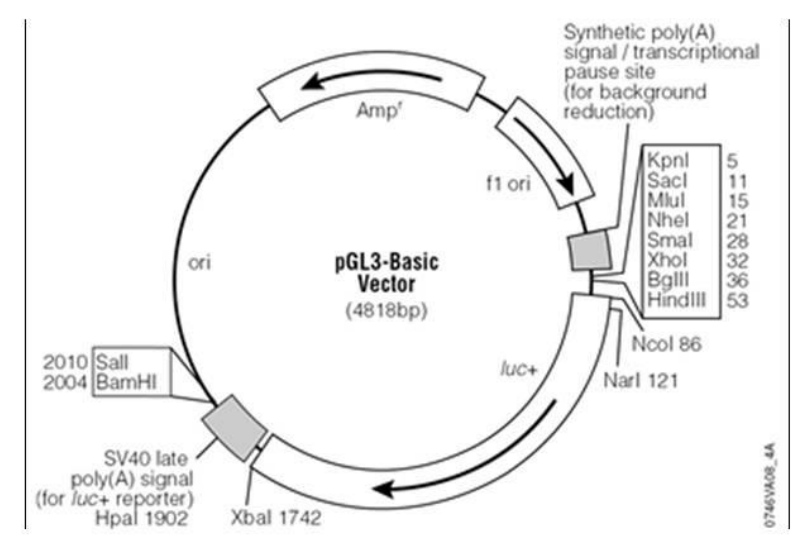

Abb. 8: Basic - Vektor: Für die Promotoranalyse wurden pGL3 - Luciferase - Reporter - Vektoren verwendet. Der Basic - Vektor hat weder Promotor noch Enhancer und dient als Negativkontrolle. Mit freundlicher Genehmigung von Promega Corporation, Madison, USA

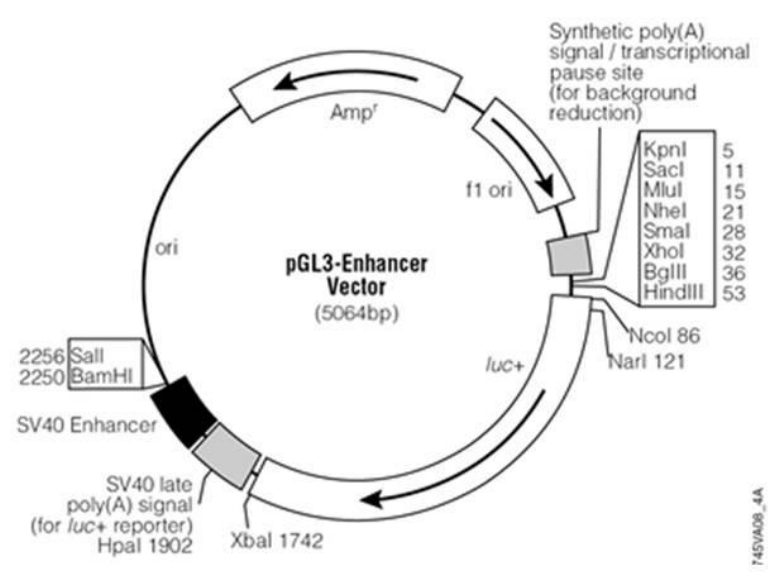

Abb. 9: Enhancer - Vektor: Der pGL3 - Enhancer - Vektor besitzt keinen Promotor, jedoch einen Enhancer. In diesen Vektor wurden die zu untersuchenden Promotoren mit Hilfe der Restriktionsenzyme Xhol, BglIII und HindIIII eingefügt. Die unbearbeitete Form diente als Negativkontrolle.

Mit freundlicher Genehmigung von Promega Corporation, Madison, USA 


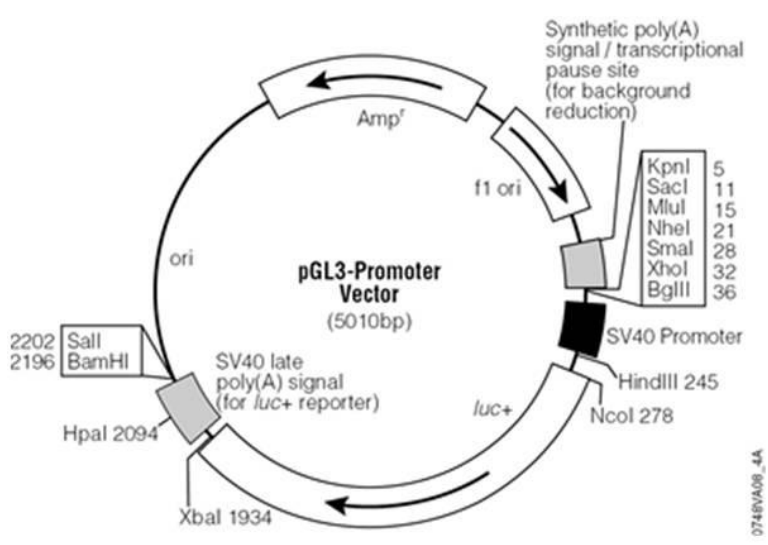

Abb. 10: Promotor - Vektor: Dieser Vektor verfügt über einen Promotor, aber keinen Enhancer und dient als Negativkontrolle.

Mit freundlicher Genehmigung von Promega Corporation, Madison, USA

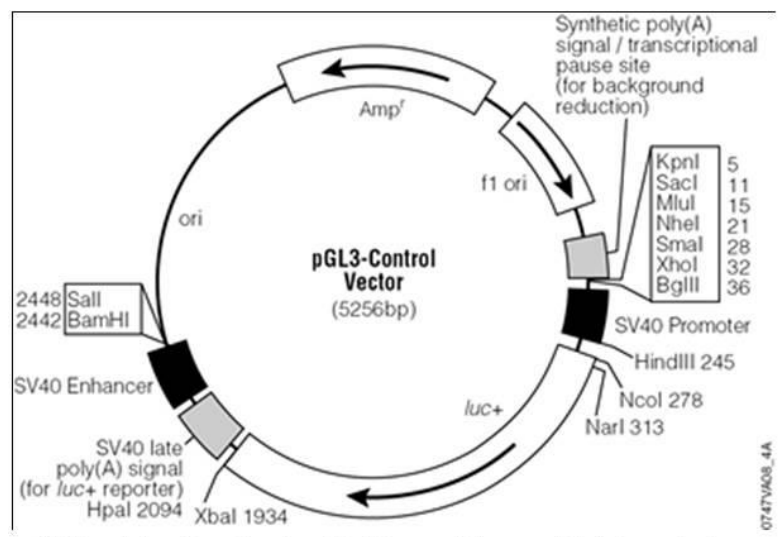

Abb. 11: Control - Vektor: Dieser Vektor hat sowohl einen Promotor als auch einen Enhancer und dient als Positivkontrolle.

Mit freundlicher Genehmigung von Promega Corporation, Madison, USA

Im Institut waren bis auf den pGL3 - Enhancer- Vektor alle anderen Vektoren vorhanden. Der fehlende Vektor konnte jedoch aus dem pGL3 - Basic und dem pGL3 - Control - Vektor hergestellt werden. Beide Vektoren wurden mit Xbal \& BamHI geschnitten. Aus dem pGL3 - Basic - Vektor wurde der Backbone (4556bp) (Abb. 12) benutzt und mit dem Enhancer + SV40 Poly A Stück (508bp) des pGl3 - Control Vektors (Abb. 13) ligiert. Nach einer Transformation in kompetente DH5a Zellen wurde der so generierte pGL3 - Enhancer - Vektor durch eine Midipräp isoliert und über einen Testverdau kontrolliert. (Abb.14) 


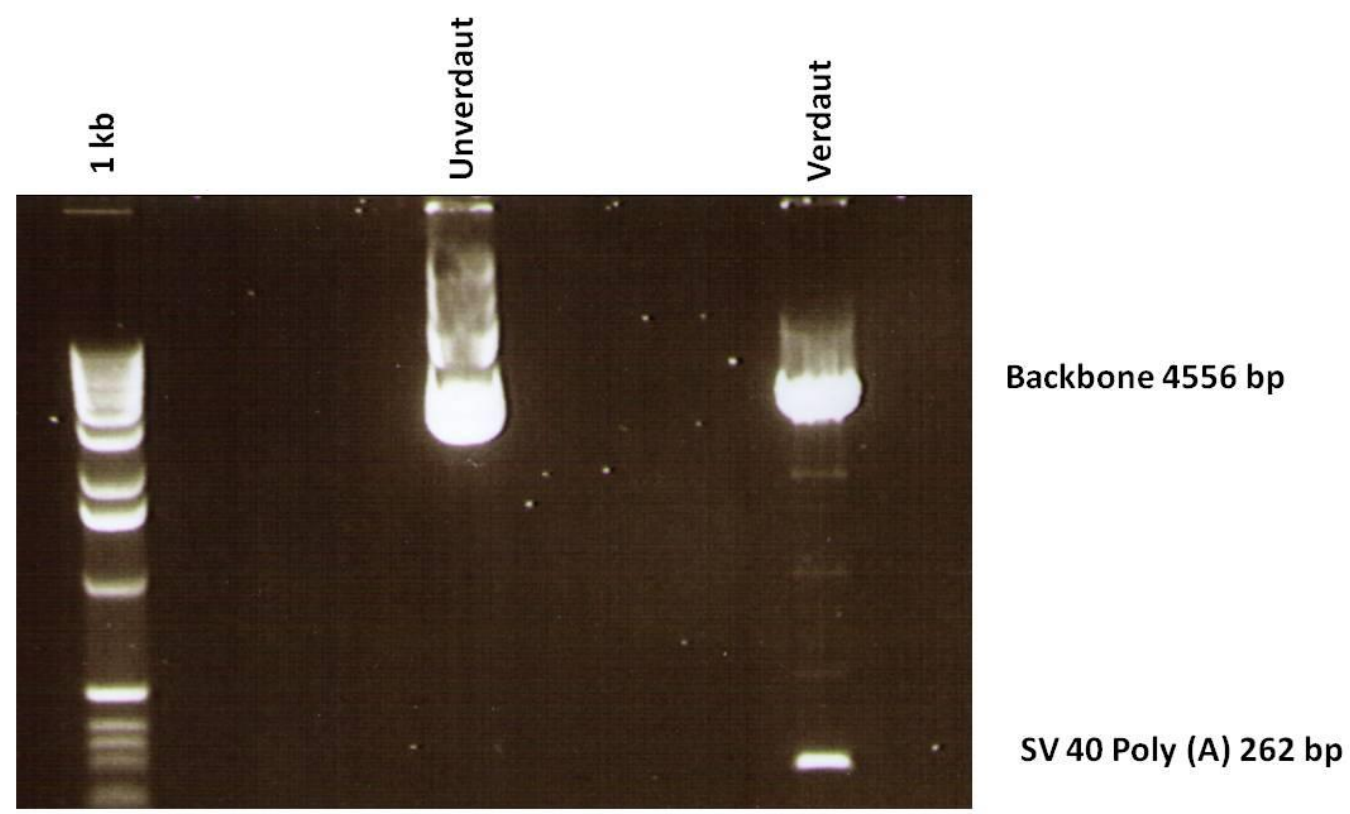

Abb. 12: Testverdau pGL3 - Basic - Vektor: Um einen pGL3 - Enhancer - Vektor herzustellen, wurde ein pGL3 - Basic - Vektor mit den Restriktionsenzymen Xbal und BamHI geschnitten und der Backbone zur weiteren Kontruktion benutzt.

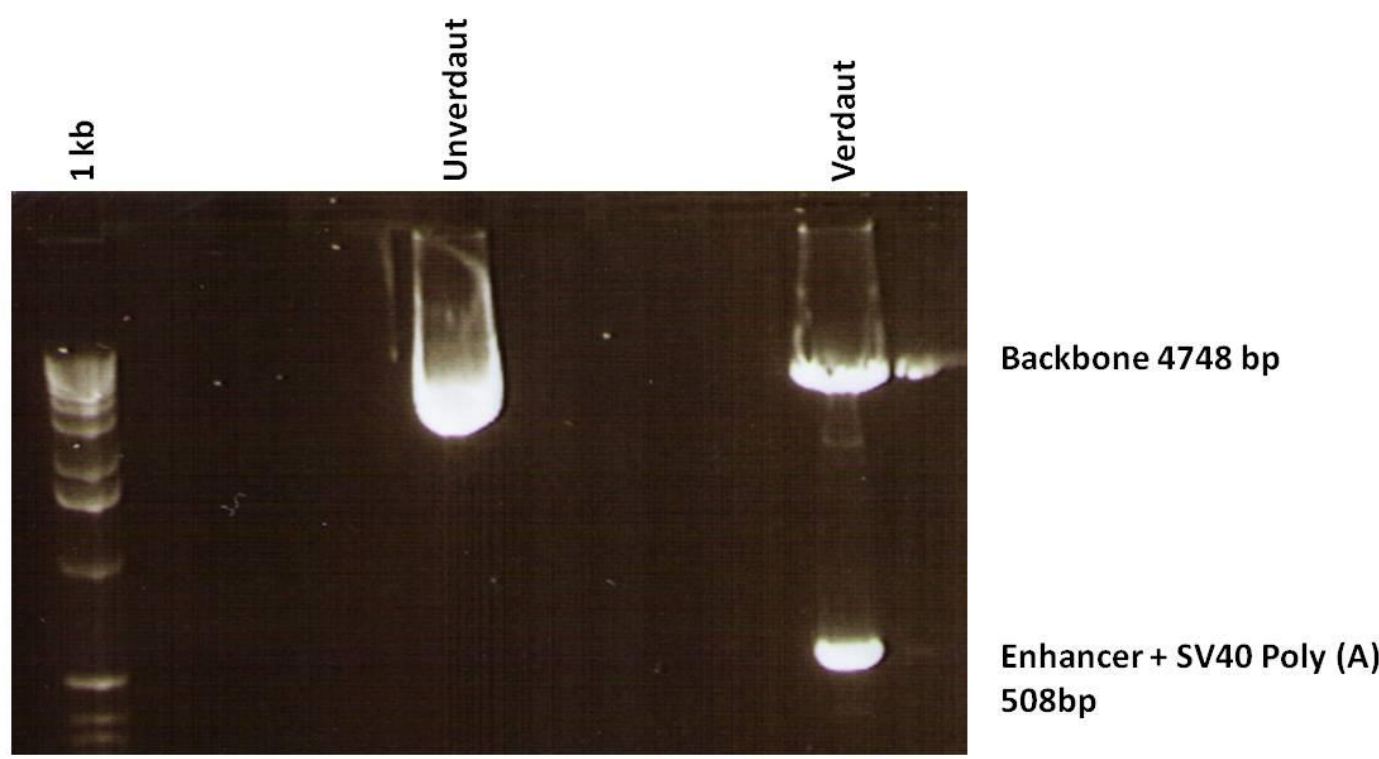

Abb. 13: Testverdau pGL3 - Control - Vektor: Um einen pGL3 - Enhancer - Vektor zu bauen, wurde ein pGL3 - Control - Vektor mit den Restriktionsenzymen Xbal und BamHI geschnitten und der Enhancer zur weiteren Kontruktion benutzt. 


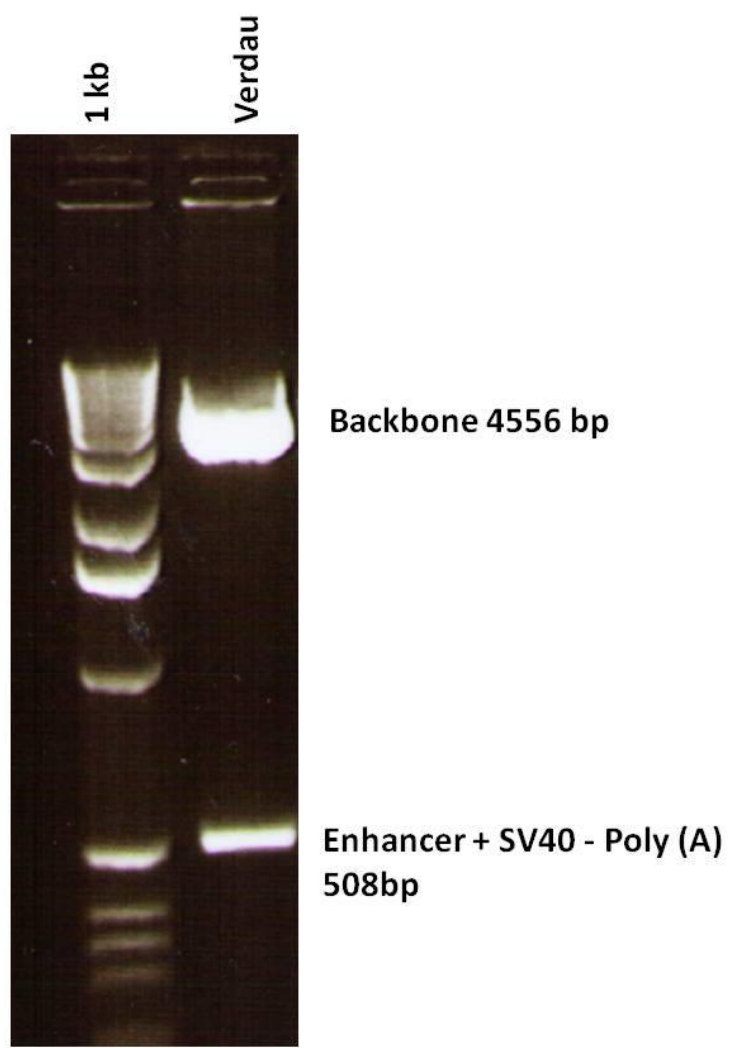

Abb. 14: Testverdau pGL3 - Enhancer nach Ligation: Der aus Abbildung 12 gewonnene Backbone (4556 bp) wurde mit dem aus Abbildung 13 gewonnenen Enhancer (508 bp) ligiert und testverdaut.

Nun standen alle vier Vektoren zu Verfügung, und es konnte mit der Klonierung der putativen Promotorensequenzen begonnen werden.

Der Luziferasevektor pGL3 - Enhancer wurde durch Restriktionsenzyme (Xhol, Bglll \& HindIII) geschnitten und die putativen Promotoren wurde in den Vektor ligiert. Dieser Vektor wurde nun in kompetente DH5a Zellen transformiert, vervielfältigt und durch eine Minipräparation isoliert. Um das Vorhandensein des Inserts zu bestätigen, wurde ein Testverdau durchgeführt. (Abb.15) 


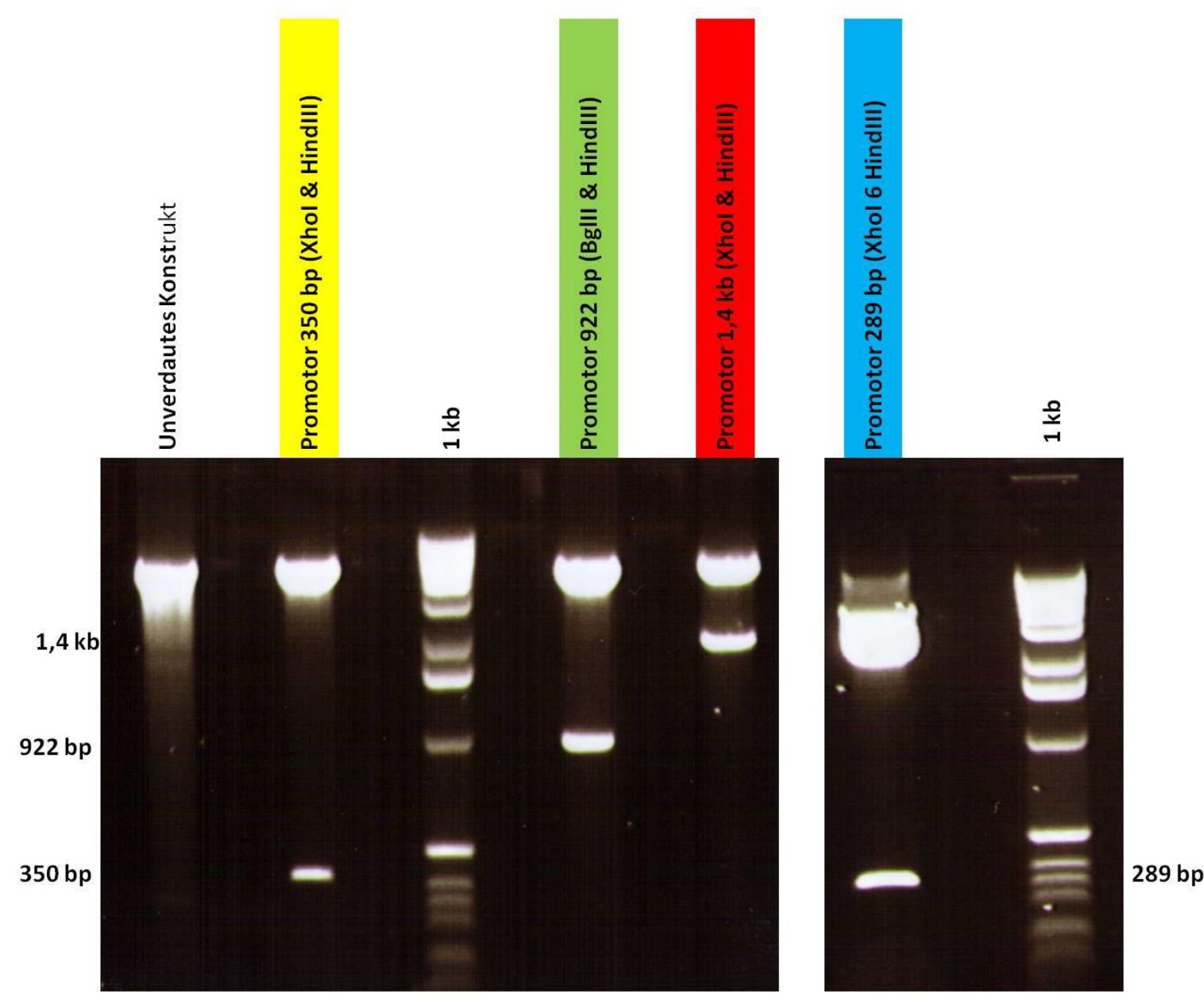

Abb. 15: Testverdau der einzelnen Konstrukte in pGL3 - Enhancer: Der in Abbildung 14 dargestellte Luziferasevektor pGL3 - Enhancer wurde durch die Restriktionsenzyme Xhol, BgIII \& HindIII geschnitten und mit den jeweiligen putativen Promotoren aus Abbildung 7 ligiert. Die so entstandenen Konstrukte wurden zur Kontrolle nochmals verdaut und gelelektrophoretisch aufgetrennt.

Nachdem nun alle vier putativen Promotoren in den pGL3 - Enhancer kloniert waren, konnte mit dem eigentlichen Versuch begonnen werden. Dazu wurden alle Plasmide getrennt voneinander in ES-R1 - Zellen transfiziert und diese 5 Tage kultiviert. Die Zellen wurden anschließend lysiert und konnten mit dem Dual-Luziferase - Reporter Assay (Promega) analysiert werden. Dabei dient das Protein Firefly - Luciferase (Photinus pyralis) als genetischer Reporter und gibt Auskunft wie stark der jeweilige Promotor aktiv ist. Das Enzym setzt Beetle Luciferin in Oxyluciferin um, wobei Licht freigesetzt wird, welches mithilfe eines Luminometers gemessen wird. Die Genauigkeit der Ergebnisse lässt sich durch die simultan exprimierte und gemessene konstitutiv aktive Renilla Luziferase verbessern. Renilla - Luciferase (Renilla reniformis) setzt Coelenterazine in Coelenteramide um, wobei Licht freigesetzt wird, welches ebenfalls im Luminometer messbar ist. Werden die Messwerte der Firefly 
durch die Messwerte der Renilla dividiert, werden womöglich vorherrschende verschiedene Transfektionseffizienzen normalisert.

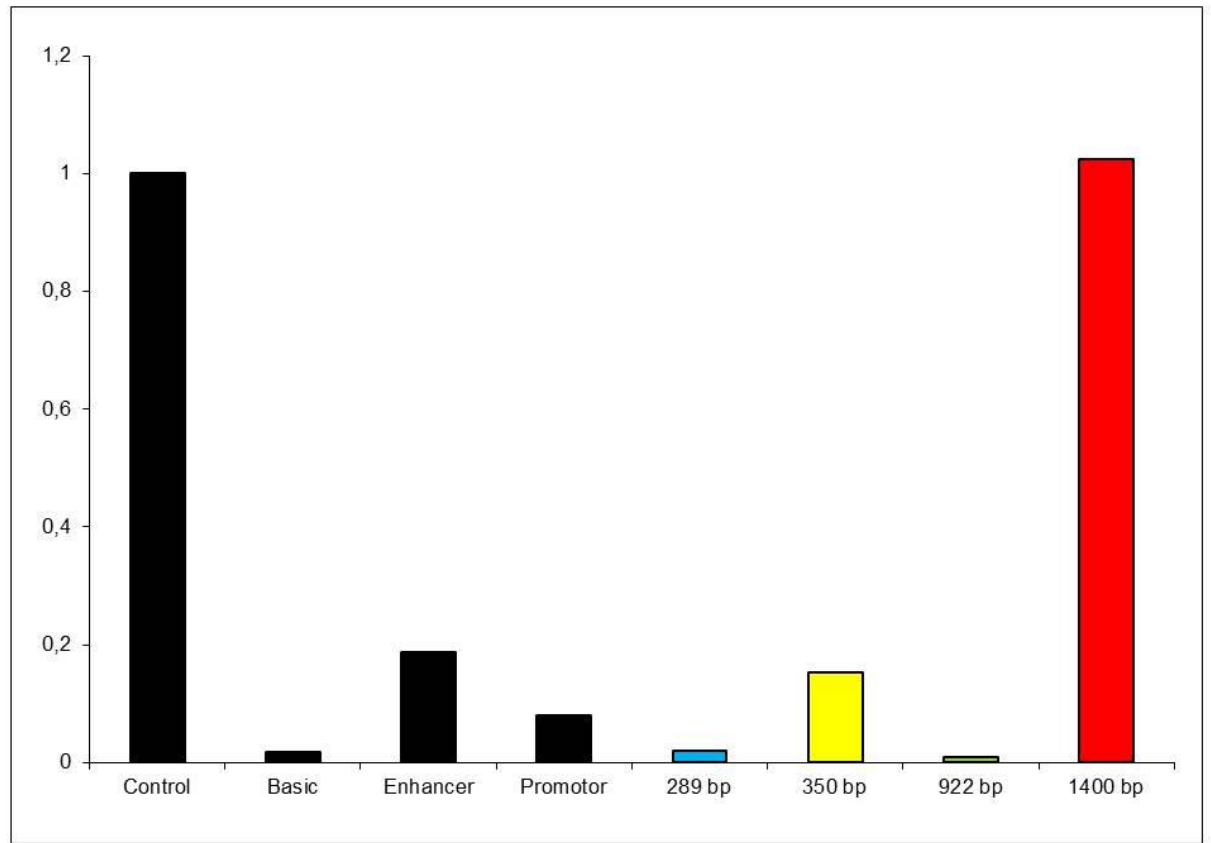

Abb. 16: Luziferasemessung: Die jeweiligen Plasmide aus Abbildung 15 wurden in ES-R1 - Zellen transfiziert und diese Zellen 5 Tage in Kultur genommen. Gleichzeitig wurde zur Transfektionskontrolle mit den Plasmiden eine konstante Menge eines pRLSV40 - Kontrukts mit transfiziert. Nach Lysierung wurden die Zellen mit Dual-Luziferase Reporter Assay gemessen. Dieses Kit misst gleichzeitig die Renillaaktivität des pRLSV40 - Konstrukts und die Fireflyaktivität des Luziferasekonstrukts und setzt dieses ins Verhältnis. Somit kann die Inensität der Luziferasereaktion nicht durch die Transfektionseffizienz beeinflußt werden.

Aus Abbildung 16 geht eindeutig hervor, dass der gewählte 1,4 kb - Promotor aktiv ist. Somit muss auch die B-Galactosidase in den Organen nachweisbar sein, in denen Stra8 aktiv war. Aufgrund dieser Ergebnisse konnte nun davon ausgegangen werden, dass der verwendete Promotor in der inneren Zellmasse (Embryoblast), die das Äquivalent zu ES-Zellen darstellt, aktiv ist. Außerdem kann man davon ausgehen, dass die nicht detektierbare LacZ - Expression auf technische Probleme bei den Färbetechniken zurückzuführen ist. Dieses deutete sich ja auch schon aufgrund der schlechten Reproduzierbarkeit an.

\subsection{Expressionsanalysen von LacZ in doppelt transgenen Mäusen}

Um zu sehen, ob LacZ überhaupt exprimiert wird, wurde eine Reverse Transkriptase PCR durchgeführt. Die gewählten Primer amplifizieren ein Produkt von 183 bp. Aus je einer Stra8-Cre/R26R, ROSA26 und WT Maus wurden Testes, Leber, Niere und Herz entnommen. Aus diesen Organen wurde RNA gewonnen, diese mit Hilfe eines 
Kits in CDNA umgeschrieben und durch eine PCR amplifiziert. Die verwendeten Primer binden komplementär an die LacZ - Sequenz. In Abbildung 17 sieht man, dass sowohl die Stra8-Cre/R26R - Maus als auch die ROSA26 - Maus in den untersuchten Organen LacZ exprimiert, nicht jedoch in den Organen einer WT-Maus, was die Spezifität der PCR belegt. Dieses Ergebnis war ein weiterer Hinweis darauf, dass die Ausgangshypothese wahrscheinlich ist.
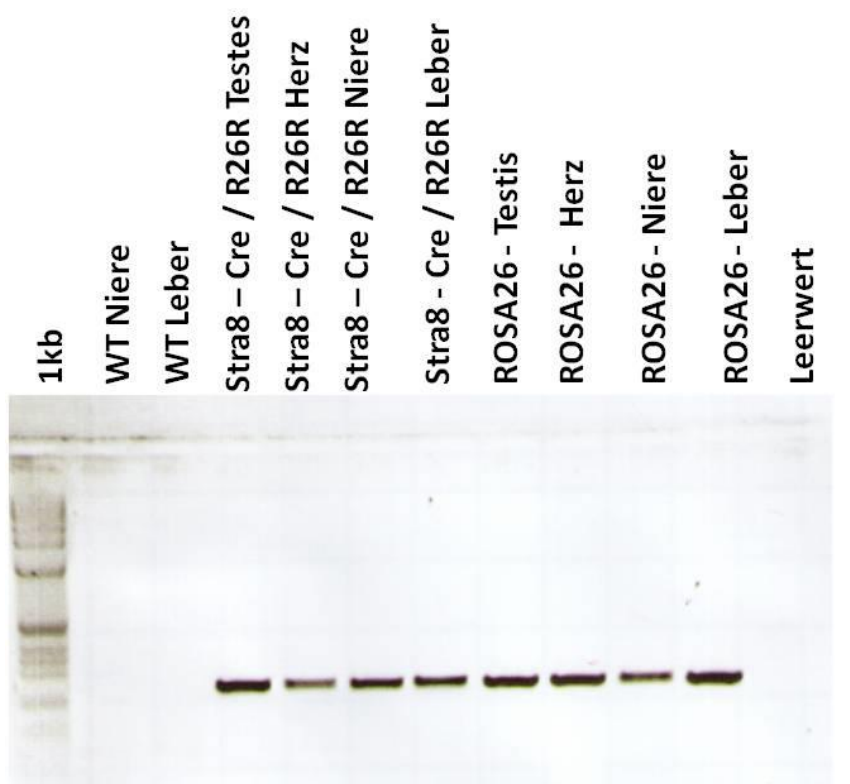

$183 \mathrm{bp}$

Abb. 17: Reverse Transkriptase PCR: Um sicher zu gehen, dass LacZ exprimiert wird, wurde RNA verschiedener Organe der Stra8 - Cre / R26R Maus mit Hilfe einer RT - PCR für LacZ untersucht. Als Negativkontrolle dienten Organe einer Wildtypmaus, als Positivkontrolle die Organe einer ROSA26 Maus. In Testes, Herz, Leber und Niere wird eindeutig eine 183 bp - Bande sichtbar, die sich in der Positivkontrolle bestätigt und in der Negativkontrolle fehlt. 


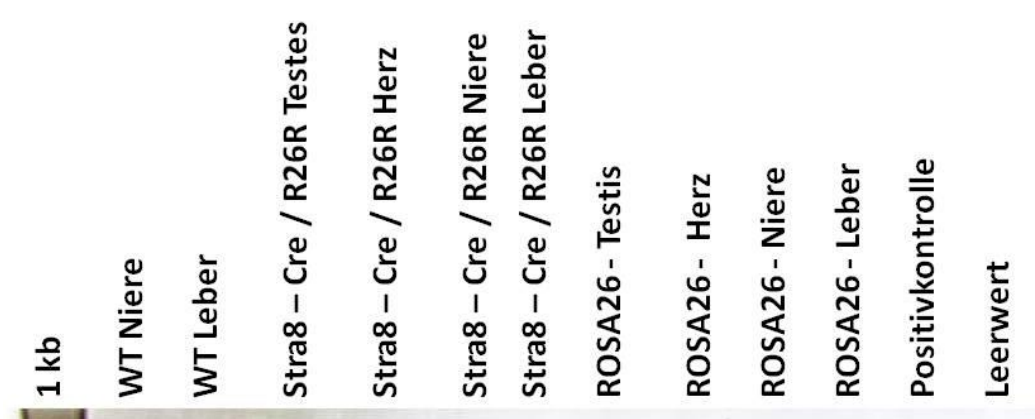

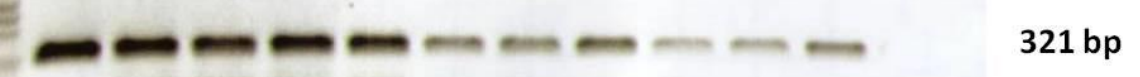

Abb. 18: HPRT - PCR: Um falsch negative Ergebnisse zu vermeiden, wurden die in Abbildung 17 benutzten Proben durch eine weitere RT - PCR untersucht. Es sollte sichergestellt werden, dass sich überhaput amplifizierbare cDNA in den Proben befindet. Die gewählten Primer (HPRT) amplifizieren einen DNA Abschnitt, der in jeder Maus vorhanden ist. Dabei entsteht eine Bande von 321 bp.

\subsection{Immunhistologie}

Nachdem nun sicher war, dass sowohl der richtige Promotor für das Konstrukt der transgenen Maus gewählt worden war, dieses auch funktioniert als auch LacZ als Detektor exprimiert wird, galt es, eine Methode zu etablieren, um LacZ zuverlässig nachzuweisen. Über Immunhistologie kann Expression auf Proteinebene mit Hilfe eines spezifischen Antikörpers gegen LacZ aufgezeigt werden.

\subsubsection{Testes in verschiedenen Entwicklungsstufen}

Während der Embryogenese wird Stra8 - Expression nur in den männlichen Gonaden gefunden, in erwachsenen Mäusen ist die Expression auf die prämeiotischen Keimzellen beschränkt (Oulad-Abdelghani et al. 1996).

Daher wurden als erstes Testes von neugeborenen, $5 \mathrm{~d}, 10 \mathrm{~d}, 15 \mathrm{~d}$ und $20 \mathrm{~d}$ alten homozygoten und heterozygoten Stra8-Cre/R26R - Mäusen untersucht. Die Testes wurden aus genotypisierten Mäusen präpariert, fixiert und in Paraffin eingebettet. Am Mikrotom wurden $5 \mu \mathrm{m}$ dünne Schnitte hergestellt und auf Objektträger aufgezogen. Diese wurden nun mit einem LacZ - Antikörper gefärbt, welcher wiederum durch den zweiten Antikörper detektiert werden konnte. Alle Entwicklungsstadien zeigten eine positive Färbung, die nicht auf die prämeiotischen Keimzellen beschränkt war. 
Um eine unspezifische Bindung des zweiten Antikörpers auszuschließen, wurde die Färbung nur mit dem zweiten Antikörper durchgeführt. Diese fiel wie erwartet negativ aus. (Abb. 21)

Die Abbildungen 19-21 zeigen Präparate, die an einem Konfokalen Laser Scanning Mikroskop bei 600 x Vergrößerung mikroskopiert wurden. 

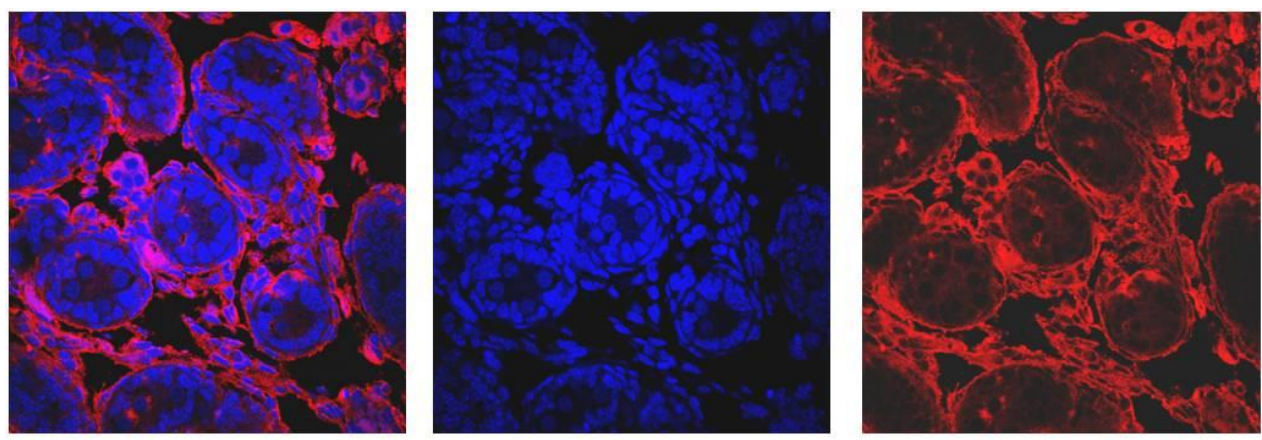

Testis 0 Tage
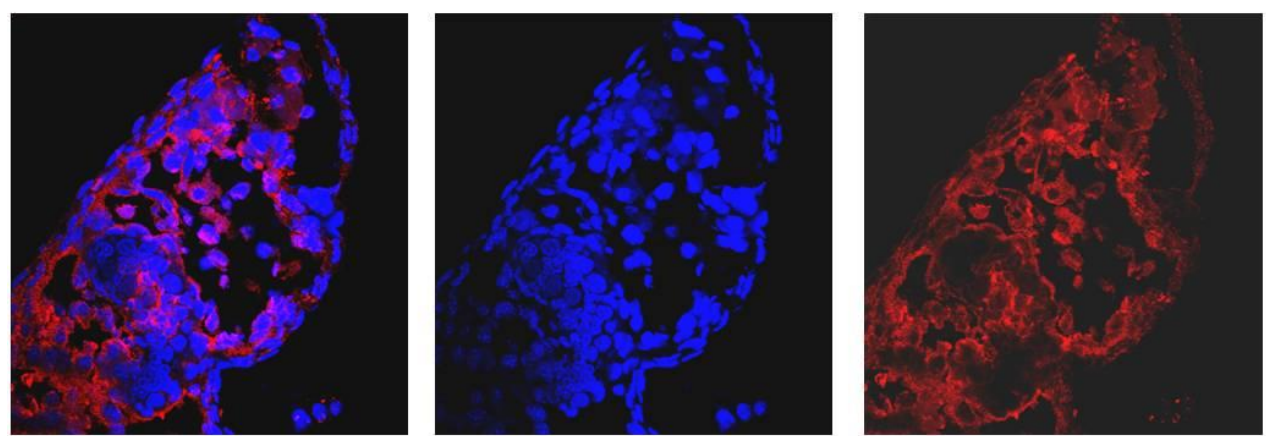

Testis 5 Tage
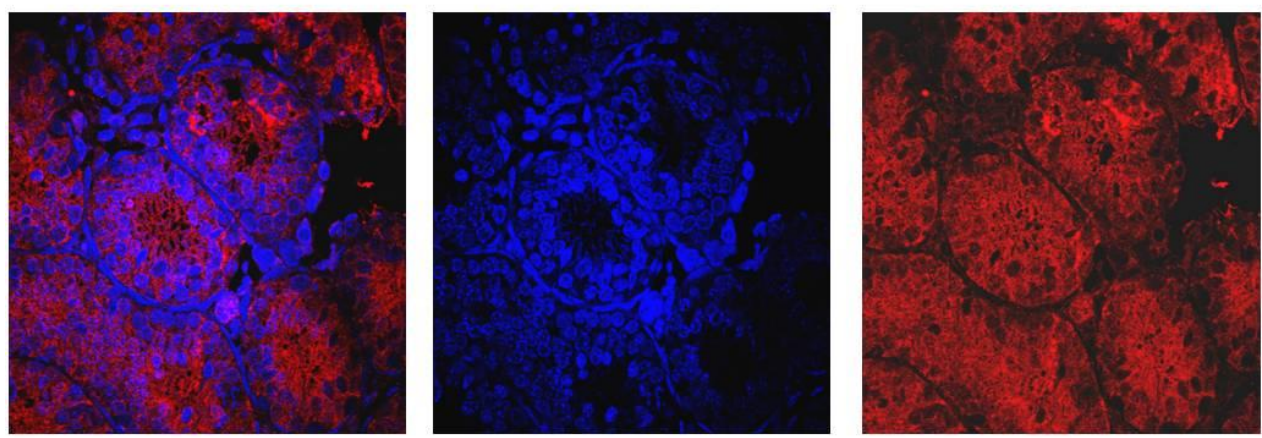

Testis 10 Tage
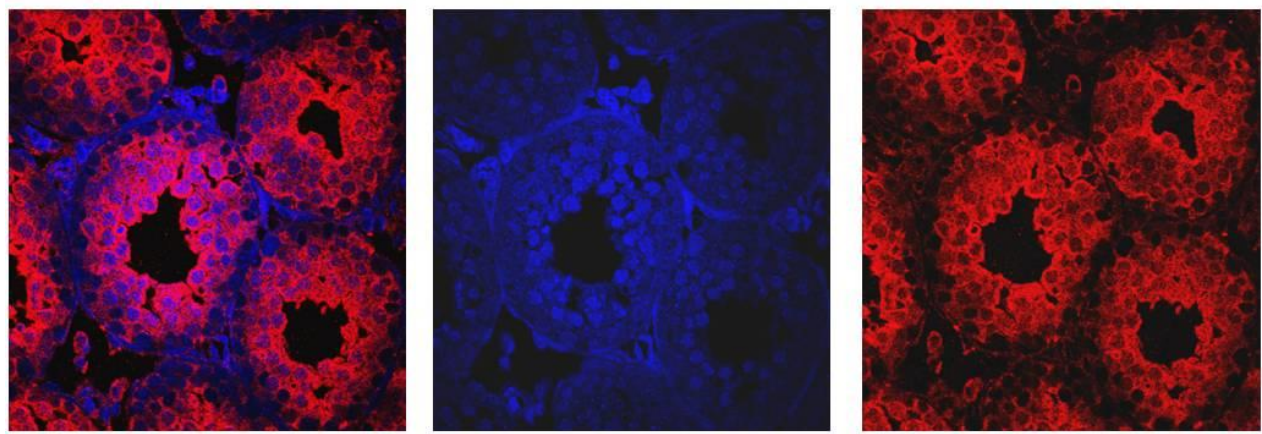

Testis 15 Tage

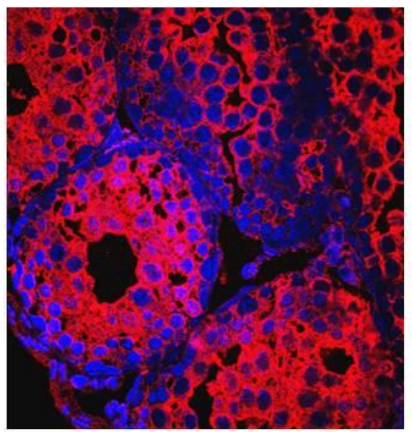

Überlagerung

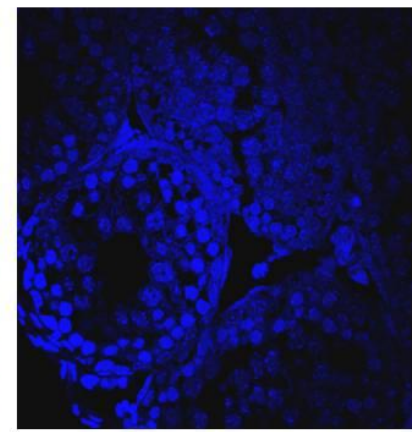

DAPI

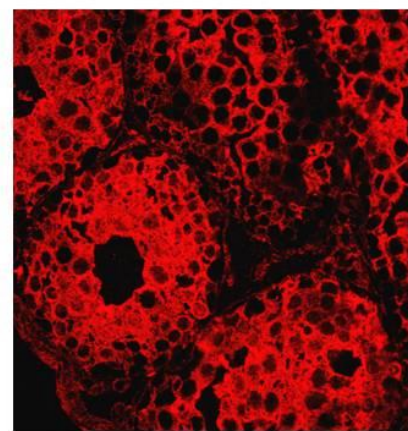

LacZ

Abb. 19: Immunhistologie in der Testisentwicklung einer heterozygoten Stra8 Cre / R26R - Maus von Tag 0 bis Tag 20: LacZ als Detektor für Stra8 wurde durch einen LacZ - Antikörper rot dargestellt. Eine ubiquitäre LacZ - Expression ist während der gesamten Testisentwicklung gegeben. 

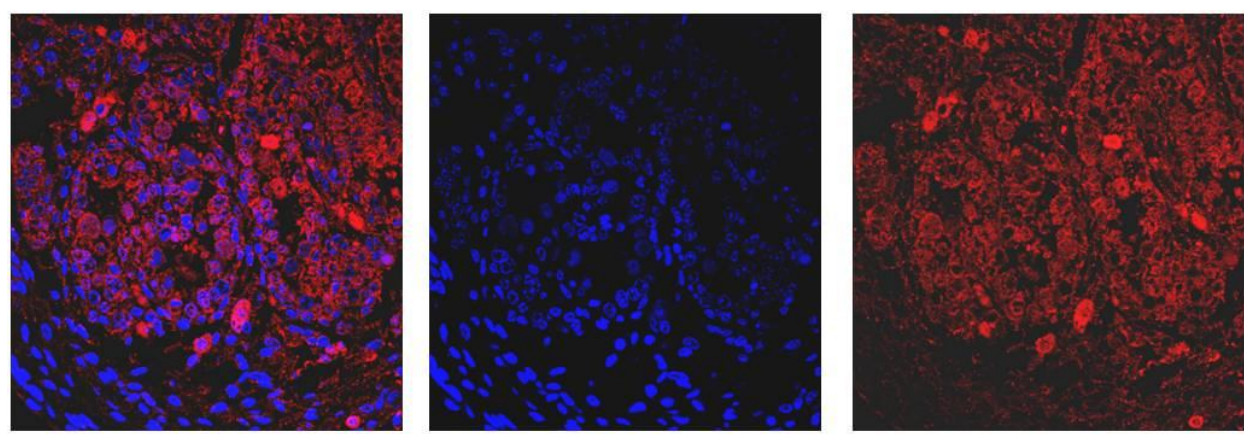

Testis 0 Tage
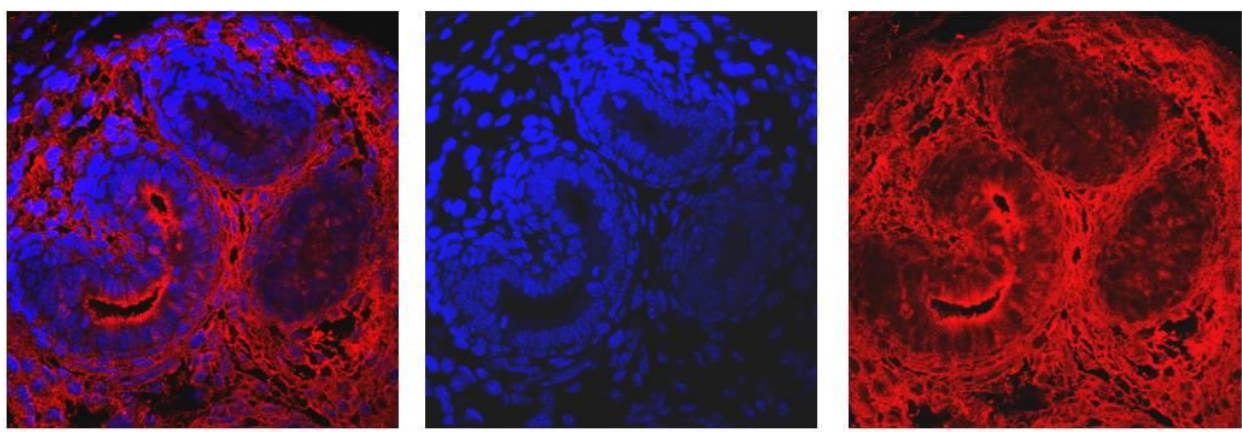

Testis 5 Tage
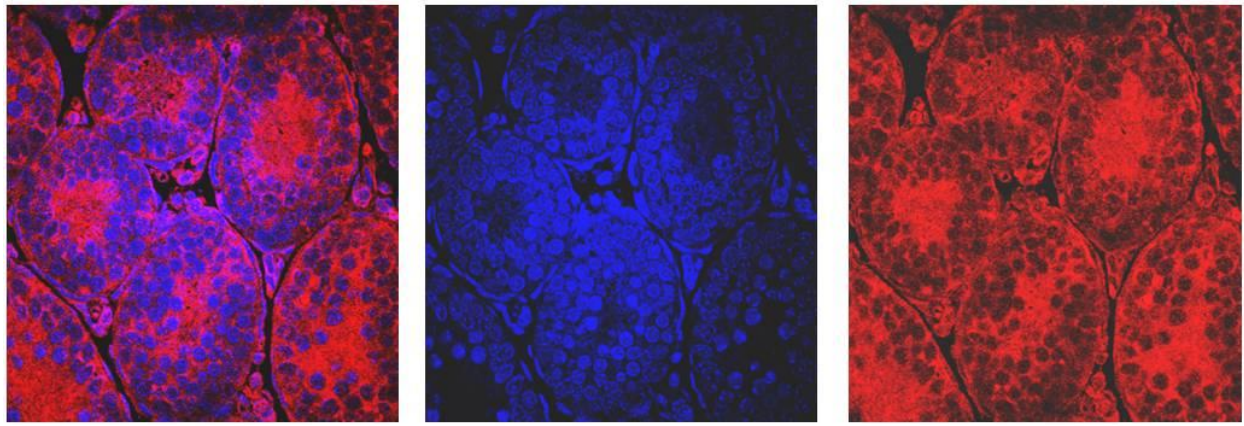

Testis 10 Tage
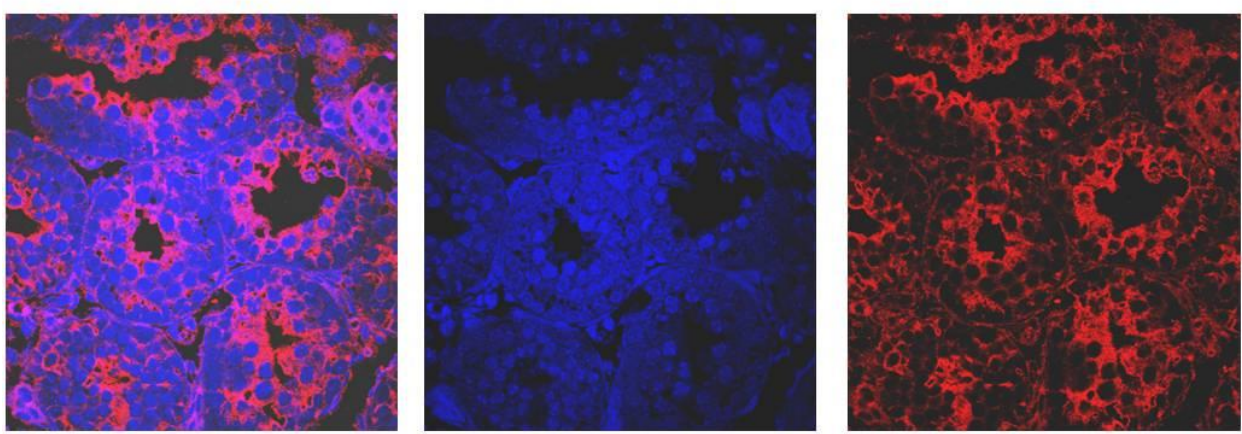

Testis 15 Tage

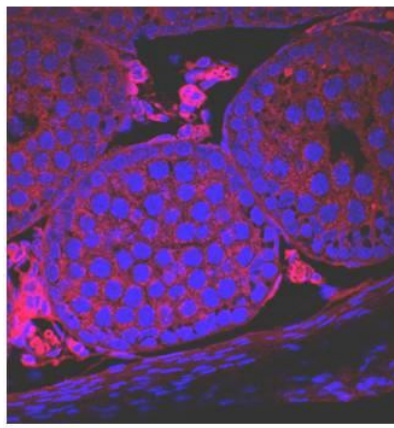

Überlagerung

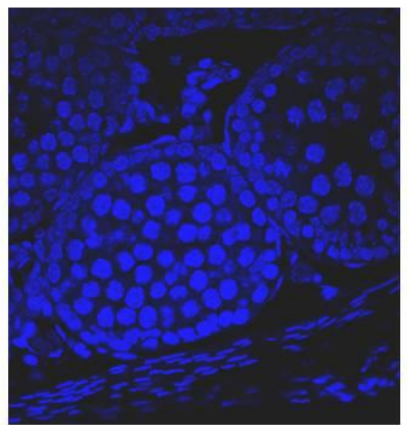

DAPI

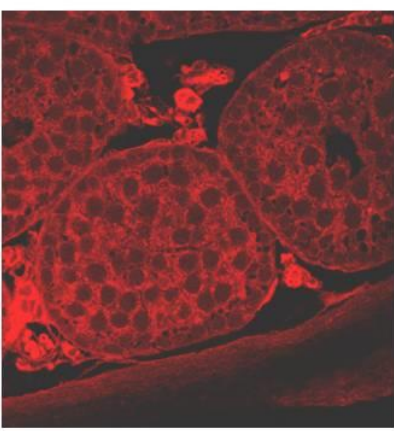

LacZ
Testis 20 Tage

Abb. 20: Immunhistologie in der Testisentwicklung einer homozygoten Stra8 - Cre / R26R Maus von Tag 0 bis Tag 20: LacZ als Detektor für Stra8 wurde durch einen LacZ - Antikörper rot dargestellt. Eine ubiquitäre LacZ - Expression ist während der gesamten Testisentwicklung gegeben. 


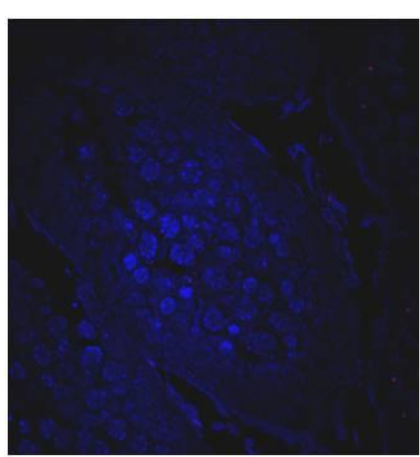

Überlagerung

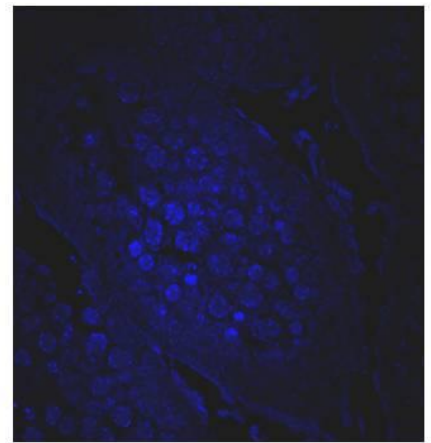

DAPI

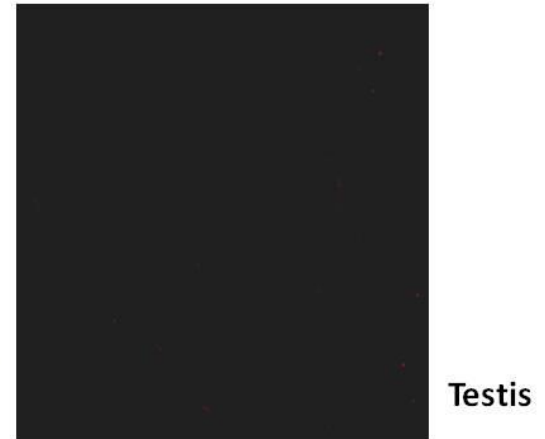

Ohne LacZ AK, nur

2. Antikörper

Abb. 21: Immunhistologie des Testis einer Stra8 - Cre / R26R - Maus nur mit 2. Antikörper (Negativkontrolle). Um eine unspezifische Bindung des zweiten Antikörpers auszuschließen, wurde die Färbung nur mit dem zweiten Antikörper durchgeführt, diese fiel negativ aus.

\subsubsection{Nachweis von LacZ in den verschiedenen Organen}

Für diesen Nachweis wurden Testes/Ovar, Leber, Milz, Niere, Herz, Gehirn, Haut, Muskel, Knochenmark (KM) und Spermien aus homozygoten und heterozygoten Stra8-Cre/R26R - Mäusen präpariert, fixiert und in Paraffin eingebettet. Am Mikrotom wurden $5 \mu \mathrm{m}$ dünne Schnitte hergestellt und auf Objektträger aufgezogen. Diese wurden nun ebenfalls mit dem LacZ - Antikörper gefärbt, über den zweiten Antikörper detektiert und fluoreszierten unter UV Licht rot. Es zeigte sich, dass alle Organe durch Immunhistologie sich mit dem LacZ - Antikörper anfärbten und ubiquitär rot fluoreszierten. Als Negativkontrolle wurden hier die äquivalenten Organe aus den einfach transgenen Stra8-Cre- und R26R- sowie aus Wildtyp- Mäusen genommen und ebenfalls durch Immunhistologie mit dem LacZ - Antikörper gefärbt. Keine der negativen Kontrollen (Stra8-Cre, R26R und Wildtyp) zeigte eine Rotfärbung (Abb. 2833). Als Positivkontrolle wurden dieselben Organe einer ROSA26 - Maus auf dieselbe Art und Weise gefärbt und fluoreszierten ubiquitär rot (Abb. 26-27).

Die Präparate in Abbildungen 22-33 wurden an einem Konfokalen Laser Scanning Mikroskop bei $600 \times$ Vergrößerung mikroskopiert. 

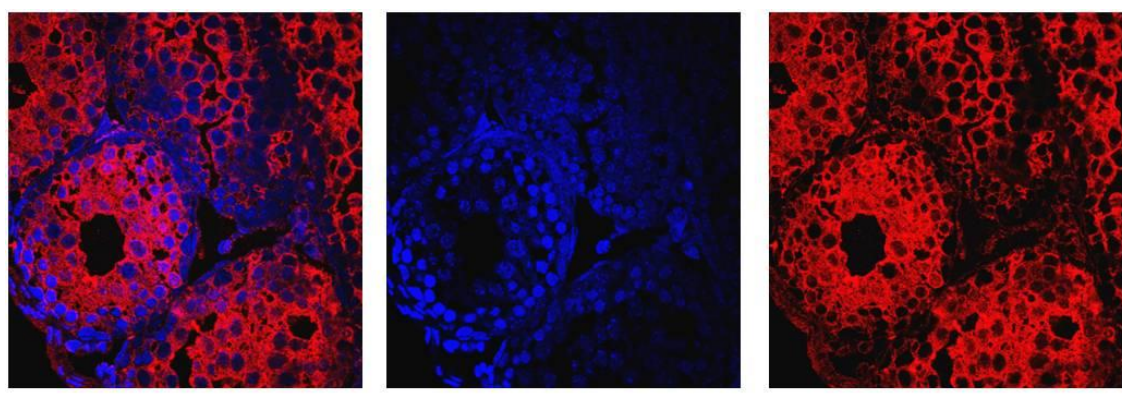

Testis
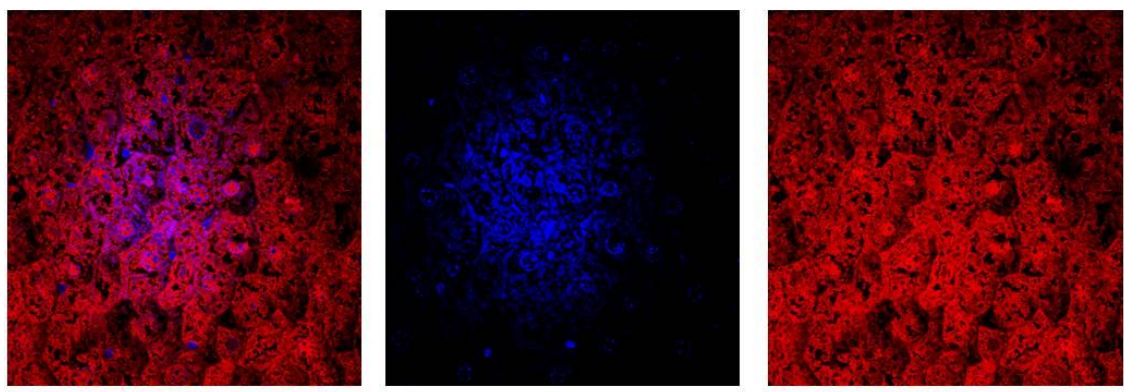

Leber
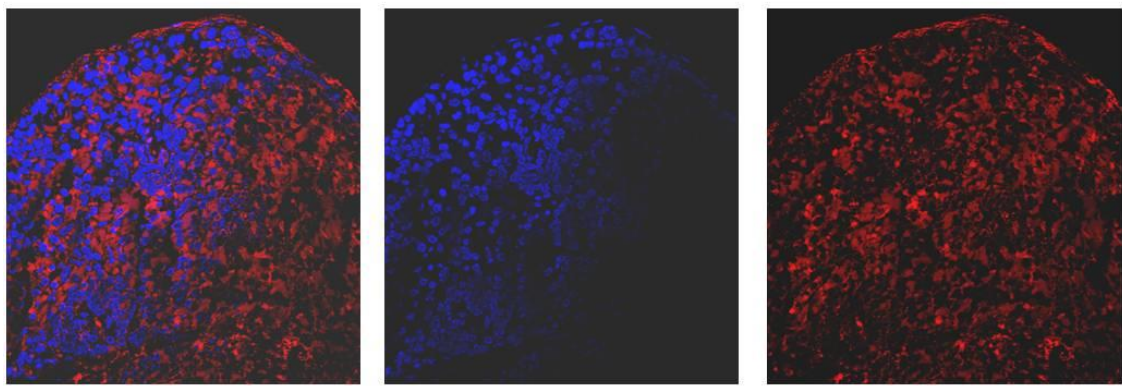

Milz
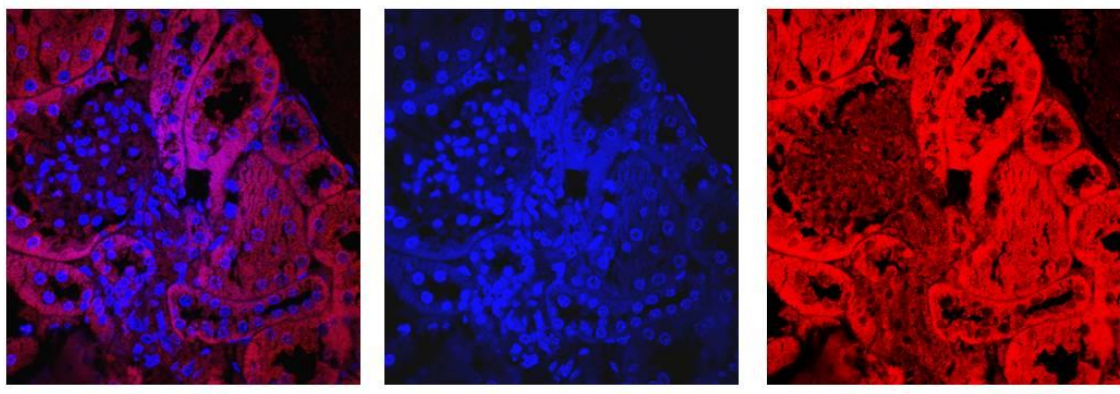

Niere

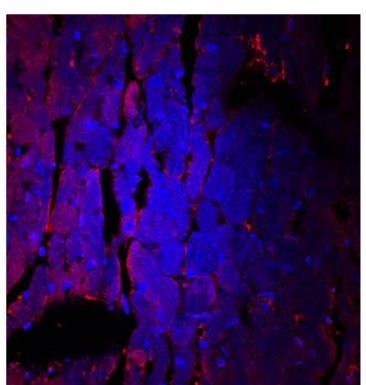

Überlagerung

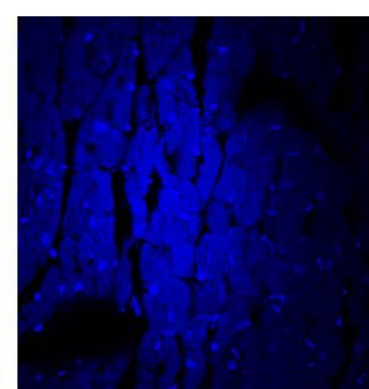

DAPI

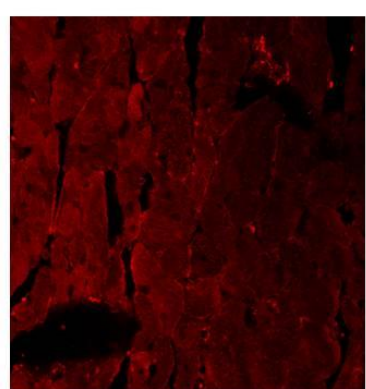

LacZ

Abb. 22: Immunhistologie des Gewebes einer heterozygoten Stra8 - Cre / R26R - Maus. LacZ als Detektor für Stra8 - Expression wurde durch einen LacZ - Antikörper rot dargestellt. Eine ubiquitäre LacZ - Expression ist in allen Organen gegeben. 

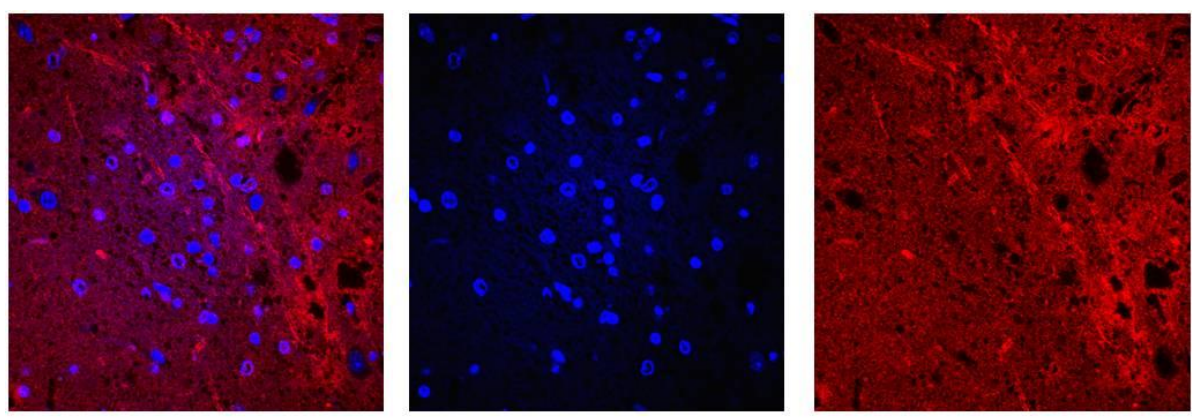

Gehirn
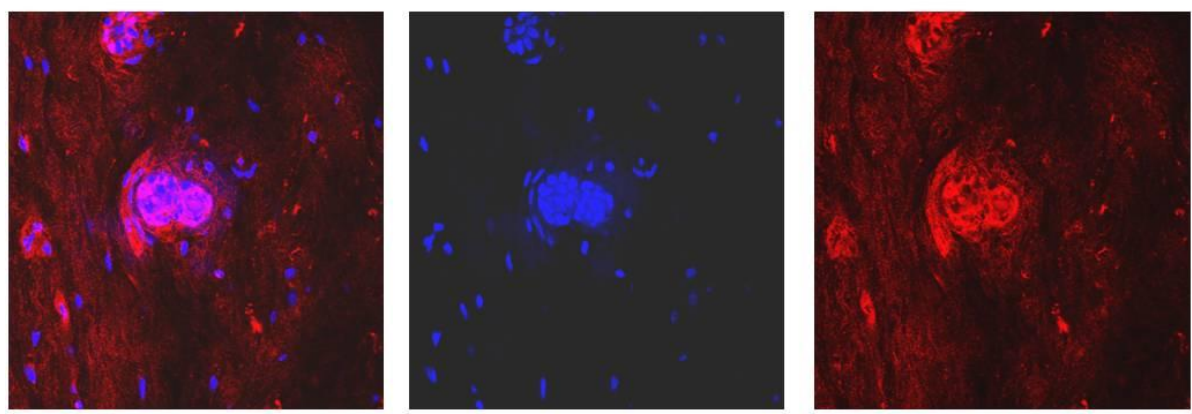

Haut
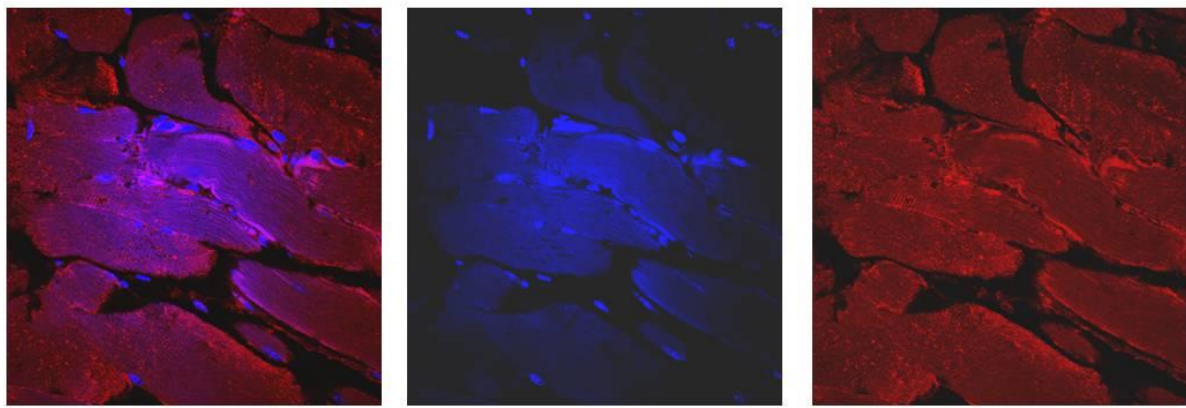

Muskel
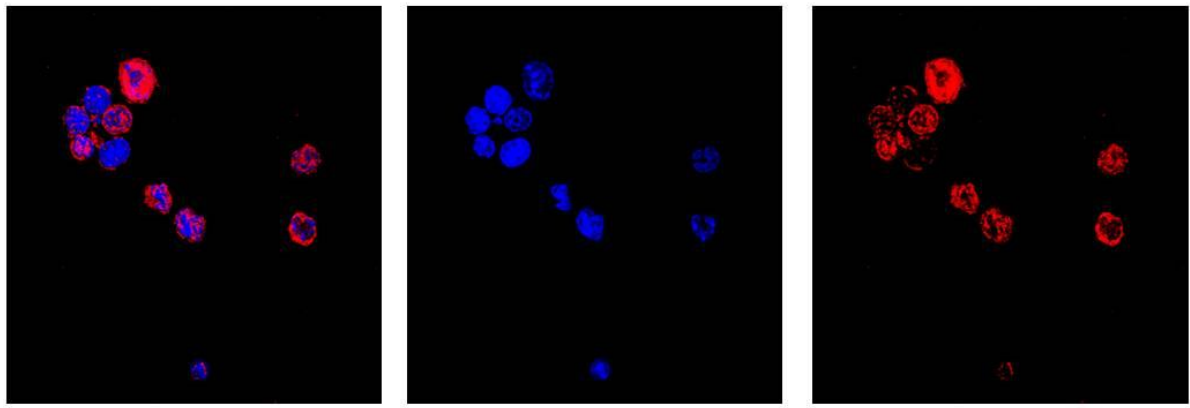

KM

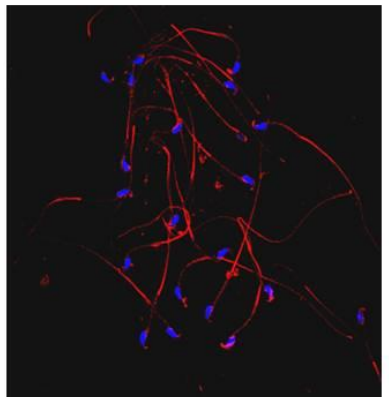

Überlagerung

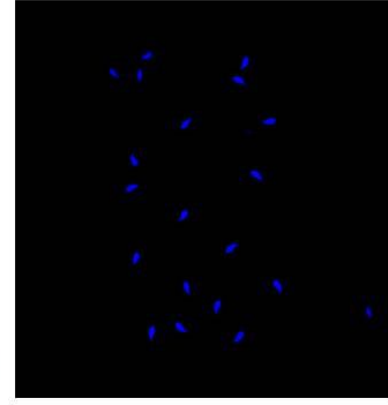

DAPI

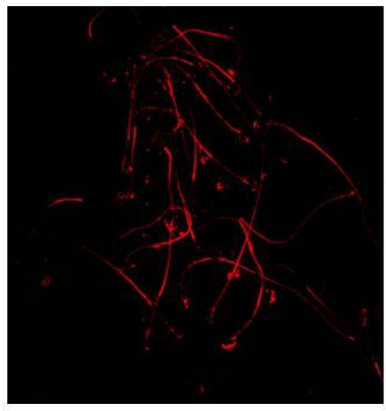

LacZ

Abb. 23: Immunhistologie des Gewebes einer heterozygoten Stra8 - Cre / R26R - Maus. LacZ als Detektor für Stra8 - Expression wurde durch einen LacZ - Antikörper rot dargestellt. Eine ubiquitäre LacZ - Expression ist in allen Organen gegeben. 

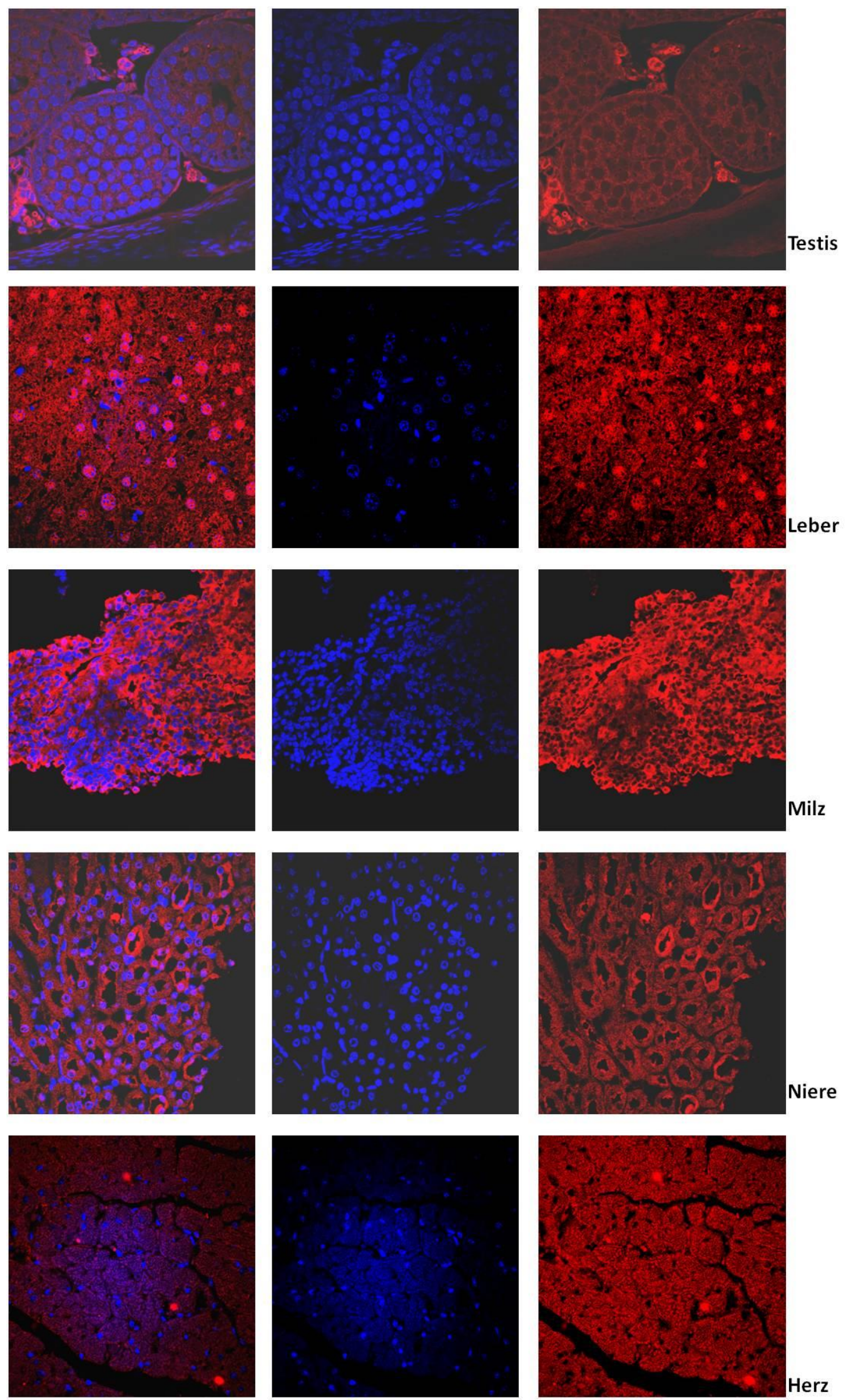

Überlagerung

DAPI

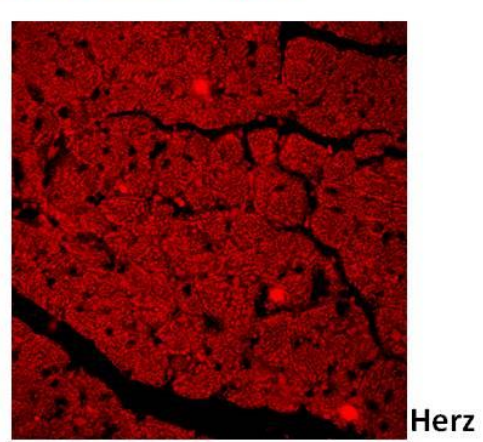

LacZ

Abb. 24: Immunhistologie des Gewebes einer homozygoten Stra8 - Cre / R26R - Maus. LacZ als Detektor für Stra8 - Expression wurde durch einen LacZ - Antikörper rot dargestellt. Eine ubiquitäre LacZ - Expression ist in allen Organen gegeben. 

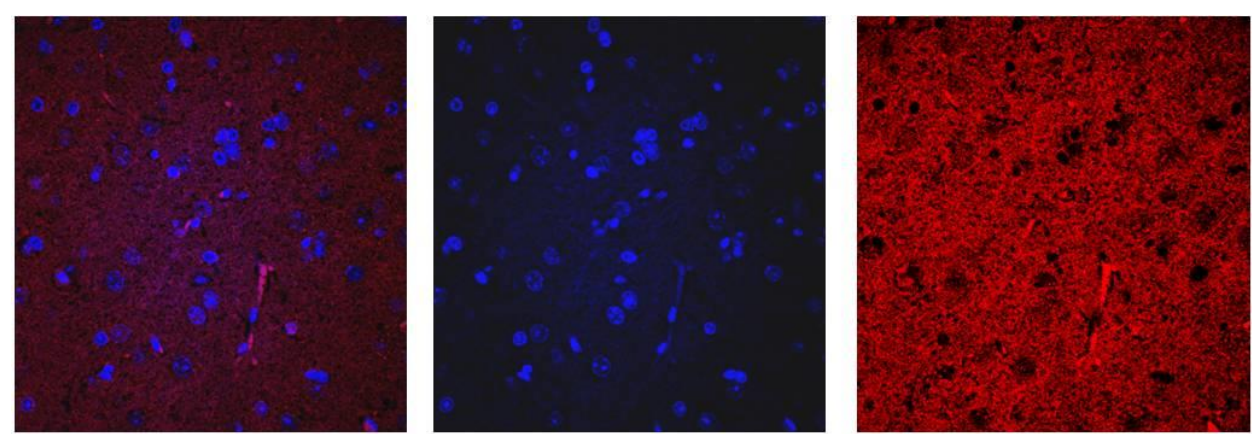

Gehirn
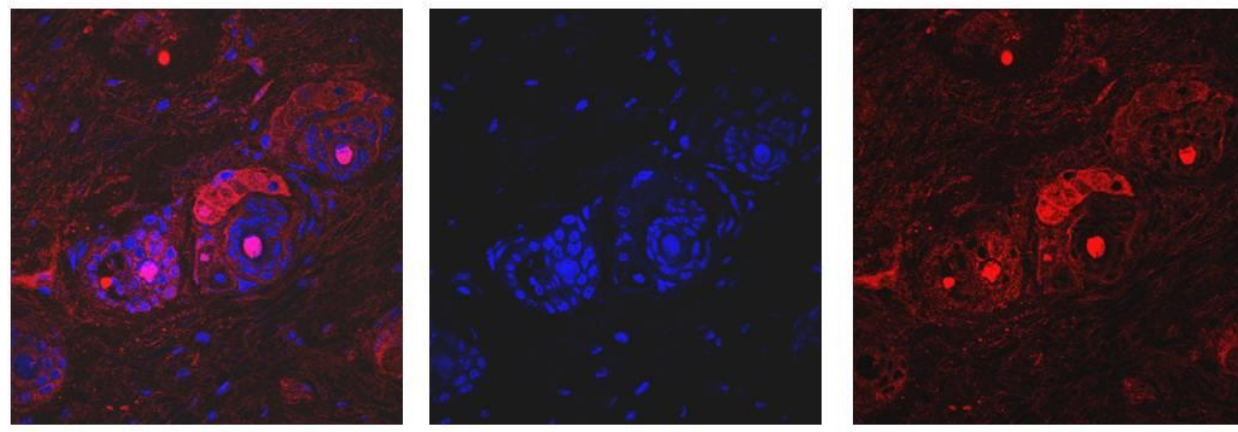

Haut
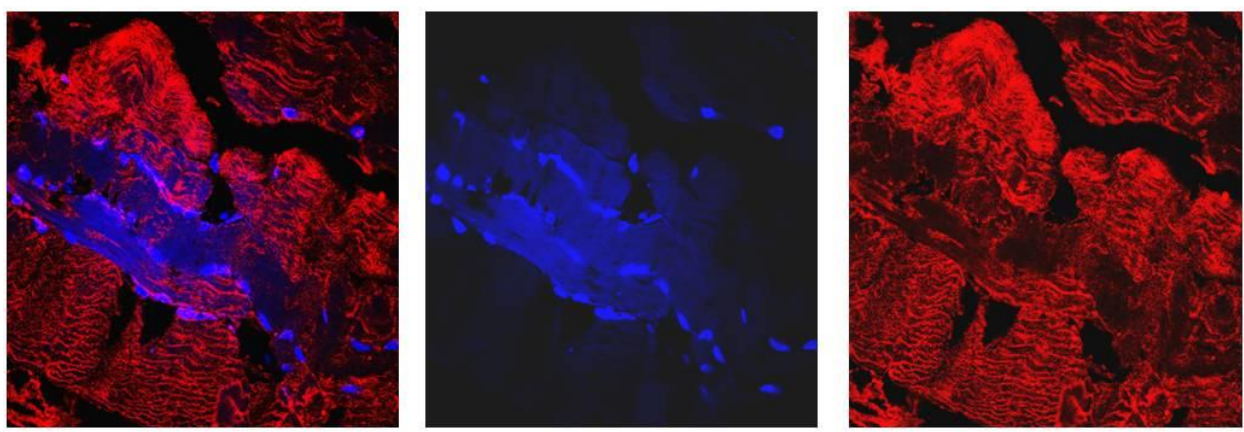

Muskel
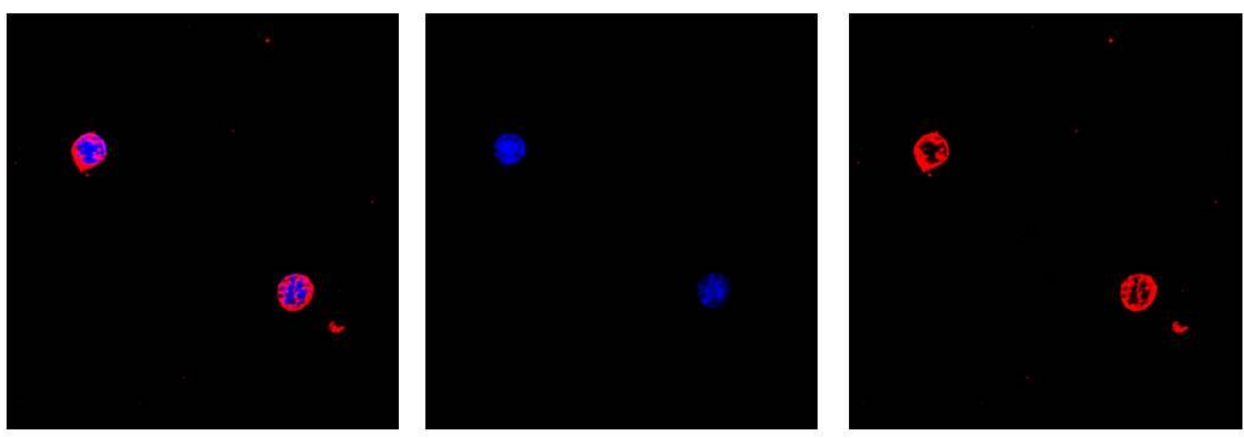

KM
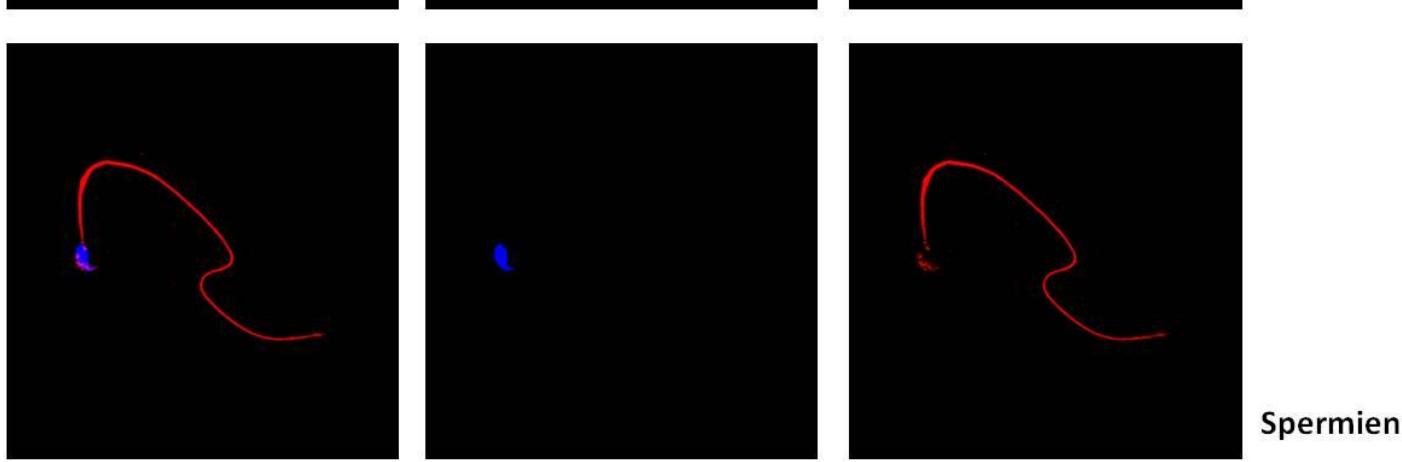

Überlagerung

Abb. 25: Immunhistologie des Gewebes einer homozygoten Stra8 - Cre / R26R - Maus. LacZ als Detektor für Stra8 - Expression wurde durch einen LacZ - Antikörper rot dargestellt. Eine ubiquitäre LacZ - Expression ist in allen Organen gegeben. 

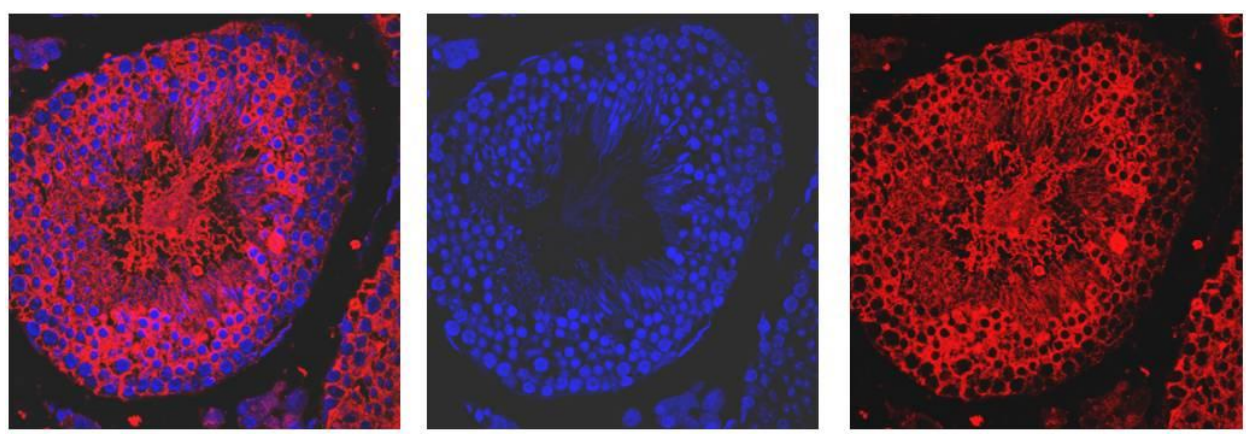

Testis
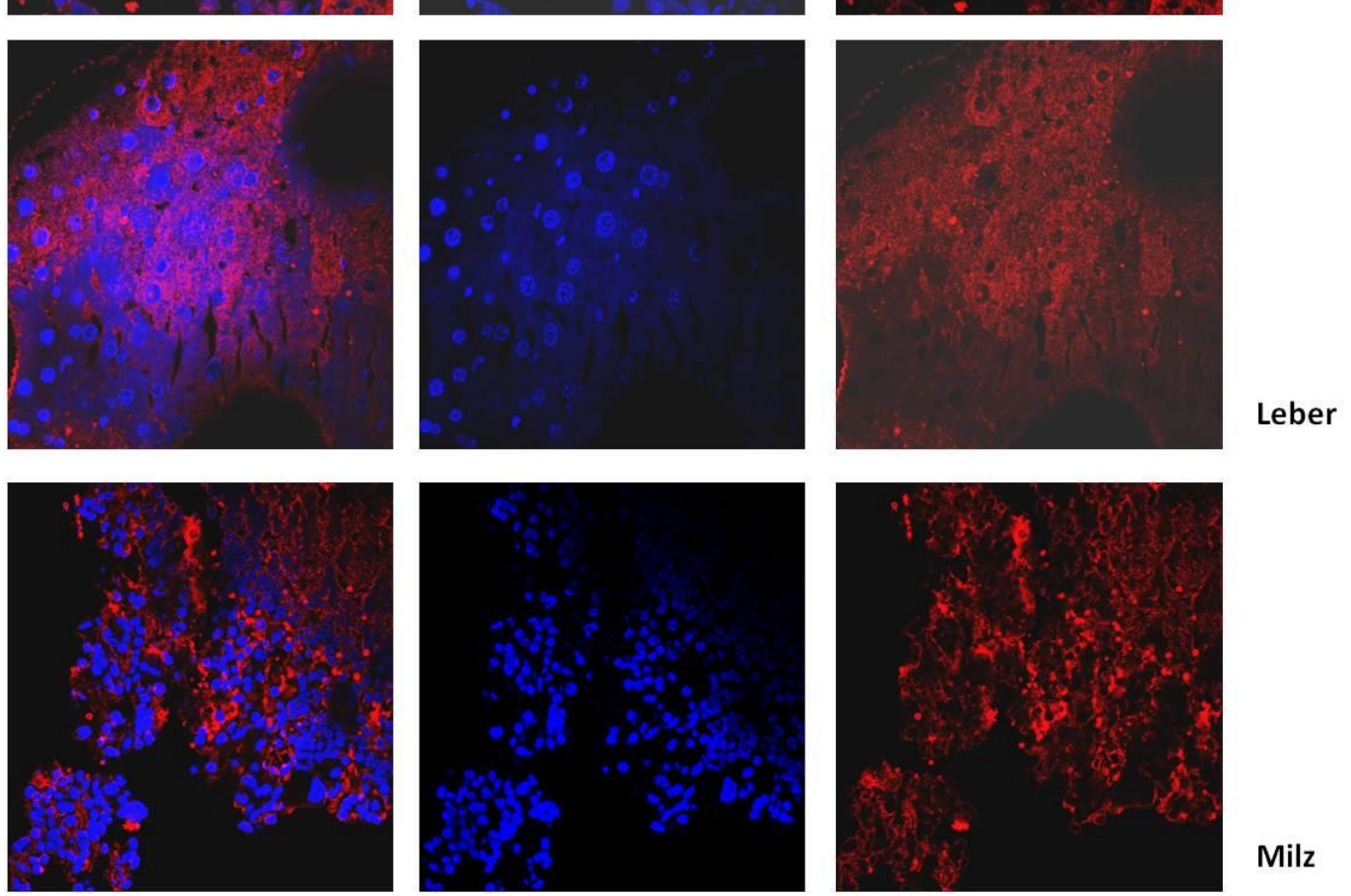

Milz
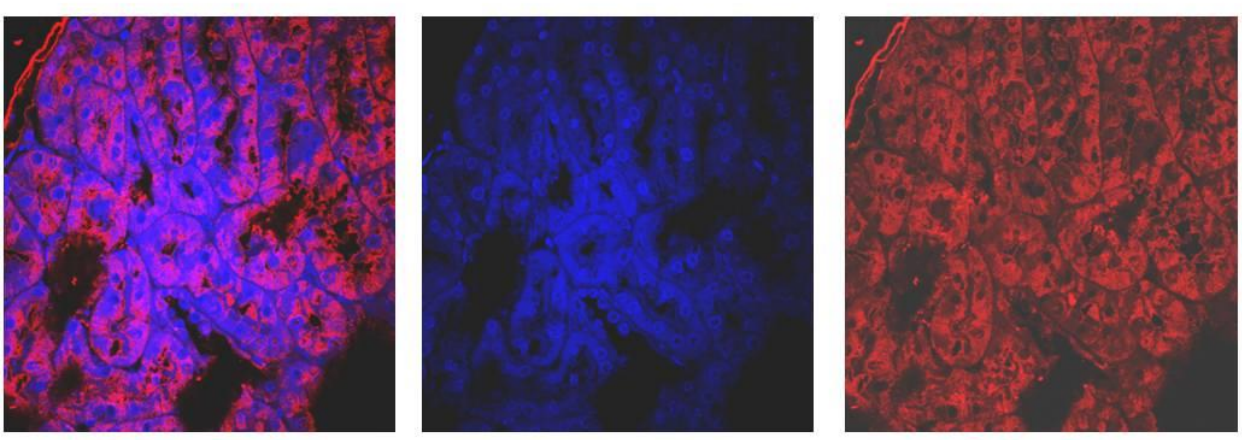

Niere
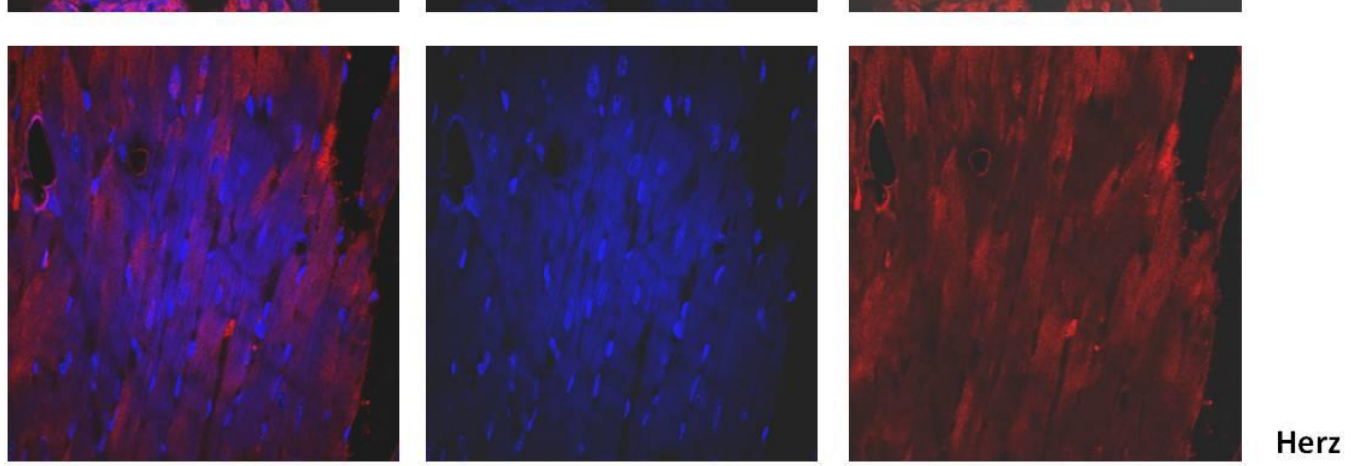

Überlagerung

DAPI

LacZ

Abb. 26: Immunhistologie des Gewebes einer ROSA26 - LacZ - Maus als Positivkontrolle. In dieser Maus ist LacZ ubiquitär exprimiert. Diese kann durch einen LacZ - Antikörper mit einem roten Farbumschlag nachgewiesen werden. 

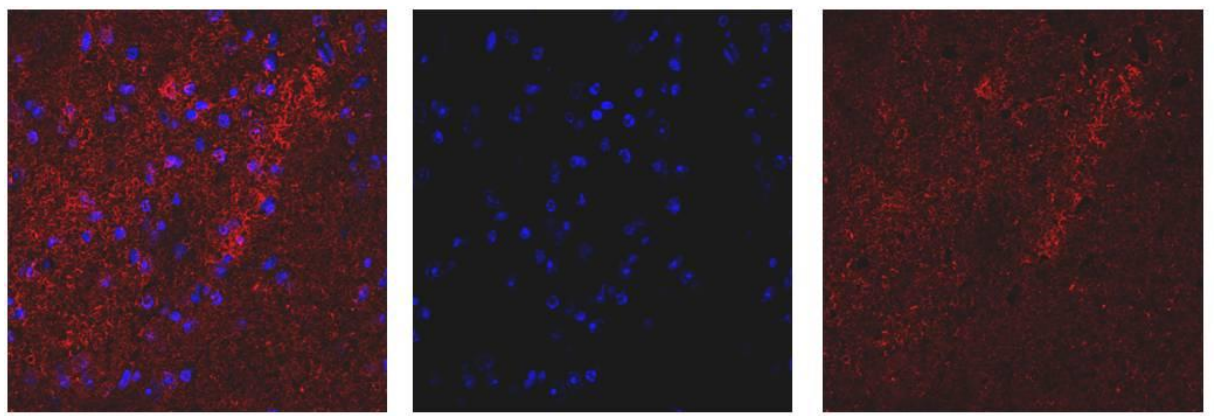

Gehirn
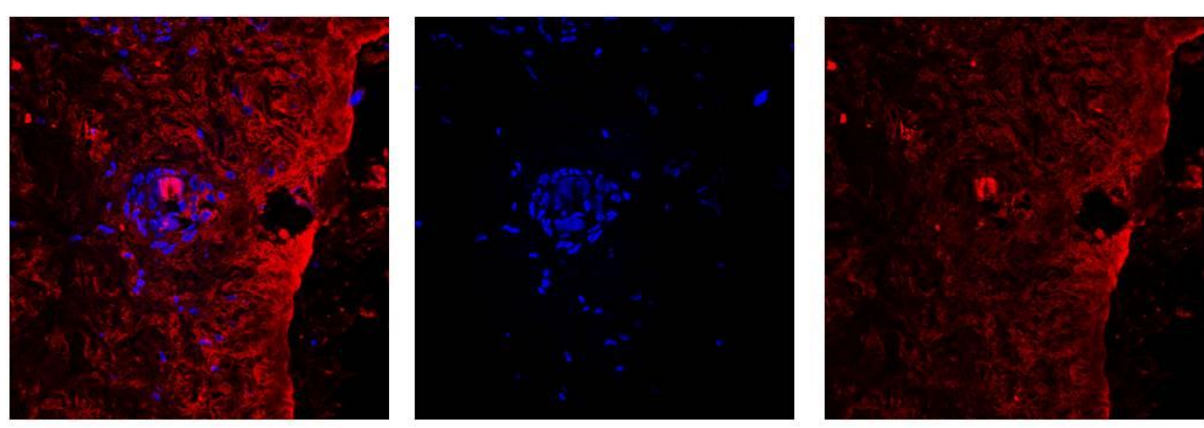

Haut
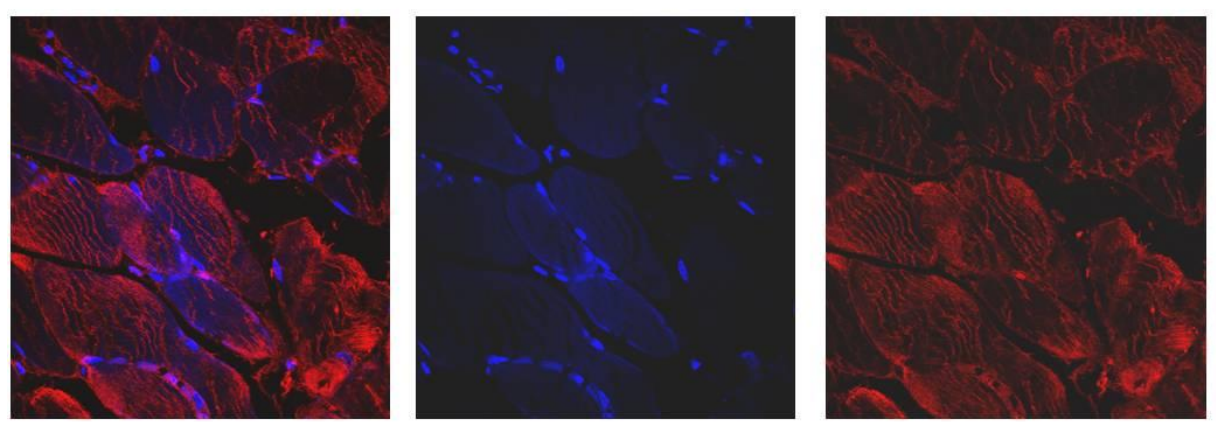

Muskel
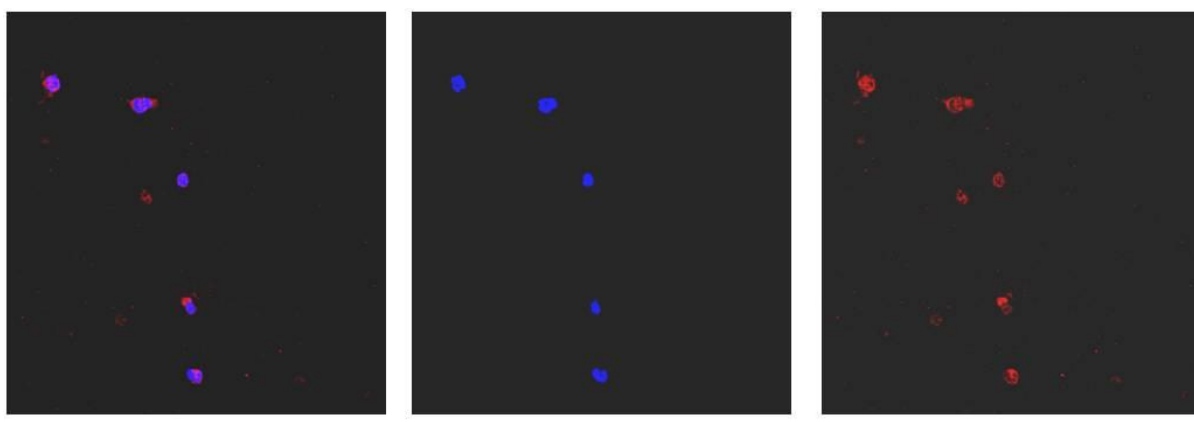

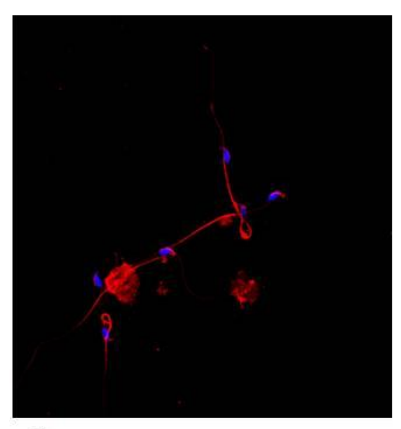

Überlagerung

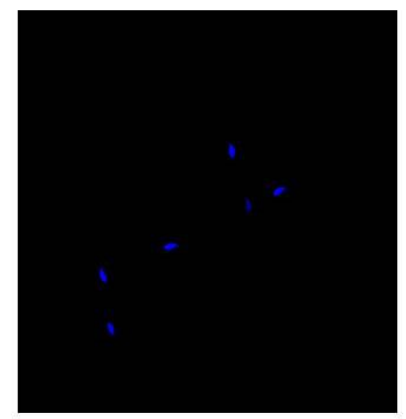

DAPI

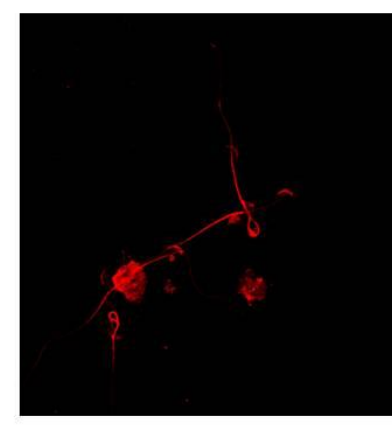

LacZ
Spermien

Abb. 27: Immunhistologie des Gewebes einer ROSA26 - LacZ - Maus als Positivkontrolle. In dieser Maus ist LacZ ubiquitär exprimiert. Diese kann durch einen LacZ - Antikörper mit einem roten Farbumschlag nachgewiesen werden. 

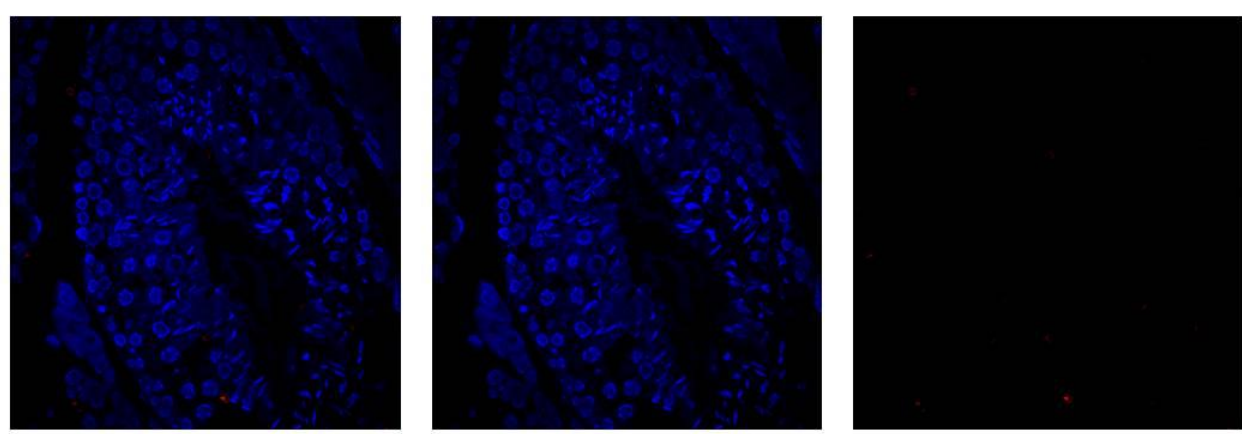

Testis
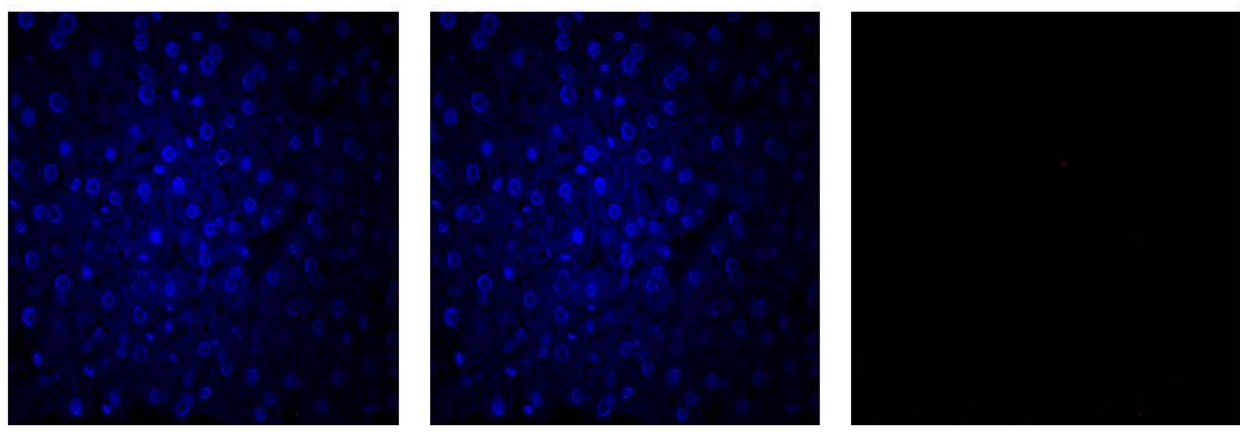

Leber
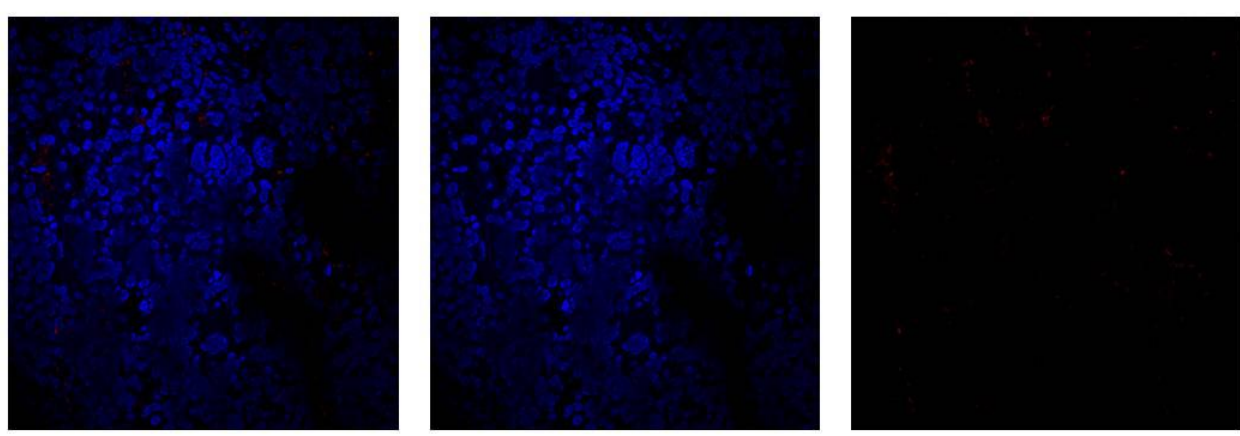

Milz
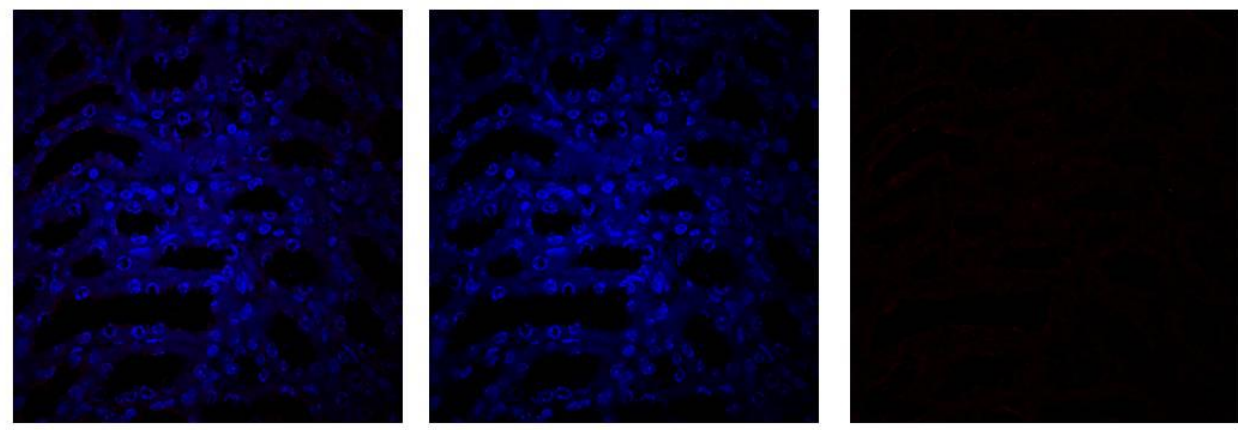

Niere
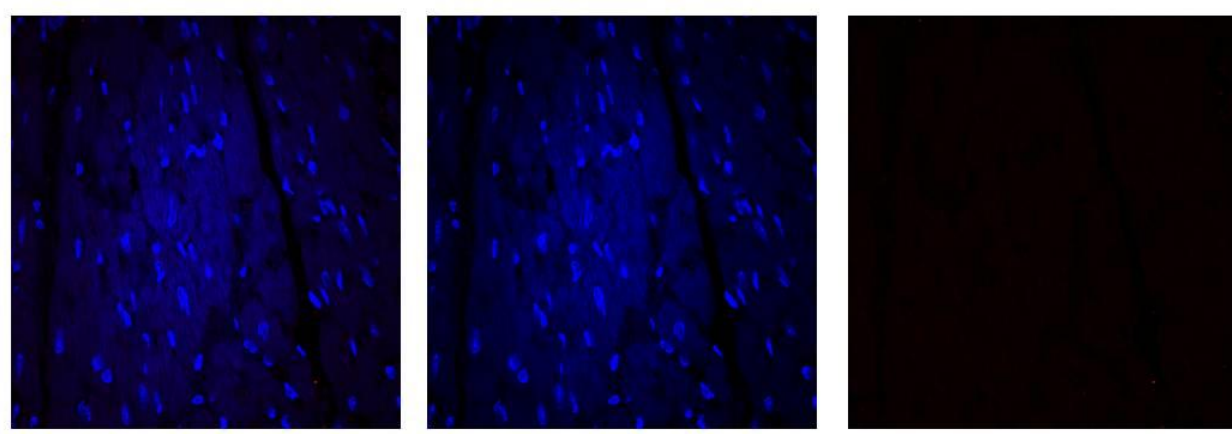

Herz

Überlagerung

DAPI

LacZ

Abb. 28: Immunhistologie des Gewebes einer Stra8 - Cre Maus als Negativkontrolle. Hier wurde an den Schnitten der Organe der Elterntiere ebenfalls ein LacZ - Antikörper eingesetzt um dessen Spezifität zu überprüfen. Dies ist aufgrund der fehlenden Rotfärbung gegeben. 

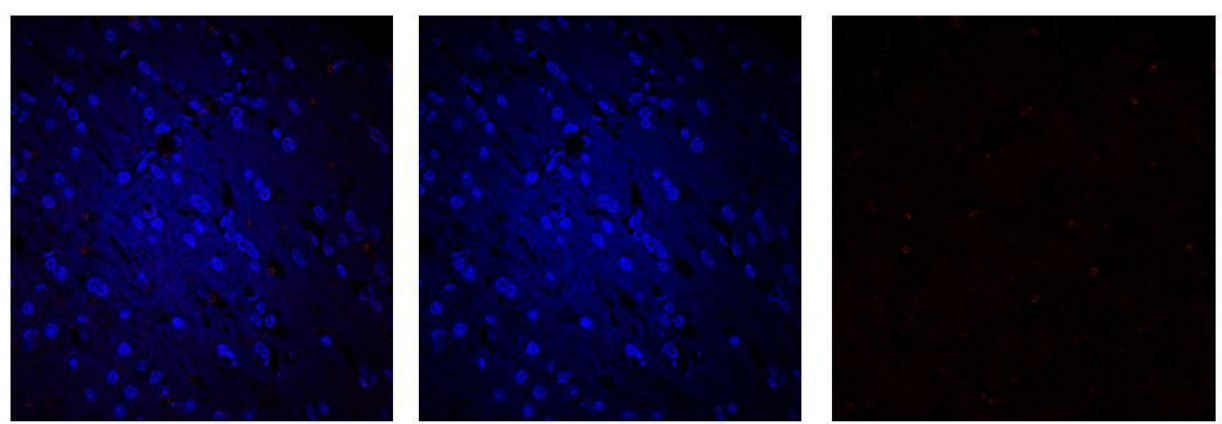

Gehirn
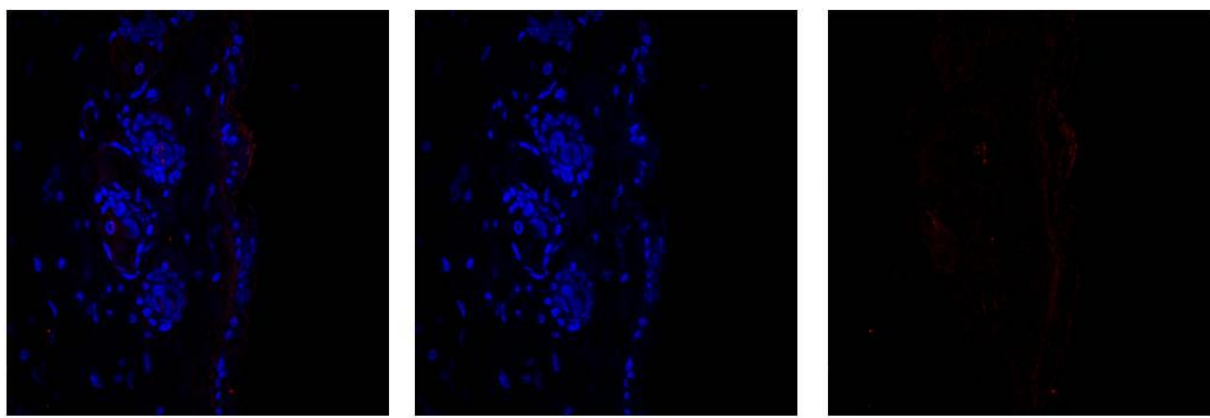

Haut
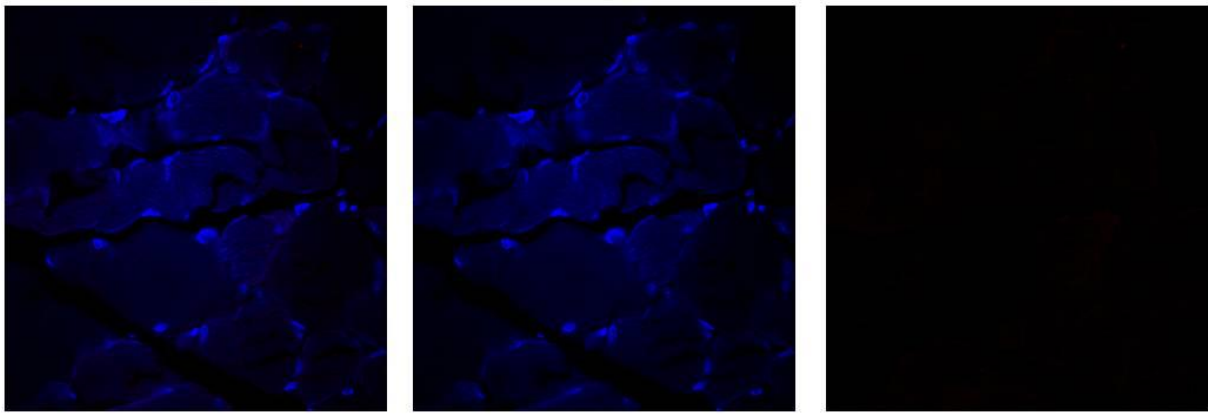

Muskel
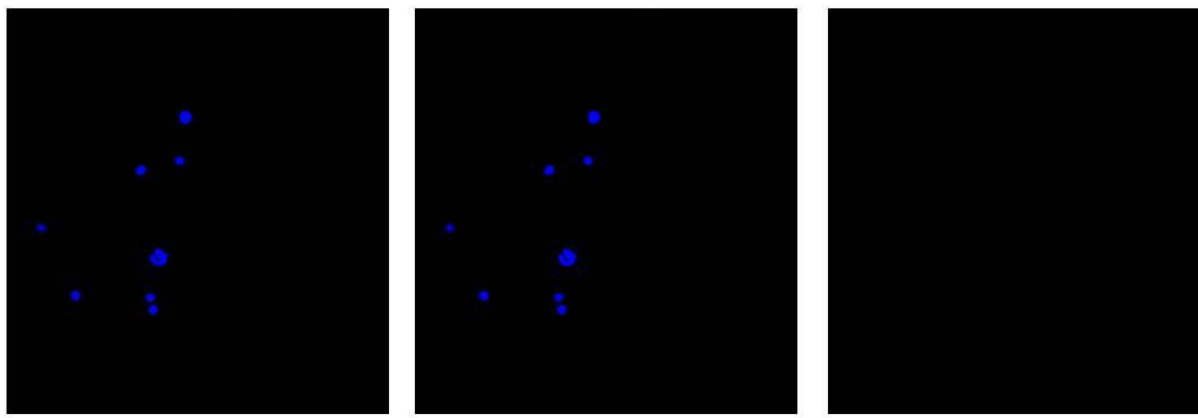

KM

Überlagerung

DAPI

LacZ

Abb. 29: Immunhistologie des Gewebes einer Stra8 - Cre Maus als Negativkontrolle. Hier wurde an den Schnitten der Organe der Elterntiere ebenfalls ein LacZ - Antikörper eingesetzt um dessen Spezifität zu überprüfen. Dies ist aufgrund der fehlenden Rotfärbung gegeben. 

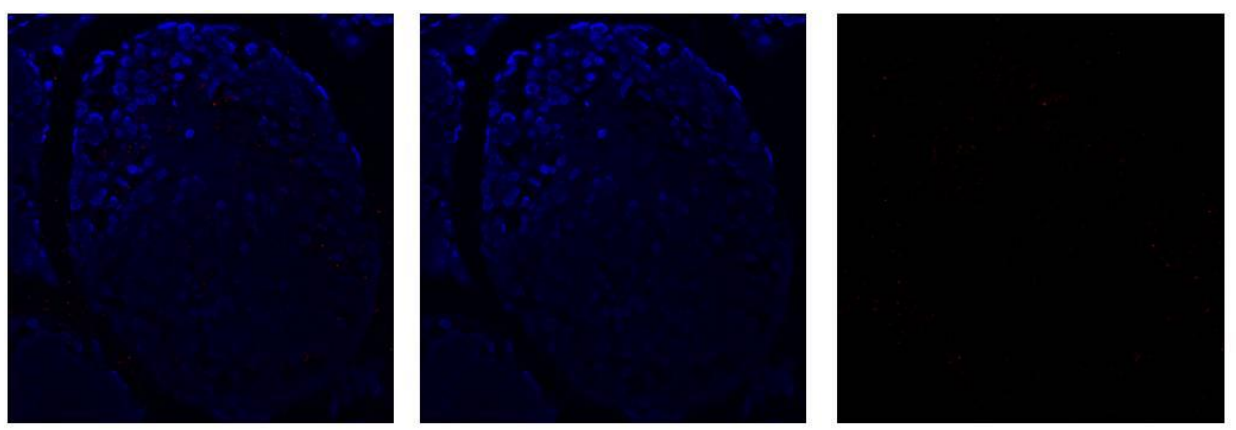

Testes
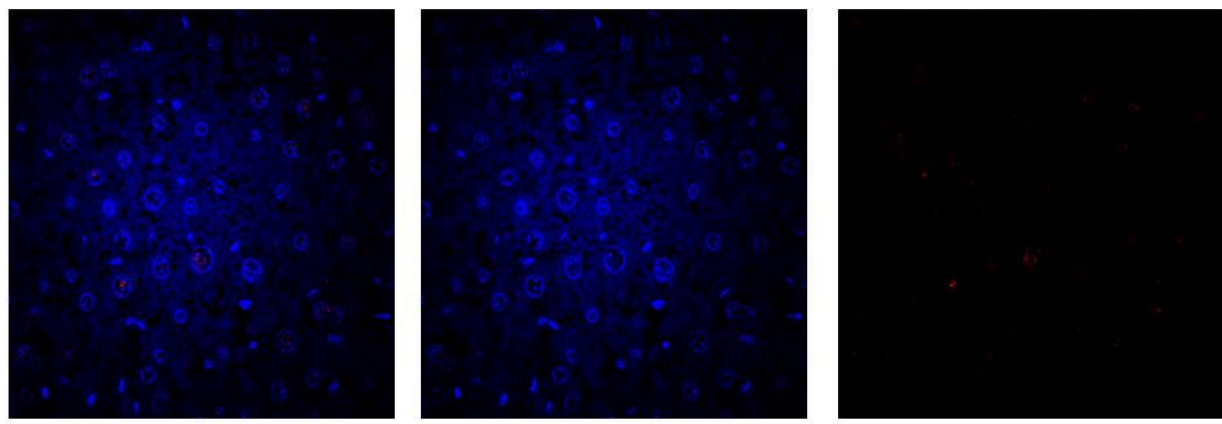

Leber
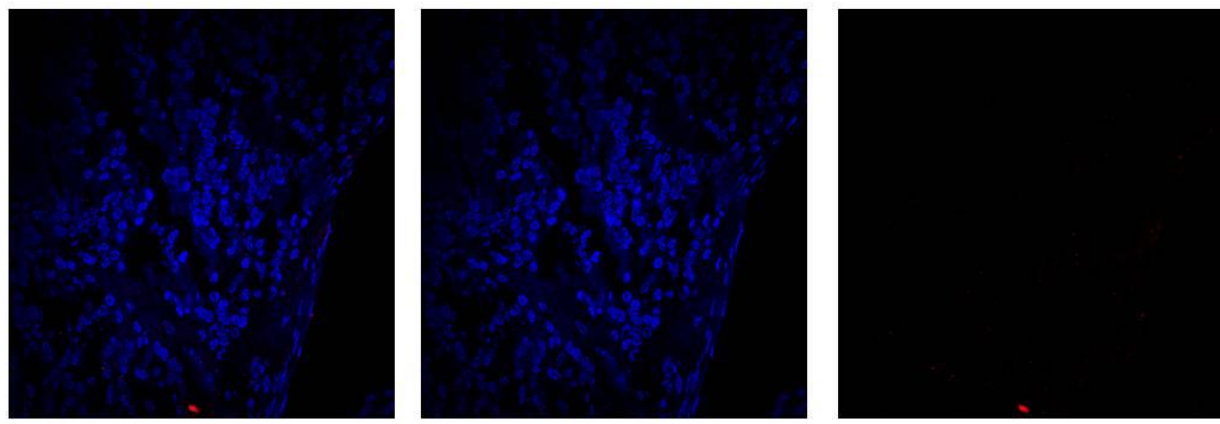

Milz
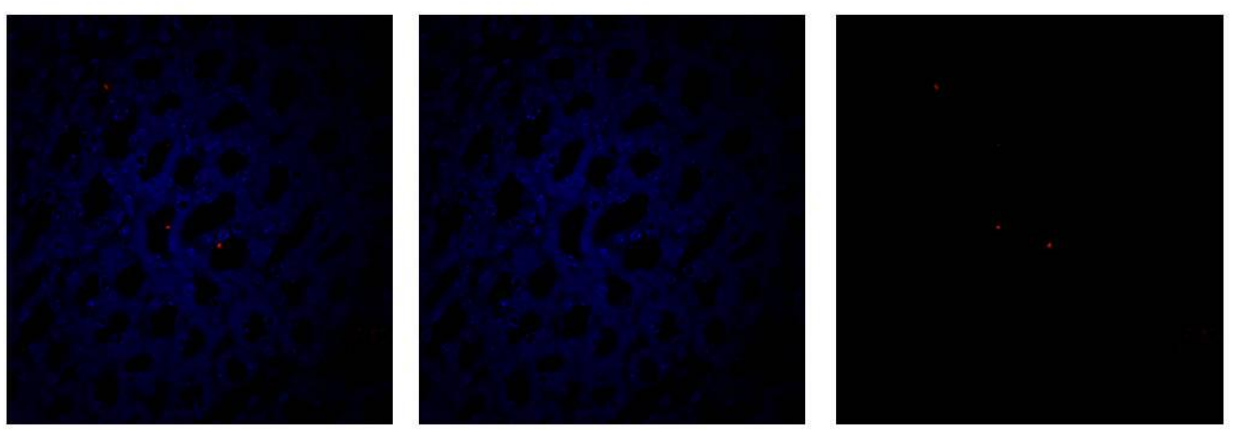

Niere
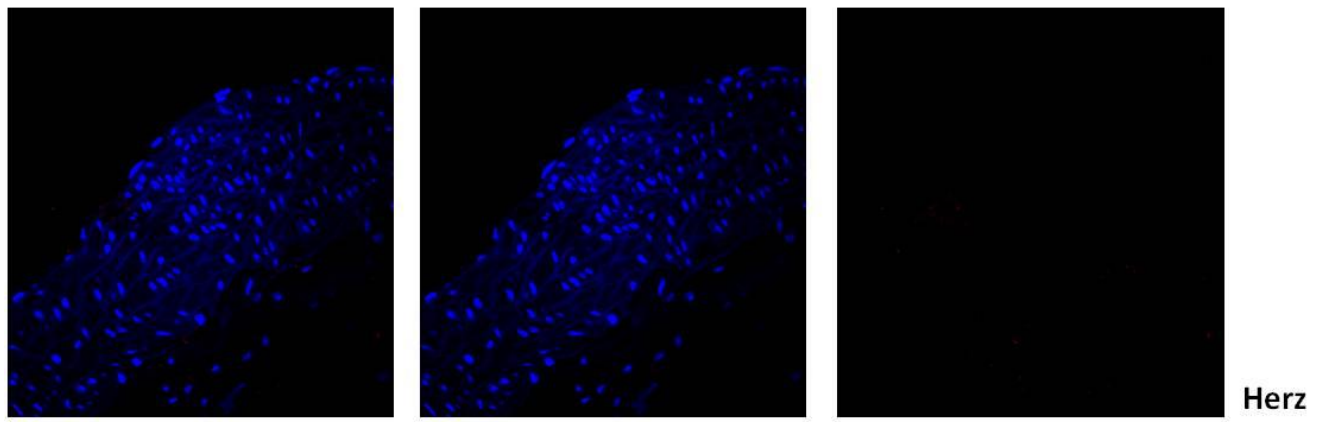

Überlagerung

DAPI

LacZ

Abb. 30: Immunhistologie des Gewebes einer R26R - Maus als Negativkontrolle. Hier wurde an den Schnitten der Organe der Elterntiere ebenfalls ein LacZ - Antikörper eingesetzt um dessen Spezifität zu überprüfen. Dies ist aufgrund der fehlenden Rotfärbung gegeben. 

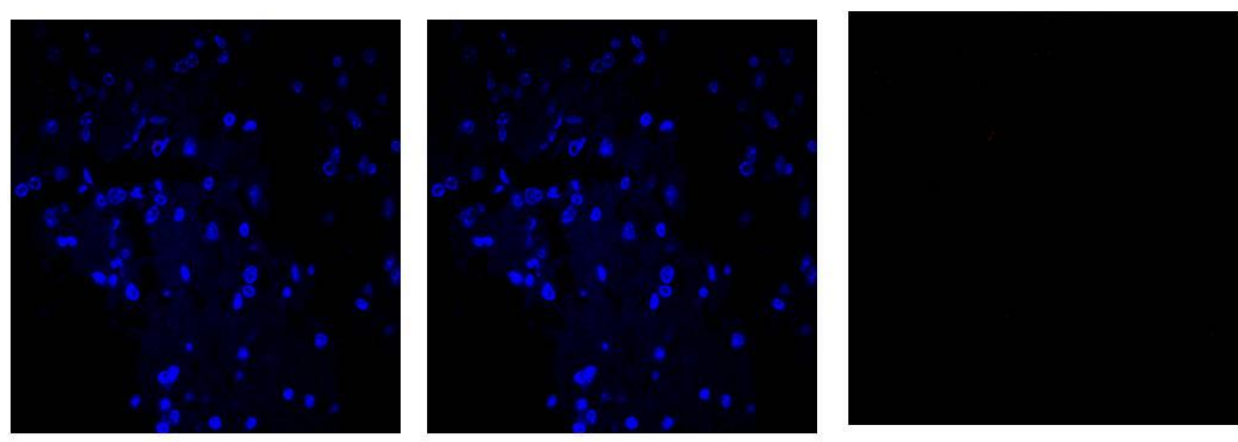

Gehirn
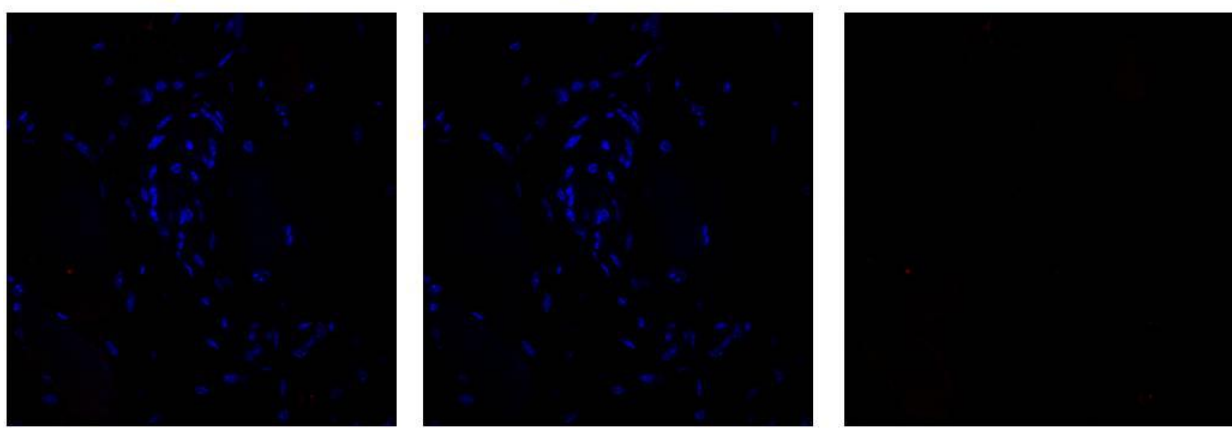

Haut
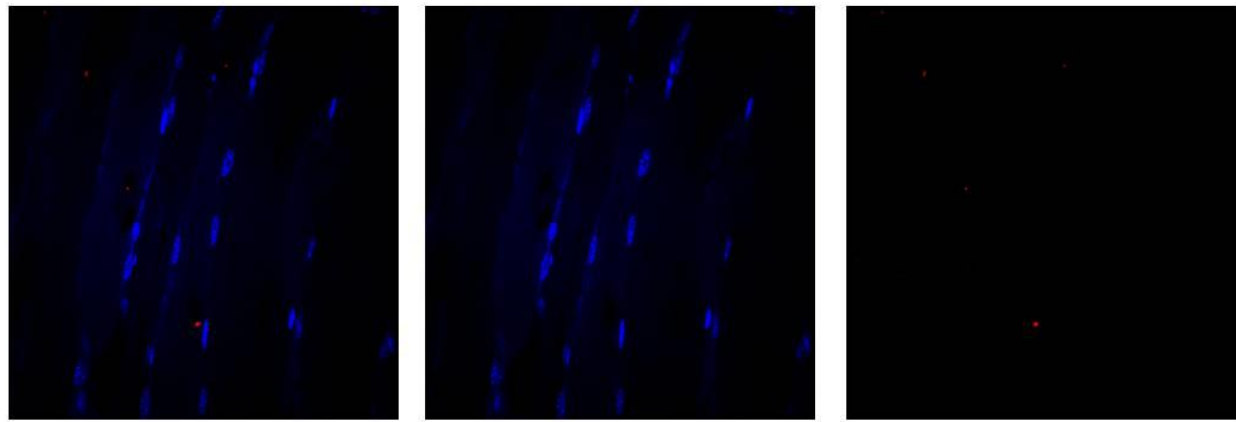

Muskel
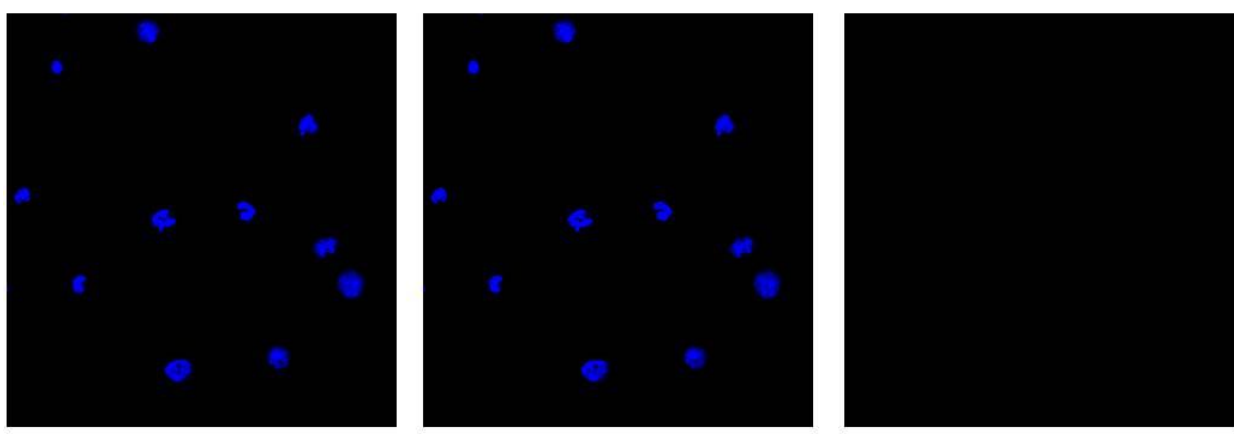

KM
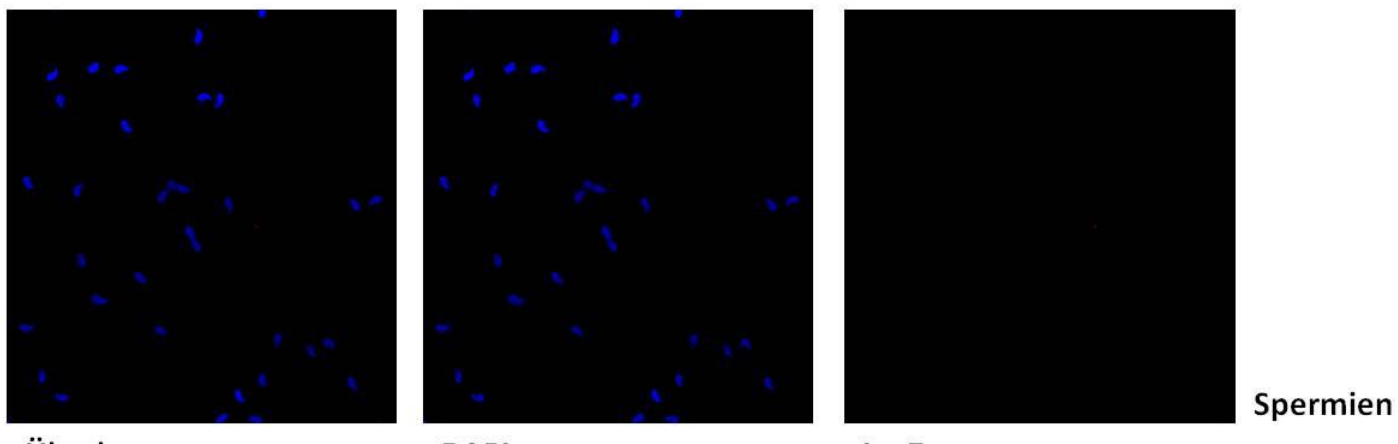

Überlagerung

DAPI

LacZ

Abb. 31: Immunhistologie des Gewebes einer R26R - Maus als Negativkontrolle. Hier wurde an den Schnitten der Organe der Elterntiere ebenfalls ein LacZ - Antikörper eingesetzt um dessen Spezifität zu überprüfen. Dies ist aufgrund der fehlenden Rotfärbung gegeben. 

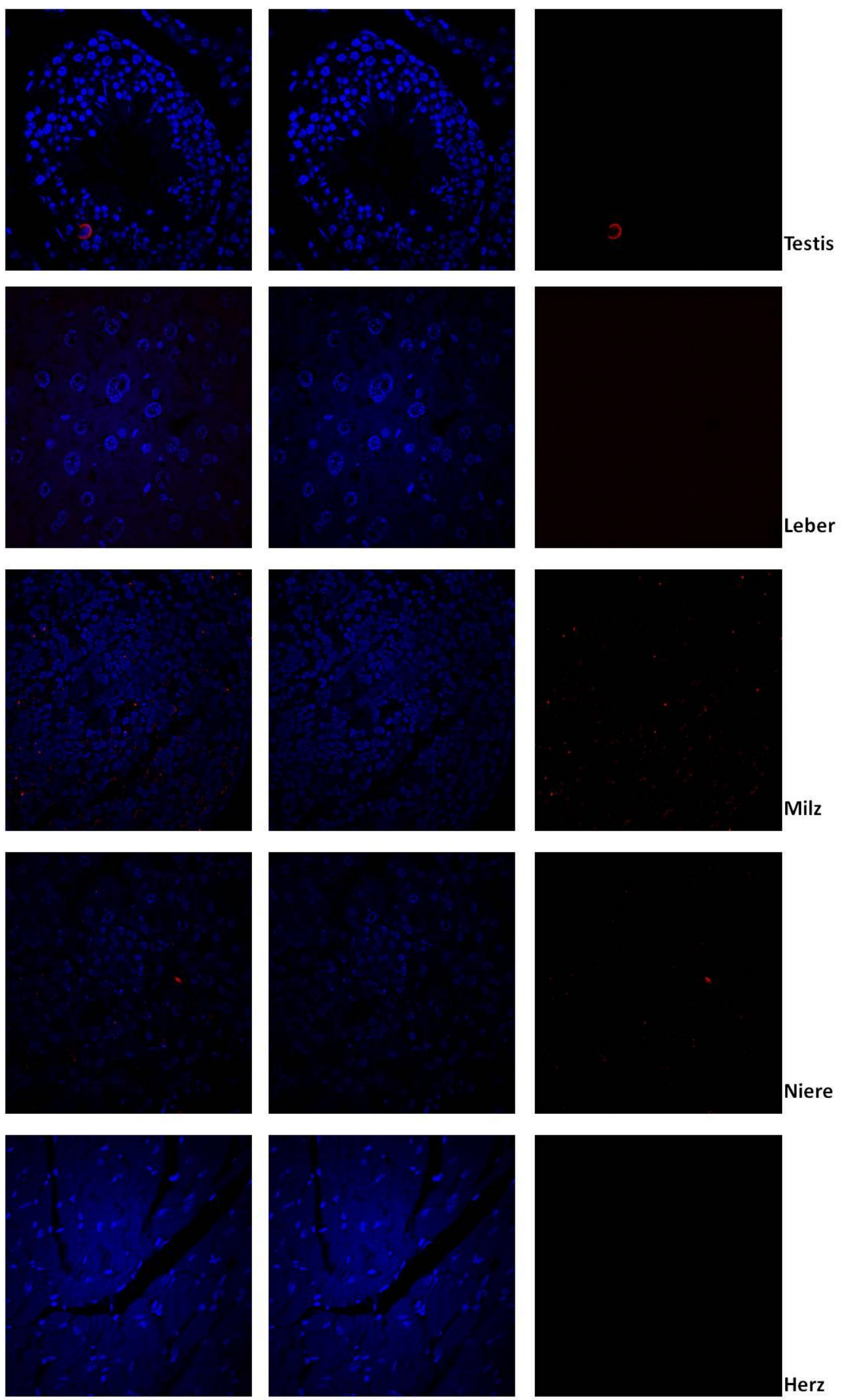

Überlagerung

DAPI

Herz

Abb. 32: Immunhistologie des Gewebes einer WT - Maus als Negativkontrolle. Hier wurde an den Schnitten der Organe der Wildtypmäusen ebenfalls ein LacZ - Antikörper eingesetzt, um dessen Spezifität zu überprüfen. Dies ist aufgrund der fehlenden Rotfärbung gegeben. 

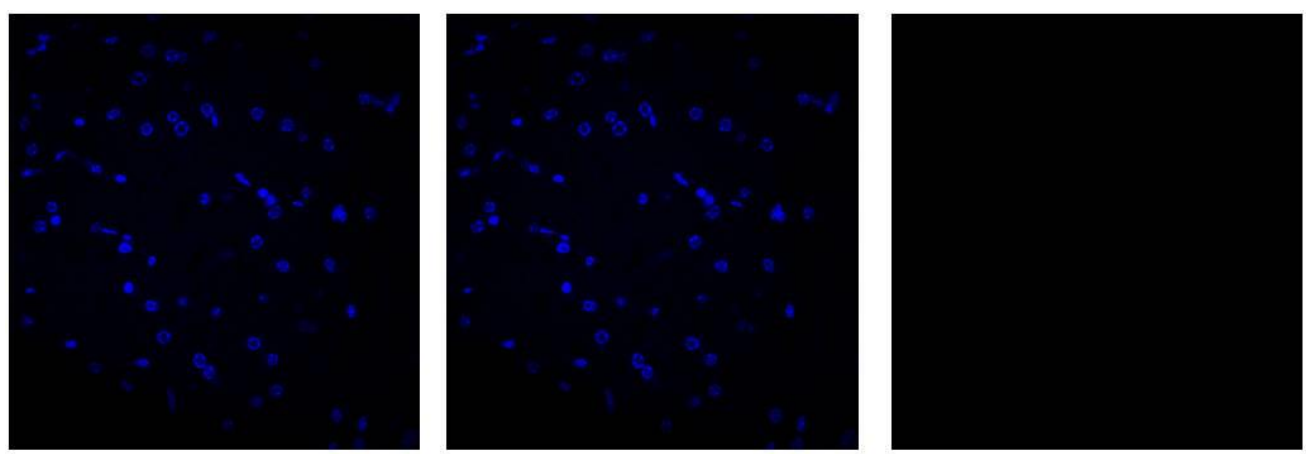

Gehirn
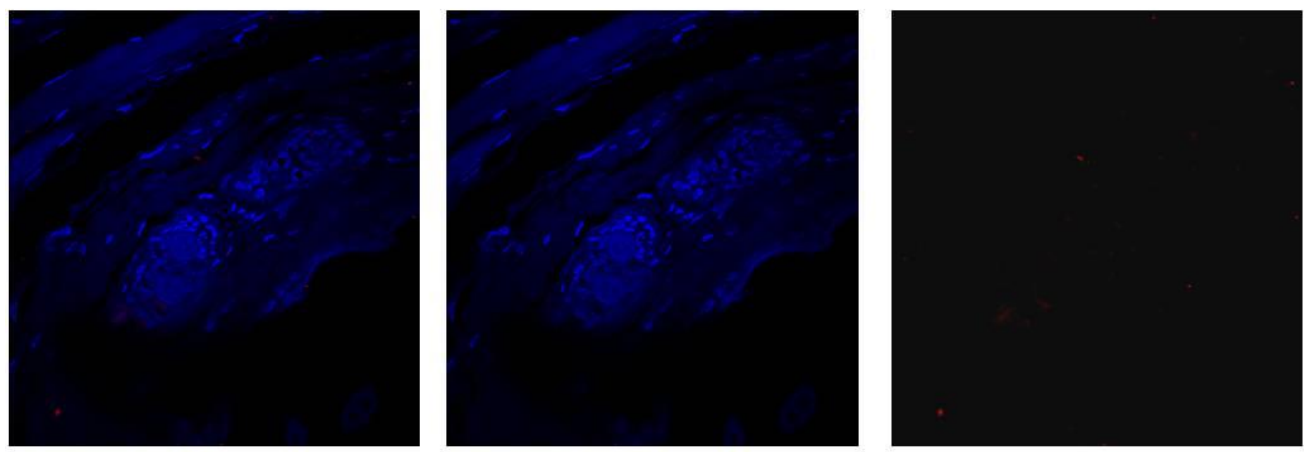

Haut
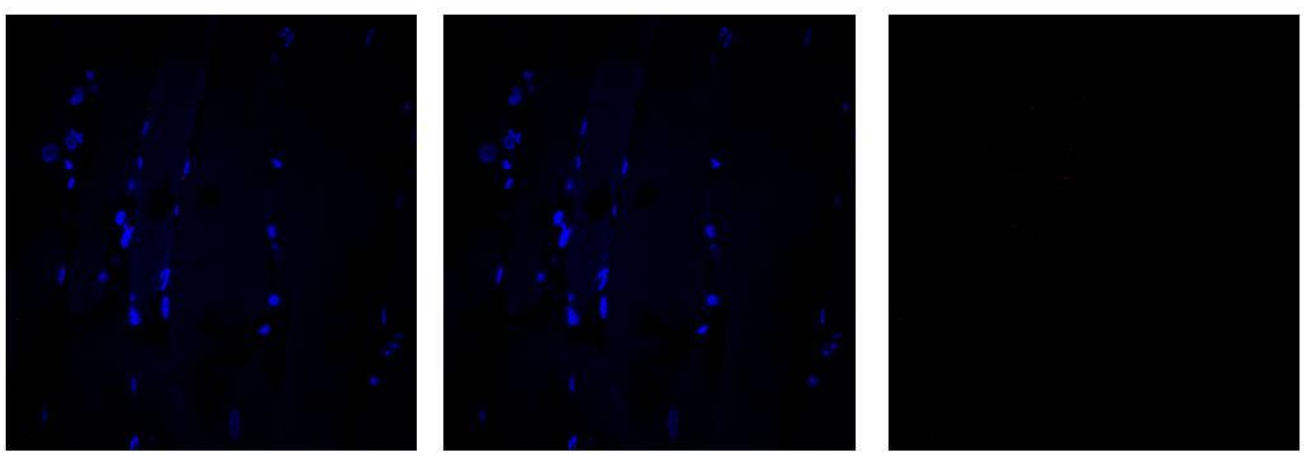

Muskel
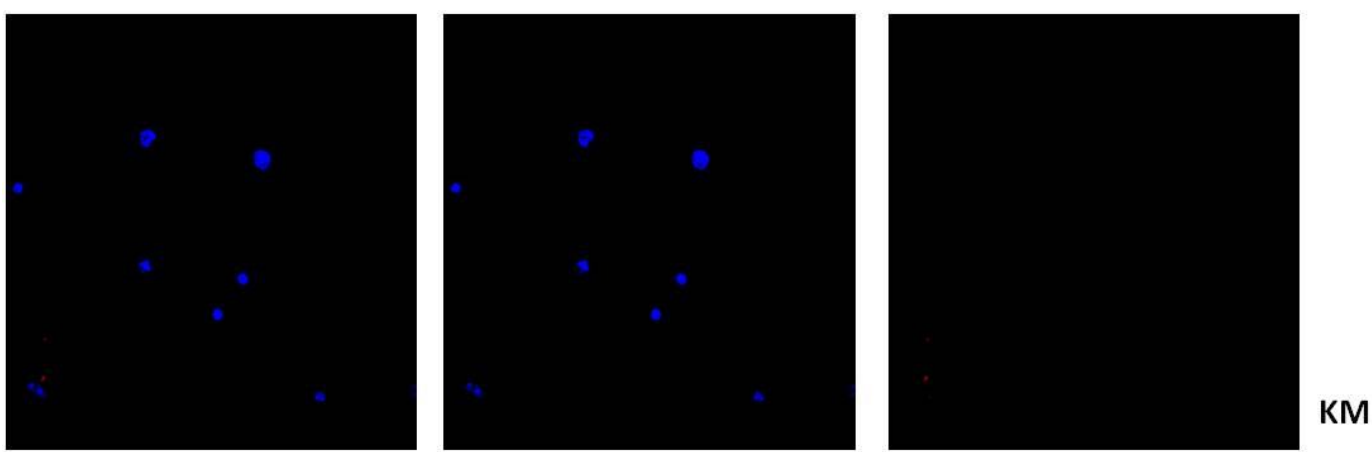

Überlagerung DAPI LacZ

Abb. 33: Immunhistologie des Gewebes einer WT - Maus als Negativkontrolle. Hier wurde an den Schnitten der Organe der Wildytpmäusen ebenfalls ein LacZ - Antikörper eingesetzt um dessen Spezifität zu überprüfen. Dies ist aufgrund der fehlenden Rotfärbung gegeben. 
Durch die immunhistologischen Untersuchungen konnte man deutlich eine ubiquitäre LacZ - Expression in allen untersuchten Organen erkennen, sowohl in doppelt heterozygoten als auch in doppelt homozygoten transgenen Stra8-Cre/R26R Mäusen.

Dies lässt die Vermutung $z u$, dass das Stra8-Gen während der Embryonalentwicklung sehr früh aktiv ist. Diese These wurde bereits in der Doktorarbeit von Dr. Jessica Nolte aus unserem Institut untersucht und bestätigt. Frau Dr. Nolte konnte mittels RT-PCR und Immunhistologie nachweisen, dass einerseits Stra8 in allen Embryonalstadien im Cytoplasma nachweisbar ist und dass Stra8 sowohls in der inneren Zellmasse von Blastozysten als auch im Trophoblasten exprimiert wird.

\subsection{Blastozystenfärbung mit LacZ - Antikörper}

Es wurden 3,5 dpc alte Blastozysten einer Stra8-Cre/R26R - Maus direkt nach der Entnahme fixiert und mit LacZ - Antikörper gefärbt. Der Uterus wurde aus einer Stra8-Cre/R26R - Maus präpariert und die Blastozysten wurden mithilfe einer Mundpipette und PBS aus dem Uterus ausgespült, aufgenommen und auf einen Objektträger gesetzt, fixiert und gefärbt. Als Negativkontrolle dienten Blastozysten einer Wildtypmaus und einer homozygoten einfach transgenen Stra8-Cre - Maus.

Die Blastozysten der Stra8-Cre/R26R - Maus zeigte eine durchgehende Färbung des Trophoblasten und der inneren Zellmasse, während die Negativkontrollen keinerlei Färbung aufwiesen. 

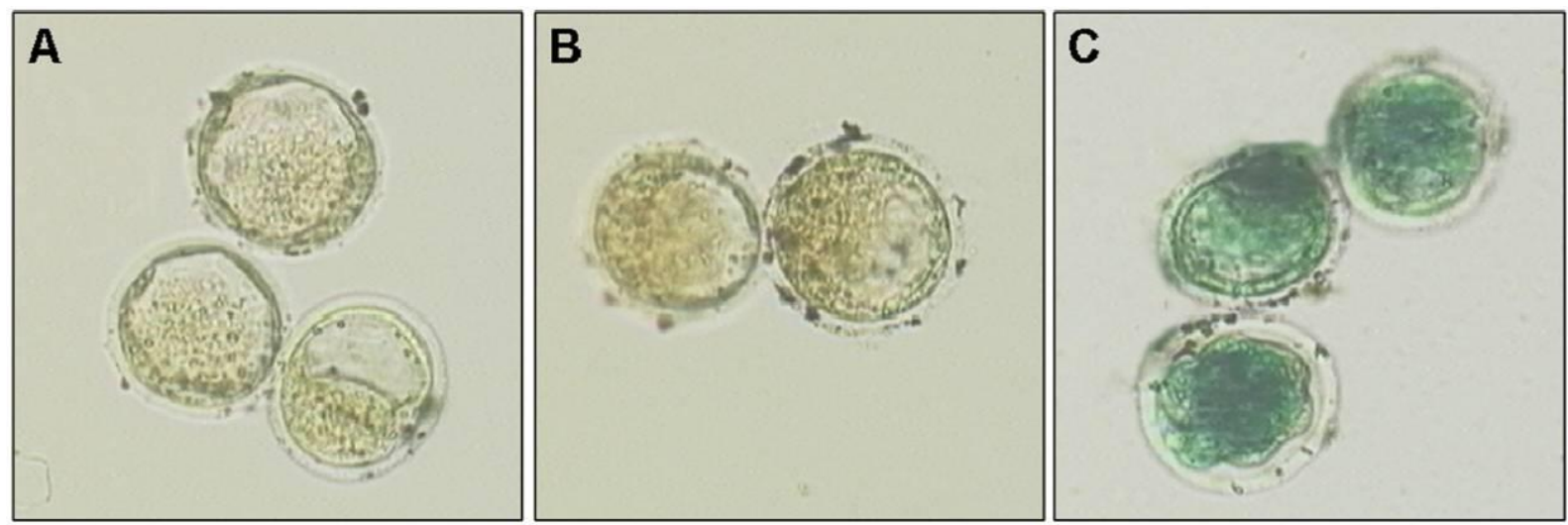

Abb. 34: Blastozystenfärbung: Hier wurden ungeschlüpfte 3,5 dpc alte Blastozysten mit einem LacZ Antikörper angefärbt. Auch hier deutet die ubiquitäre Grünfärbung auf LacZ hin.

Als Negativkontrolle wurde der Versuch mit der X - Gal - Färbung auf Wildtyp - Blastozysten (A) und homozygoten Stra8 - Cre - Maus Blastozysten (B) wiederholt.
A: Wildtyp - Blastozysten
B: Stra8 - Cre - Blastozysten
C: Stra8 - Cre / R26R - Blastozysten

\subsection{Geschlüpfte Blastozysten mit LacZ - Antikörperfärbung}

Um den nächsten Schritt der Embryonalentwicklung darzustellen, wurden aus Stra8Cre/R26R - Mäusen gewonnene Blastozytsen auf einen Objektträger mit Feederlayer gesetzt. Nachdem der Embryoblast (ICM) aus der Blastozysten ausgewandert war und anfing zu proliferieren (drei Tagen Inkubation bei $37^{\circ} \mathrm{C}$ ) wurde diese Formation mit LacZ - Ak gefärbt.

Die geschlüpfte Blastozyste zeigte ebenfalls eine ubiquitäre Expression von LacZ (Abb.35).
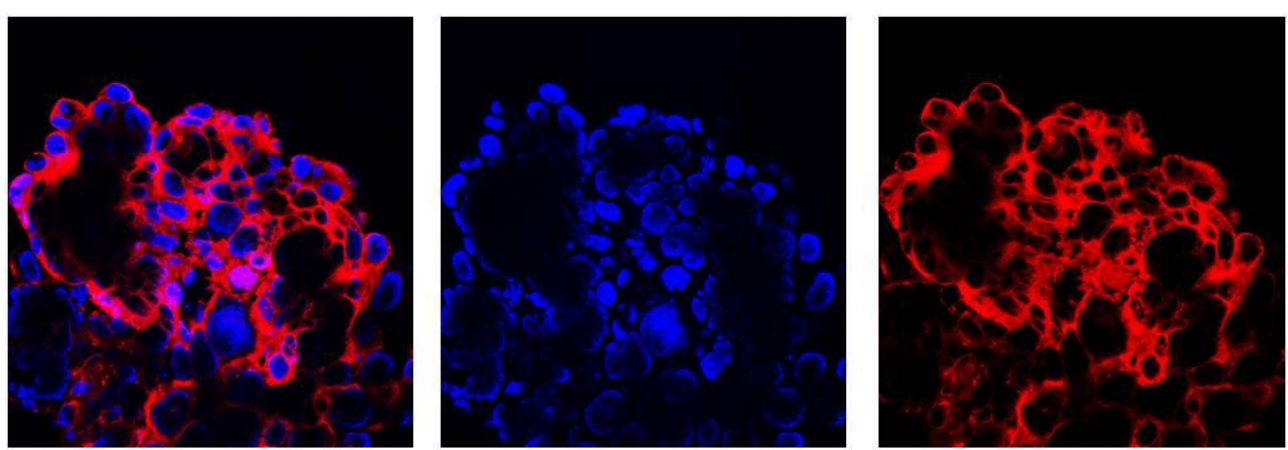

Abb. 35: Geschlüpfte Blastozyste einer Stra8 - Cre / R26R - Maus. Blastozysten einer 3,5 dpc schwangeren Maus wurden aus dem Uterus ausgespült und auf einem Objektträger mit Feederlayer drei Tage bei $37^{\circ} \mathrm{C}$ inkubiert. Nachdem der Embryoblast (ICM) aus der Blastozyste ausgewachsen war und anfing sich zu proliferieren, wurde diese Formation mit einem LacZ - Antikörper gefärbt. Sie zeigt eine ubiquitäre Rotfärbung. Diese Rotfärbung zeigt Zellen an, die LacZ exprimieren und somit eine Stra8 Aktivität aufweisen. 


\subsection{Färbung von Embryonen 13,5 dpc mit X - Gal}

Um die LacZ - Expression in weitaus späteren Embryonalstadien zu betrachten, wurden Embryonen einer Stra8-Cre/R26R - Maus 13,5 Tage post coitum untersucht. Die Embryonen wurden aus dem Uterus herauspräpariert, fixiert und 10 Tage in $\mathrm{X}$ Gal Färbelösung bei $37^{\circ} \mathrm{C}$ inkubiert. Bereits nach wenigen Tagen färbten sich die Embryonen tief blau an, am Ende der Inkubationszeit waren sie vollständig von außen blau gefärbt und weisen somit auf eine ebenfalls ubiquitäre LacZ - Expression hin.

A
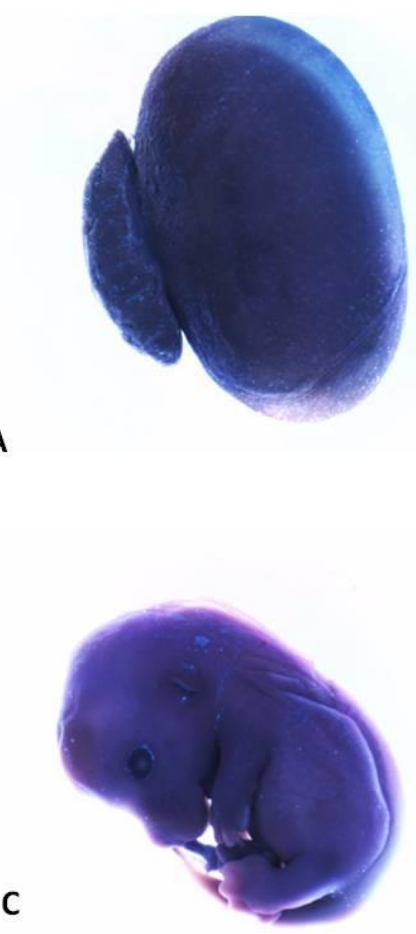

B
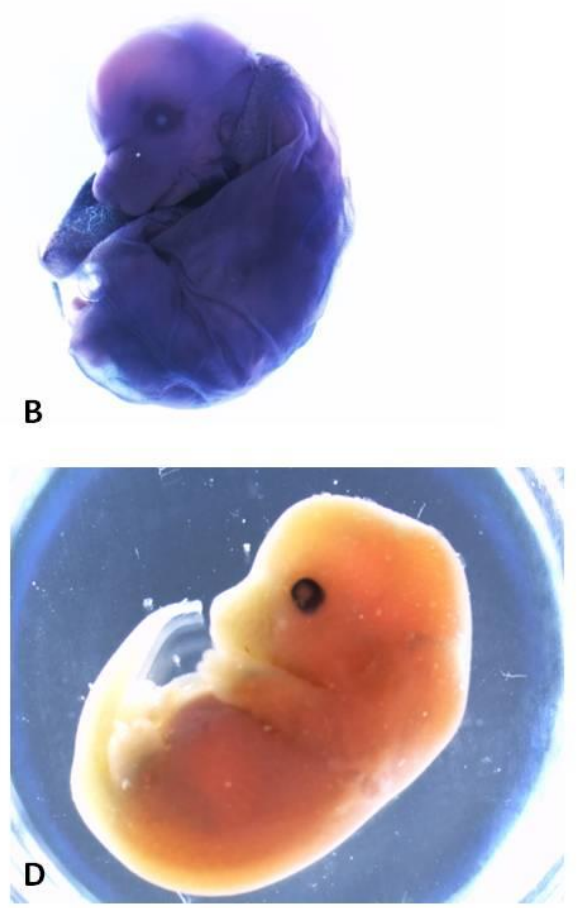

Abb. 36: X - Gal - Färbung von Embryonen 13,5 dpc einer Stra8 -Cre / R26R Maus und einer WT - Maus als Negativkontrolle. Um zu zeigen, dass Stra8 bereits in der Embryonalentwicklung aktiv ist, wurden 13,5 dpc. alte Embryonen mit X - Gal gefärbt und zeigten anhand der Blaufärbung eine ubiquitäre LacZ - Färbung. Als Negativkontrolle wurde ein ebenfalls 13,5 dpc alter Wildtypembryo mitgefärbt und und zeigte keinerlei Blaufärbung.
A: geschlossene Fruchtblase
B: halbgeöffnete Fruchblase mit Embryo
C: Embryo
D: Negativkontrolle WT 


\section{DISKUSSION}

\subsection{Zusammenfassung}

Im Rahmen dieser Doktorarbeit konnte Stra8-Expression bereits in der ICM (inner cell mass) von 3,5 dpc alten Blastozysten nachgewiesen werden, was ein Hinweis auf eine sehr frühe Aktivität des Stra8 - Gens in der Embryonalentwicklung ist.

Stra8 (stimulated by retinoic acid gene 8) ist ein Keimbahnzellmarker, der ausschließlich in prämeiotischen Stadien der Spermatogenese von adulten männlichen Mäusen und in prämeiotischen Folikeln von weiblichen Mäusen exprimiert wird (Oulad-Abdelghani et al. 1996; Baltus et al. 2006; Zhou et al. 2008a, 2008b). Unsere Arbeitsgruppe konnte aus dem Hoden adulter Mäuse spermatogoniale Stammzellen (SSCS) gewinnen, die nach Kultur und Reprogrammierung in vitro ähnliche Eigenschaften wie ESCs aufweisen und als ,multipotent adult germline stem cells' (maGSC) bezeichnet werden. Für die Isolierung der SSCs aus Maus - Testes existieren in unserer Arbeitsgruppe bereits zwei transgene Mauslinien Stra8-EGFP sowie Stra8-EGFP/Rosa26, die mit dem keimzellspezifischen Promotor $(1,4 \mathrm{~kb})$ ausgestattet sind (Guan et al. 2006; siehe 4.2).

Auch in dieser Arbeit wurde dieser Promotor in einem Mausmodell (Stra8-Cre) als Behelfsmarker für SSCS benutzt. Es sollte damit überprüft werden, ob diese SSCS von ihrer ursprünglichen Lokalisation in den Gonaden auswandern und als Vorläuferzellen anderer Zelltypen am Ort eines Insultes (z.B. im Herzen) fungieren können.

Das verwendete Mausmodell wurde aus einer transgenen Mauslinie Stra8/R26R generiert. Es wurde durch die Kreuzung zweier transgener Linien erzeugt, und zwar die Stra8-Cre- Linie und die R26R - Linie (siehe Abbildung 1). In der R26R - Linie (Soriano 1999) wird die Expression des eingebrachten beta-Galactosidase - Gens von dem ROSA26 - Promotor reguliert und im Normalfall durch die vorangeschaltete Stoppsequenz blockiert und nicht abgelesen. Diese Stoppsequenz wird von zwei loxP-Sequenzen eingeschlossen. Diese von loxP flankierte Stoppsequenz kann mit einer Cre-Rekombinase herausgeschnitten werden, so dass es zu einer Expression von LacZ kommt. Die Stra8-Cre - Linie exprimiert eine solche Cre-Rekombinase unter der Kontrolle des 1,4 kb Stra8-Promotors. Werden nun die beiden transgenen 
Linien miteinander verpaart, so wird die Stoppsequenz überall dort herausgeschnitten, wo der Stra8-Promotor entweder gerade aktiv ist oder in Vorläuferzellen aktiv war. Diese Exzision ist nicht reversibel.

Es konnte in dieser Arbeit in einem Mausmodell mithilfe der Immunhistochemie eine Stra8-Expression bereits in Blastozysten (3,5 dpc) nachgewiesen werden. Diese sehr frühe Promotoraktivität ist ein Hinweis auf die mögliche Funktion von Stra8 im Pluripotenznetzwerk (siehe 4.2). In der Vergangenheit zeigte sich, dass es eine Vielzahl von keimzellspezifischen Genen gibt, die in Zusammenhang mit den pluripotenten Eigenschaften von Zellen stehen (z.B. Oct4, Nanog; Näheres siehe Tabelle Abschnitt 4.2). Tedesco et al. haben 2009 einen Shuttle des Stra8 - Proteins zwischen Zytoplasma und Nukleus beschrieben und haben zudem auf eine HelixLoop-Helix - Domäne und eine glutaminreiche Domäne im Protein hingewiesen. Hieraus ergeben sich zwei mögliche Aufgaben von Stra8: Da das Protein in pluripotenten Stammzellen überwiegend im Kern lokalisiert ist, weist die Helix-LoopHelix - Domäne auf eine Funktion als Transkriptionsfaktor im Pluripotenznetzwerk hin. Die glutaminreiche Domäne reguliert den Eintritt der Keimzellen in die Meiose (Baltus et al. 2006), wobei Stra8 im Testes nur als zytoplasmatisches Protein detektiert werden kann. (Siehe 4.3)

Die in der vorliegenden Arbeit durchgeführten Promotoranalysen stellten entsprechend den Ergebnissen von Guan et al. (2006) und Jaroszynski (2005) die Aktivität des verwendeten 1,4 kb - Promotors für Stra8 als aktivsten Promotor dar. (Siehe 4.2)

Wenn Stra8 nicht nur in pluripotenten und spermatogonialen Stammzellen exprimiert ist, sondern bereits in der ICM von Blastozysten, dann ergibt sich in der weiteren Entwicklung der Blastozyste und dem daraus ausdifferenzierten Gewebe eine ubiquitäre LacZ - Expression. Somit ist LacZ als Detektionsmarker für eingewanderte SSCs in testesferne Strukturen nicht geeignet, da bereits das testesferne Gewebe ebenfalls eine ubiquitäre LacZ - Expression aufweist und somit nicht zwischen ortsständigen Zellen und eingewanderten SSCs unterschieden werden kann. Aus diesem Grund konnte eine SSC-Wanderung zum Ort des Insultes in der vorliegenden Arbeit nicht analysiert werden. (Siehe 4.3) 


\subsection{Folgerungen aus den Ergebnissen}

Spermatogoniale Stammzellen (spermatogonial stem cells, SSCs) liegen vereinzelt an der Basalmembran der Tubuli seminiferi im Testis. Sie sorgen sowohl durch die Fähigkeit der Selbsterneuerung (self renewal) als auch durch die Differenzierung für lebenslange Spermatogenese bei männlichen Individuen. Während der Embryonalentwicklung gehen SSCs aus primordialen Keimzellen (primordial germ cells, PGCs) hervor. Anfang der 90er Jahre gelang es sowohl Matsui et al. (1992) als auch Resnick et al. (1998) aus PGCs undifferenzierte, embryonale Keimzellen, sogenannte EGCs (embryonic germ cells) zu gewinnen, die sowohl in vitro als auch in vivo (Teratombildung) zu Derivaten aller drei Keimblätter ausdifferenzieren konnten und die Pluripotenzmarker Oct4 und Nanog exprimierten.

Der Anteil an spermatogonialen Stammzellen im Testis von Säugern ist mit 0,05\% sehr gering (Tegelenbosch und de Rooij 1993). Bis heute wurde noch kein Marker gefunden, der ausschließlich SSCs markiert. In den Testes von neonatalen Mäusen ist der Anteil an Spermatogonien sehr viel höher als bei adulten Mäusen. Bei diesen teilt sich die Spermatogenese bereits in Spermatozyten, Spermatogonien, Spermatiden und Spermien. Kanatsu-Shinohara et al. wählten daher 2004 den Ansatz, die Hoden neonataler Mäuse für die Isolierung von SSCS zu nehmen, da diese durch den hohen prozentualen Anteil an Spermatogonien gleichzeitig eine natürliche Anreicherung an SSCs enthalten. So gelang es erstmalig, SSCs aus dem Testis neugeborener Mäuse zu isolieren.

Um eine ähnliche Anreicherung von SSCs aus adulten Testes zu erzielen, wählte unsere Arbeitsgruppe Stra8 als Hilfsmittel. Stra8 (stimulated by retinoic acid gene 8) wurde von Bouillet et al. erstmals 1995 beschrieben. Ein Jahr später zeigten OuladAbdelghani et al., dass Stra8 testesspezifisch ist, wobei sich die Expression auf die prämeiotischen Stadien der Spermatogenese beschränkte. Dies bestätigte sich 2005 in der Dissertationsarbeit von Jaroszynski mit einem transgenen Mausmodell, welches EGFP unter der Kontrolle des 1,4kb - Promotors von Stra8 exprimierte. Dieses Mausmodell war 2006 die Grundlage für die Arbeit von Guan et al.. Dort gelang es durch die Isolierung und Kultivierung EGFP positiver Zellen SSCs aus adulten Maustestes anzureichern, die nach Kultur und daraus resultierender Reprogrammierung in vitro ähnliche Eigenschaften wie ESCs aufwiesen und als ,multipotent adult germline stem cells' (maGSC) bezeichnet wurden. Die maGSCs 
können in vitro in alle drei Keimblätter differenzieren und nach subkutaner Injektion in immundefizienten Mäusen Teratome bilden. Zum Teil exprimieren aus maGSCs differenzierte Kardiomyozyten myozytäre Marker, generieren Aktionspontentiale und setzen spontan Calcium aus dem noch unreifen sarkoplasmatischen Retikulum frei, was eine Eigenschaft unreifer Kardiomyozyten ist (Guan et al. 2006)

Zur Prüfung unserer Hypothese, ob Stammzellen aus dem Hoden auswandern und sich in geschädigtem Gewebe ansiedeln, ausdifferenzieren und in den Zellverband integrieren können, schien zur Beginn der Arbeit Stra8 als Hilfe zur Gewinnung von SSCs im Hoden ideal. Das verwendete Mausmodell war so aufgebaut, dass bei doppelt transgenen Mäusen Stra8-Cre/R26R die spezifische Expression von Cre in spermatogonialen Stammzellen durch die Entfernung der Stopp-Kassette die Aktivierung des Rosa26 - Promotors bewirkt. Dies sollte zu einer dauerhaften Elimination der Stopp-Kassette führen, sobald Stra8 exprimiert wird. Dadurch sollten die SSCs im Laufe der Embryonalentwicklung markiert werden. Wenn bei adulten doppelt-transgenen Mäusen blau angefärbte, ausdifferenzierte Zellen im Herzen nachweisbar sind, würde dies zeigen, dass SSCS Vorläuferzellen der Kardiomyozyten sein können.

Bereits 2008 wurde ein Stra8-Cre - transgenes Mausmodel veröffentlicht (SadateNgatchou et al.). Ausgehend von einer Publikation unserer Arbeitsgruppe (Nayernia et al., 2004) nutzten die Autoren ebenfalls den 1,4kb - Promotor von Stra8. Unter Verwendung einer LacZ/GFP-Reportermaus konnte gezeigt werden, dass die CreAktivität unter der Kontrolle des Stra8 - Promotors spezifisch in den Spermatogonien nachzuweisen ist. Dies allerdings nur, wenn das Männchen einer Verpaarung Stra8Cre und das Weibchen die Reportermaus war. Daraus schlossen die Autoren, dass der Stra8 - Promotor und damit die Cre-Aktivität spezifisch ist für männliche Keimzellen. Da endogene Stra8-Expression aber auch in weiblichen Keimzellen nachgewiesen werden kann (Menke et al. 2003), stellte sich für uns die Frage, ob es eventuell mehrere verschiedene aktive Promotoren für Stra8 gibt und ob die 1,4kb eventuell spezifisch für die männlichen Keimbahn sind. Aus diesem Grund wurde eine umfassende Promotoranalyse durchgeführt (siehe nächster Abschnitt). Bei der Analyse unserer Stra8-Cre - Maus zeigte sich eine Diskrepanz zu der Arbeit von Sadate-Ngatchou. Mit der von uns verwendeten Reportermaus (R26R) von Soriano (1999) konnten wir eine Cre-Aktivität bereits in frühen Embryonalstadien (siehe nächster Abschnitt) nachweisen. Dies stimmt überein mit der bereits im Vorfeld 
dieser Arbeit untersuchten endogenen Stra8 - Expression. Dies ließ uns vermuten, dass die Verwendung geeigneter Reportermäusen von zentraler Bedeutung sein kann. Nach Rücksprache mit Herrn Adham (Humangenetik) und der AG Kessel (MPI), die ebenfalls Experimente mit unserer Stra8 - Cre - Maus durchgeführt haben, lässt sich zusammenfassend sagen, dass der Stra8 - Promotor sehr wohl in frühen Embryonalstadien aktiv ist, allerdings mit deutlich verminderter Aktivität. Dies führt dazu, dass die Menge an Cre - Rekombinase nicht bei allen Reportermäusen ausreicht, um eine Rekombination zu starten. Da in unserem Experiment der Rosa26 - Locus als Reporter dient, welcher in einem heterochromatinen Bereich auf der DNA lokalisiert ist, vermuten wir, dass die ,Erreichbarkeit' der Zielsequenz ausschlaggebend für eine Wirkung der Cre - Rekombinase ist. Diese Beobachtung konnte ebenfalls von der unabhängigen Arbeitsgruppe um Bao bestätigt werden (Bao et al. 2013).

Für die Detektion einer Cre - Aktivität an unserem Mausmodell (siehe Abb.1 \& Abb.4.1) benutzten wir die einfache Methode der X - Gal - Färbung. Diese Methode erwies sich jedoch wieder erwartend technisch nicht umsetzbar und es konnten keine reproduzierbaren Ergebnisse erzielt werden. Um zu klären, ob sich dieser Unterschied aufgrund eines aktiveren, als dem bisher in der Literatur beschriebenen $1,4 \mathrm{~kb}$ - Promotor ergibt, oder, ob das verwendete Mausmodell mit einem ineffizienten Promotor arbeitet, wurde zunächst eine Promotoranalyse durchgeführt. Die Promotoranalyse ergab eindeutig, dass der bisher verwendete 1,4kb - Promotor der aktivste aller putativen Promotoren ist und somit eine eindeutige Färbung zu erwarten war. Außerdem zeigte neben der Promotoranalyse auch der Nachweis von Stra8 in einer Expressionsanalyse mithilfe der RT - PCR in doppelt transgenen Mäusen in Testes, Herz, Niere und Leber, dass Stra8 in dem verwendeten Mausmodell exprimiert wird. Durch den Nachweis der Expression von Stra8 im Mausmodell war davon auszugehen, dass in diesem Modell mit der X - Gal-Färbung LacZ zumindest in Testes, Herz, Niere und Leber nachzuweisen sein sollte. Anstatt der klassischen X - Gal-Färbung wurde im Rahmen einer Methodenerweiterung ein Antikörper gegen LacZ verwendet und zunächst in der Entwicklungsreihe der Hoden und später auch in allen untersuchten Geweben ubiquitär LacZ nachgewiesen. Aufgrund des ubiquitären Nachweises von LacZ in allen untersuchten Gewebeschnitten der einzelnen Organe durch komplette Blaufärbung ist anzunehmen, dass die Cre - Aktivität unter der Kontrolle des Stra8 - Promotors sehr 
früh in der Embryonalentwicklung nachgewiesen werden kann. Um dies genauer zu untersuchen, wurden 3,5dpc alte Blastozysten, geschlüpfte Blastozysten und 13,5 dpc alte Embryonen mit X - Gal gefärbt. Es zeigte sich eine ubiquitäre LacZ Färbung bereits bei 3,5dpc alten Blastozysten, was eine Erklärung für die komplette Blaufärbung, der aus den Blastozystenzellen stammenden Organen, zulässt.

\subsection{Begründung des Verwerfens der ursprünglichen Hypothese}

Stra8 wurde als testesspezifisches Gen, dessen Expression auf die prämeiotischen Stadien der Spermatogenese beschränkt ist, beschrieben (Oulad-Abdelghani et al. 1996). Das Stra8 - Protein ist im Zytoplasma lokalisiert. Ein weitere Beschreibung der Expression von Stra8 folgte bereits 1999 durch Sapin et al., die zeigen konnten, dass die Stra8 - Expression nicht nur auf den Testes beschränkt ist, sondern auch in so genannten "Giant"-Zellen des Trophoblasten im Embryonalstadium 10,5-15,5 dpc darzustellen ist. Wenige Jahre später zeigte sich in den Arbeiten von Menke et al. (2003) und Zhou et al. (2008a), dass auch Ovarien in verschiedenen Embryonalstadien Stra8 exprimieren. In unserer Arbeitsgruppe konnte Frau Kotzenberg dies bestätigen (Kotzenberg 2010). Sie konnte zeigen, dass im transgenen Mausmodell, welches ebenfalls EGFP unter der Kontrolle eines 1,4kb Stra8 - Promotors exprimiert, Stra8 nicht nur im Ooplasma der Oozyte im Ovar lokalisiert ist, sondern auch post partum nach der Ovulation in unbefruchteten Oozyten. Darüber hinaus ist es nach ihr auch in den Präimplantationsstadien der Embryonalentwicklung auf RNA - und Proteinebene nachweisbar. Diese sehr frühe im Embryonalstadium aktive Stra8 - Expression konnte auch in der vorgelegten Arbeit bestätigt werden.

Über die Bedeutung von Stra8 in der Oogenese ist noch wenig bekannt. In einem Versuch mit homozygoten Stra8 - knockout - Mäusen beider Geschlechter konnten. Baltus et al. (2006) zeigen, dass diese infertil sind. Dies ist auf den Meiosearrest der Keimbahnzellen beider Geschlechter zurückzuführen und weist auf eine wichtige Funktion von Stra8 sowohl in der männlichen als auch in der weiblichen Meiose hin (Anderson et al. 2008). Ein weiterer Hinweis auf die Funktion von Stra8 während der Meiose ergibt sich aus der Arbeit von Nayernia et al. (2004), die die Stra8 Expression zur Gewinnung von männliche Keimzellen aus Teratokarzinomzellen nutzten, und Stra8 wurde als Marker für den Übertritt in die frühe prämeiotische 
Phase genutzt. Es gelang den Autoren, diese Zellen zu isolieren. Diese Arbeit lieferte einen weiteren Beweis für die spezifische Stra8 - Expression in Keimzellen.

Stra8 scheint darüber hinaus noch weitere Funktionen zu haben, welche in Verbindung mit den pluripotenten Eigenschaften von Stammzellen stehen. Denn wie bereits oben erwähnt, konnten Guan et al. (2006) mithilfe des 1,4kb - Stra8 Promotors erfolgreich pluripotente maGScs aus den multipotenten SSCs im Testis gewinnen, die in der Lage waren in alle drei Keimblätter zu differenzieren. Die Aktivität dieses Promotors konnte in der vorliegenden Arbeit durch eine Promotoranalyse ebenfalls bestätigt werden. Dies wirft in der Folge die Frage auf, ob die Expression von Stra8 eventuell einen Einfluss auf das Pluripotenznetzwerk von Zellen hat? Es gibt eine Vielzahl von keimzellspezifischen Genen, die im Zusammenhang mit den pluripotenten Eigenschaften von Zellen stehen. Tabelle 1 zeigt eine Übersicht mehrerer keimzellspezifischer Gene, die in pluripotenten Zellen exprimiert werden. 


\begin{tabular}{|l|l|}
\hline Keimzellspezifische Gene & Referenz \\
\hline Oct4 & (Pesce und Scholer 2001) \\
\hline Nanog & (Chambers et al. 2003) \\
\hline Dppa2 & $\begin{array}{l}\text { (Maldonado-Saldivia et al. } \\
\text { 2007) }\end{array}$ \\
\hline Dppa3 & (Saitou et al. 2002) \\
\hline Dppa4 & $\begin{array}{l}\text { (Maldonado-Saldivia et al. } \\
\text { 2007) }\end{array}$ \\
\hline Ifitm3 & (Saitou et al. 2002) \\
\hline Kit & (Horie et al. 1991) \\
\hline DAZIL & (Clark et al. 2004) \\
\hline Sox2 & (Western et al. 2005) \\
\hline Zfp206 & (Wang et al. 2007a+b) \\
\hline Stra8 & (Xu et al. 2011) \\
\hline
\end{tabular}

Tabelle 1: Auswahl keimzellspezifischer Gene, die in pluripotenten Zellen exprimiert werden (modifiziert nach Kotzenberg 2010)

Auch die Tatsache, dass Stra8 sowohl in embryonalen Stammzellen als auch in maGSCs neben anderen Pluripotenzgenen wie Oct3/4, Nanog, Utf1, Esg1, Rex1 noch nach mehreren Passagen exprimiert wird (Nolte 2008), ist als ein weiterer Hinweis für den Einfluss der Expression von Stra8 auf das Plurioptenznetzwerk von Zellen zu werten. Hingegen verschwand die Stra8 - Expression im gleichen Zug wie die Expression anderer Pluripotenzgene bei der Ausdifferenzierung zu Zellen. In der vorgelegten Arbeit konnte zudem gezeigt werden, dass auch in den frühen Embryonalstadien, in denen die Zellen noch über pluri- bzw. totipotentes Differenzierungspotenial verfügen, Stra8 exprimiert wird. Eine eventuelle regulatorische Funktion im Pluripotenznetzwerk beschreibt die Arbeit von Tedesco et al. (2009), in der gezeigt wird, dass ein Shuttle des Stra8 - Proteins zwischen Zytoplasma und Nukleus vonstattengeht, und dass das Stra8 - Protein nicht nur zytoplasmatisch, sondern auch teilweise intranukleär lokalisiert ist. Diese teils zytoplasmatische und teils nukleäre Lokalistaion konnte in der Dissertationsarbeit von Dr. Nolte (2008) aus unserer Arbeitsgruppe bestätigt werden. Betrachtet man die 
Proteinstruktur von Stra8, die sowohl eine Helix - Loop - Helix - Domäne aufweist als auch eine glutaminreiche Domäne, wodurch Stra8 zwei weitere Aufgaben zu haben scheint. Helix - Loop - Helix (HLH) Domänen sind charakteristisch für Proteine, die an DNA binden können und so als Transkriptionsfaktoren fungieren. Außerdem sind glutaminreiche Domänen charakteristisch für Proteine, die die Transkription anderer Gene durch Protein - Protein - Interaktionen aktivieren können. Tedesco et al. (2009) konnten in diesem Zusammenhang zeigen, dass das Stra8 - Protein in der HLHDomäne ein "nuclear localisation signal" (NLS) aufweist und sich stromabwärts davon drei "nuclear export signals"(NES1-3) befinden, von denen die Funktion von NLS und NES2 durch Tedesco et al. experimentell bestätigt werden konnte. Diese Arbeitsgruppe konnte somit einen aktiven Transport von Stra8 in den Zellkern aufzeigen. Auf diese Weise kann Stra8 an DNA binden, um Transkriptionsprozesse zu aktivieren.

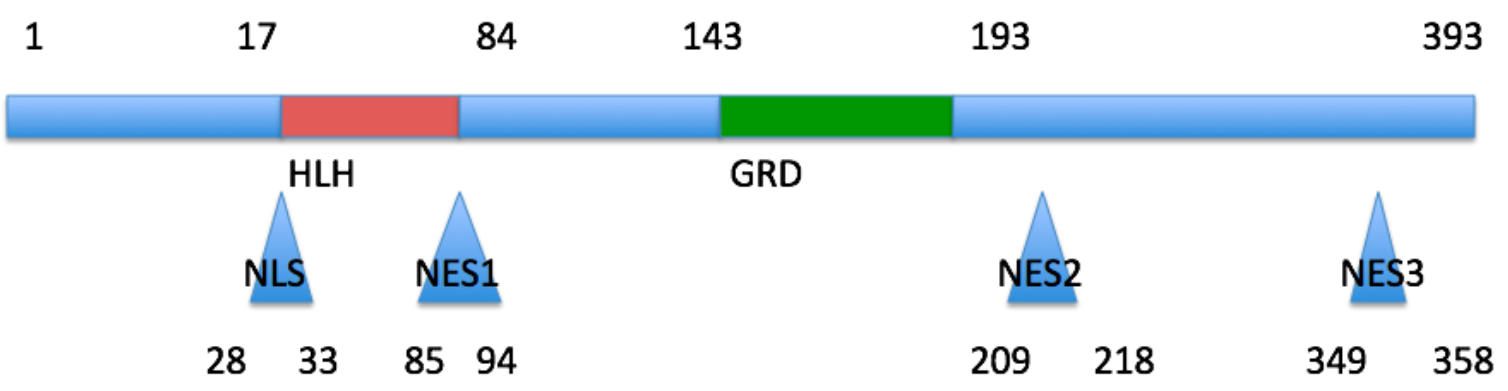

Abb. 37: Struktur des Stra8 Proteins (modifiziert nach Tedesco et al. 2009)

HLH: Helix - Loop - Helix - Domäne

GRD: glutaminreiche Domäne

NLS: nuclear localisation signal

NES: nuclear export singnal

Die wichtigsten bisher bekannten Pluripotenzgene wie Oct4, Sox2 und Nanog sind gleichzeitig auch Transkriptionsfaktoren. So ist die Hypothese naheliegend, dass Stra8 folgende zwei Funktionen haben könnte. Die Helix - Loop - Helix - Domäne weist auf die Aufgabe als Transkriptionsfaktor im Pluripotenznetzwerk hin, da das Protein in pluripotenten Stammzellen überwiegend im Kern lokalisiert ist. Die 
glumtaminreiche Domäne reguliert dagegen den Eintritt der Keimzellen in die Meiose (Baltus et al. 2006), wobei es im Testis nur als zytoplasmatisches Protein detektiert werden kann. Eine Schlüsselfunktion in der Aufrechterhaltung von Pluripotenz wird Stra8 jedoch nicht haben, denn Stra8 - knockout - Mäuse sind infertil, ohne weitere phänotypische Veränderungen (Baltus et al., 2006). Auch konnte Kotzenberg (2010) in ihrer Arbeit durch Blastozysteninjektion mit Stra8 positiven ES - Zellen im Vergleich mit einer Mischpopulation von Stra8 - positiven und negativen ES - Zellen kein eindeutiges Ergebnis hinsichtlich einer Beteiligung der Stra8 - negativen ES Zellen an der Chimärenbildung erreichen.

Um die Funktion von Stra8 in pluripotenten Zellen weiter zu untersuchen, wurde in unserer Arbeitsgruppe ein Stra8 - knockdown mittels synthetisch hergestellter siRNA in ES-Zellen durchgeführt. Als Reaktion hierauf zeigte sich in der Expressionsanalyse eine Hochregulation der Pluripotenzgene Nanog, Oct3/4, Klf4 und Zfp206. Gleichzeitig wurden Markergene für Zelldifferenzierung geringer exprimiert. Um den Einfluss einer Stra8 - Überexpression auf das Pluripotenznetzwerk zu untersuchen, wurden in unserer Arbeitsgruppe zwei Vektoren konstruiert. Im Kontrollvektor wird EGFP unter der Kontrolle des humanen Elongation - Faktor 1 alpha - Promotors (hEF1 alpha-EGFP) exprimiert, im Versuchsvektor hingegen wird anstatt EGFP Stra8 unter demselben Promotor (hEF1 alpha-Stra8) exprimiert. Diese beiden Vektoren wurden stabil in ES - RI - Zellen transfiziert und der Effekt mittels qRT-PCR analysiert. Die Stra8 - Überexpression resultierte in einer signifikanten Herunterregulation von Pluripotenzmarkern. Gleichzeitig konnte man eine signifikante Hochregulation der mesodermalen Differenzierungsmarker Vimentin und Eomesodermin verzeichnen. Dies deutet auf eine gerichtete mesodermale Differenzierung von ES - Zellen bei einer Überexpression von Stra8 hin.

So scheint die Stra8 - Expression eher Einfluss auf die Differenzierungsoption von pluripotenten Zellen zu haben als eine Schlüsselfunktion im Pluripotenznetzwerk zu besitzen.

\subsection{Lösungsmöglichkeit der Fragestellung}

In der vorliegenden Arbeit sollte mit Hilfe eines Mausmodells die Hypothese überprüft werden, dass spermatogoniale Stammzellen als Vorläufer für andere Zelltypen fungieren können, z.B. für Kardiomyozyten. Aufgrund der Ergebnisse, die zeigen, dass Stra8 nicht nur in pluripotenten und spermatogonialen Stammzellen exprimiert 
ist, sondern bereits in der ICM von Blastozysten, ist das hier verwendete Mausmodell nicht geeignet, um die Fragestellung zu beantworten. Um eine definitive Aussage machen zu können, müsste eine transgene Maus entsprechend der Stra8 - Cre Maus generiert werden, die statt des Stra8 - Promotors einen SSC - spezifischen Promotor beinhaltet. Bis dato ist allerdings kein Marker - Gen bekannt, dessen Expression ausschließlich in den SSCs detektierbar ist. Somit kann die Fragestellung nach dem derzeitigen Stand der Forschung nicht abschließend geklärt werden. 


\section{LITERATURVERZEICHNIS}

Adham IM, Nayernia K, Engel W (1997). Spermatozoa lacking acrosin protein show delayed fertilization. Mol Reprod Dev $\underline{46}(3):$ 370-376.

Altschul SF, Gish W, Miller W, Myers E W, Lipman DJ (1990). Basic local alignment search tool. J Mol Biol 215(3): 403-10.

Anderson EL, Baltus A E, Roepers-Gajadien HL, Hassold TJ, de Rooij D G, Pelt AM van, Page D C (2008). Stra8 and its inducer, retinoic acid, regulate meiotic initiation in both spermatogenesis and oogenesis in mice. Proc Natl Acad Sci U S A 105(39): 14976-80.

Anderson LD und Hirshfield AN (1992). An overview of follicular development in the ovary: from embryo to the fertilized ovum in vitro. Md Med J $\underline{41}$ (7): 614-20.

Baltus AE, Menke DB, Hu YC, Goodheart ML, Carpenter AE, de Rooij DG, Page DC (2006). In germ cells of mouse embryonic ovaries, the decision to enter meiosis precedes premeiotic DNA replication. Nat Genet 38(12): 1430-4.

Bao J, Ma HY, Schuster A, Lin YM, Yan W (2013). Incomplete cre - mediated excision leads to phenotypic differences between Stra8 - iCre; Mov10l1(lox/lox) and Stra8 - iCre; Mov1011(lox/Delta) mice. Genesis 51(7): 481-90.

Beltrami AP, Barlucchi L, Torella D, Baker M, Limana F, Chimenti S, Kasahara H, Rota M, Musso E, Urbanek K, Leri A, Kajstura J, Nadal-Ginard B, Anversa P (2003). Adult cardiac stem cells are multipotent and support myocardial regeneration. Cell 114(6): 763-76.

Birnboim HC, Doly J (1979). A rapid alkaline extraction procedure for screening recombinant plasmid DNA. Nucleic Acids Res $\underline{7}(6)$ : 1513-23. 
Borum K (1961). Oogenesis in the mouse. A study of the meiotic prophase. Exp Cell Res 24: 495-507.

Bouillet P, Chazaud C, Oulad - Abdelghani M, Dolle P und Chambon P (1995). Sequence and expression pattern of the Stra7 (Gbx-2) homeobox-containing gene induced by retinoic acid in P19 embryonal carcinoma cells. Dev Dyn 204(4): 372-82.

Chambers I, Colby D, Robertson M, Nichols J, Lee S, Tweedie S, Smith A. (2003). Functional expression cloning of Nanog, a pluripotency sustaining factor in embryonic stem cells. Cell 113(5): 643-55.

Cheng I F, Kaiser D, Huebscher D, Hasenfuss G, Guan K und Schafer K (2012). Differentiation of multipotent adult germline stem cells derived from mouse testis into functional endothelial cells. J Vasc Res 49(3): 207-20.

Chien A, Edgar DB, Trela JM (1976). Deoxyribonucleic acid polymerase from the extreme thermophile Thermus aquaticus. J Bacteriol 127(3): 1550-7.

Clark AT, Bodnar MS, Fox M, Rodriquez RT, Abeyta MJ, Firpo MT, Pera RA (2004). Spontaneous differentiation of germ cells from human embryonic stem cells in vitro. Hum Mol Genet 13 (7): 727-39.

Clark JM (1988). Novel non-templated nucleotide addition reactions catalyzed by procaryotic and eucaryotic DNA polymerases. Nucleic Acids Res 16(20): 9677-86.

Crosby HA, Strain AJ (2001). Adult liver stem cells: bone marrow, blood, or liver derived? Gut $\underline{48}(2):$ 153-4.

Friedrich G, Soriano P (1991). Promoter traps in embryonic stem cells: a genetic screen to identify and mutate developmental genes in mice. Genes Dev $\underline{5}(9)$ : 151323. 
Gage FH (2000). Mammalian neural stem cells. Science 287(5457): 1433-8.

Giuili G, Tomljenovic A, Labrecque N, Oulad-Abdelghani M, Rassoulzadegan M, Cuzin F (2002). Murine spermatogonial stem cells: targeted transgene expression and purification in an active state. EMBO Rep $\underline{3}(8): 753-9$.

Green SH, Zuckerman S (1951). The number of oocytes in the mature rhesus monkey (Macaca mulatta). J Endocrinol Z(2): 194-202.

Guan K, Hasenfuss G (2007). Do stem cells in the heart truly differentiate into cardiomyocytes? J Mol Cell Cardiol 43 (4): 377-87.

Guan K, Nayernia K, Maier LS, Wagner S, Dressel R, Lee JH, Nolte J, Wolf F, Li M, Engel W, Hasenfuss $\mathbf{G}$ (2006). Pluripotency of spermatogonial stem cells from adult mouse testis. Nature $\underline{440}(7088): 1199-203$.

Hanahan D (1983). Studies on transformation of Escherichia coli with plasmids. J Mol Biol 166(4): 557-80.

Horie K, Takakura K, Taii S, Narimoto K, Noda Y, Nishikawa S, Nakayama N, Fujita J, Mori T (1991). The expression of c-kit protein during oogenesis and early embryonic development. Biol Reprod 45(4): 547-52.

Jaroszynski L (2005). Expression and function analysis of Tex18 and Stra8 genes in male germ cells. Math.-Naturwiss. Diss. Göttingen

Joannides A, Gaughwin P, Schwiening C, Majed H, Sterling J, Compston A, Chandran $S$ (2004). Efficient generation of neural precursors from adult human skin:

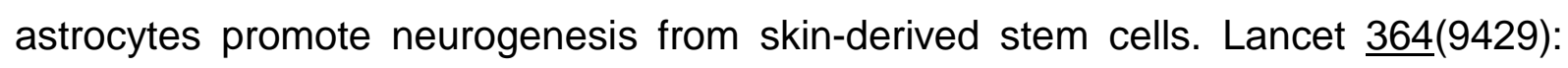
$172-8$. 
Johnson J, Bagley J, Skaznik-Wikiel M, Lee HJ, Adams GB, Niikura Y, Tschudy KS, Tilly JC, Cortes ML, Forkert R, Spitzer T, lacomini J, Scadden DT, Tilly JL (2005). Oocyte generation in adult mammalian ovaries by putative germ cells in bone marrow and peripheral blood. Cell 122(2): 303-15.

Johnson J, Canning J, Kaneko T, Pru JT, Tilly JL (2004). Germline stem cells and follicular renewal in the postnatal mammalian ovary. Nature $\underline{428}(6979)$ : 145-50.

Kanatsu-Shinohara M, Inoue K, Lee J, Yoshimoto M, Ogonuki N, Miki H, Baba S, Kato T, Kazuki Y, Toyokuni S, Toyoshima M, Niwa O, Oshimura M, Heike T, Nakahata T, Ishino F, Ogura A, Shinohara T (2004). Generation of pluripotent stem cells from neonatal mouse testis. Cell 119(7): 1001-12.

Kotzenberg L (2010). Zur Rolle von Stra8 in pluripotenten Stammzellen. Med. Diss. Göttingen

Kruse C, Kajahn J, Petschnik AE, Maass A, Klink E, Rapoport DH, Wedel T (2006). Adult pancreatic stem/progenitor cells spontaneously differentiate in vitro into multiple cell lineages and form teratoma-like structures. Ann Anat 188(6): 503-17.

Laird PW, Zijderveld A, Linders K, Rudnicki MA, Jaenisch R, Berns A (1991). Simplified mammalian DNA isolation procedure. Nucleic Acids Res 19 (15): 4293.

Maldonado-Saldivia J, van den Bergen J, Krouskos M, Gilchrist M, Lee C, Li R, Sinclair AH, Surani MA und Western PS (2007). Dppa2 and Dppa4 are closely linked SAP motif genes restricted to pluripotent cells and the germ line. Stem Cells $\underline{25}(1): 19-28$.

Martin GR, Evans MJ (1975). Differentiation of clonal lines of teratocarcinoma cells: formation of embryoid bodies in vitro. Proc Natl Acad Sci U S A 72(4): 1441-5.

Matsui Y, Zsebo K, Hogan BL (1992). Derivation of pluripotential embryonic stem cells from murine primordial germ cells in culture. Cell $\underline{70}(5): 841-7$. 
McLaren A (1984). Meiosis and differentiation of mouse germ cells. Symp Soc Exp Biol 38: 7-23.

Menke DB, Koubova J, Page DC (2003). Sexual differentiation of germ cells in XX mouse gonads occurs in an anterior-to-posterior wave. Dev Biol 262(2): 303-12.

Murray CJ, Lopez AD (1997). Mortality by cause for eight regions of the world: Global Burden of Disease Study. Lancet 349(9061): 1269-76.

Nagy A, Rossant J, Nagy R, Abramow-Newerly W, Roder JC (1993). Derivation of completely cell culture-derived mice from early-passage embryonic stem cells. Proc Natl Acad Sci U S A g0 (18): 8424-8.

Nayernia K, Li M, Jaroszynski L, Khusainov R, Wulf G, Schwandt I, Korabiowska M, Michelmann HW, Meinhardt A, Engel W (2004). Stem cell based therapeutical approach of male infertility by teratocarcinoma derived germ cells. Hum Mol Genet 13(14): 1451-60.

Nolte J (2008). Zur Pluripotenz spermatogonialer Stammzellen. Math. Naturwiss. Diss. Göttingen

Oulad-Abdelghani M, Bouillet P, Decimo D, Gansmuller A, Heyberger S, Dolle P, Bronner S, Lutz Y, Chambon P (1996). Characterization of a premeiotic germ cellspecific cytoplasmic protein encoded by Stra8, a novel retinoic acid-responsive gene. J Cell Biol 135(2): 469-77.

Pesce M, Scholer HR (2001). Oct-4: gatekeeper in the beginnings of mammalian development. Stem Cells 19(4): 271-8.

Peters H (1970). Migration of gonocytes into the mammalian gonad and their differentiation. Philos Trans R Soc Lond B Biol Sci 259(828): 91-101. 
Resnick JL, Ortiz M, Keller JR, Donovan PJ (1998). Role of fibroblast growth factors and their receptors in mouse primordial germ cell growth. Biol Reprod $\underline{59}(5)$ : 1224-9.

Sadate-Ngatchou PI, Payne CJ, Dearth AT, Braun RE (2008). Cre recombinase activity specific to postnatal, premeiotic male germ cells in transgenic mice. Genesis 46 (12): 738-42.

Saiki RK, Gelfand DH, Stoffel S, Scharf SJ, Higuchi R, Horn GT, Mullis KB, Erlich HA (1988). Primer-directed enzymatic amplification of DNA with a thermostable DNA polymerase. Science 239(4839): 487-91.

Saitou M, Barton SC, Surani MA (2002). A molecular programme for the specification of germ cell fate in mice. Nature $\underline{418}(6895)$ : 293-300.

Sambrook J, Fritsch EF, Maniatis T: Molecular cloning: A Laboratorial manual. 2. Auflage; Cold Spring Harbour Laboratory Press, Cold Spring Harbour N.Y. 1989

Sanger F, Nicklen S, Coulson AR (1977). DNA sequencing with chain-terminating inhibitors. Proc Natl Acad Sci U S A 74 (12): 5463-7.

Sans S, Kesteloot H, Kromhout D (1997). The burden of cardiovascular diseases mortality in Europe. Task Force of the European Society of Cardiology on Cardiovascular Mortality and Morbidity Statistics in Europe. Eur Heart J 18(12): 123148.

Smith AG, Heath JK, Donaldson DD, Wong GG, Moreau J, Stahl M, Rogers D (1988). Inhibition of pluripotential embryonic stem cell differentiation by purified polypeptides. Nature $\underline{336}(6200):$ 688-90.

Soriano P (1999). Generalized lacZ expression with the ROSA26 Cre reporter strain. Nat Genet 21 (1): 70-1. 
Streckfuss-Bomeke K, Vlasov A, Hulsmann S, Yin D, Nayernia K, Engel W, Hasenfuss G, Guan K (2009). Generation of functional neurons and glia from multipotent adult mouse germ-line stem cells. Stem Cell Res $\underline{2}(2): 139-54$.

Tedesco M, La Sala G, Barbagallo F, De Felici M, Farini D (2009). STRA8 shuttles between nucleus and cytoplasm and displays transcriptional activity. J Biol Chem 284(51): 35781-93.

Tegelenbosch RA, de Rooij DG (1993). A quantitative study of spermatogonial multiplication and stem cell renewal in the $\mathrm{C} 3 \mathrm{H} / 101 \mathrm{~F} 1$ hybrid mouse. Mutat Res 290(2): 193-200.

Wang Z X, Kueh JL, Teh CH, Rossbach M, Lim L, Li P, Wong KY, Lufkin T, Robson P, Stanton LW (2007a). Zfp206 is a transcription factor that controls pluripotency of embryonic stem cells. Stem Cells $\underline{25}(9): 2173-82$.

Wang ZX, Teh CH, Kueh JL, Lufkin T, Robson P, Stanton LW (2007b). Oct4 and Sox2 directly regulate expression of another pluripotency transcription factor, Zfp206, in embryonic stem cells. J Biol Chem 282(17): 12822-30.

Ware LM, Axelrad AA (1972). Inherited resistance to $\mathrm{N}$ - and B-tropic murine leukemia viruses in vitro: evidence that congenic mouse strains SIM and SIM.R differ at the Fv-1 locus. Virology 50(2): 339-48.

Western P, Maldonado-Saldivia J, van den Bergen J, Hajkova P, Saitou M, Barton S and Surani MA (2005). Analysis of Esg1 expression in pluripotent cells and the germline reveals similarities with Oct4 and Sox2 and differences between human pluripotent cell lines. Stem Cells $\underline{23}(10):$ 1436-42. 
Xu X, Pantakani DV, Luhrig S, Tan X, Khromov T, Nolte J, Dressel R, Zechner U, Engel W (2011). Stage-specific germ-cell marker genes are expressed in all mouse pluripotent cell types and emerge early during induced pluripotency. PLoS One $\underline{6}(7)$ : e22413.

Zambrowicz BP, Imamoto A, Fiering S, Herzenberg LA, Kerr WG, Soriano P (1997). Disruption of overlapping transcripts in the ROSA beta geo 26 gene trap strain leads to widespread expression of beta-galactosidase in mouse embryos and hematopoietic cells. Proc Natl Acad Sci U S A 94(8): 3789-94.

Zhou Q, Li Y, Nie R, Friel P, Mitchell D, Evanoff RM, Pouchnik D, Banasik B, McCarrey JR, Small C, Griswold MD (2008a). Expression of stimulated by retinoic acid gene 8 (Stra8) and maturation of murine gonocytes and spermatogonia induced by retinoic acid in vitro. Biol Reprod 78 (3): 537-45.

Zhou Q, Nie R, Li Y, Friel P, Mitchell D, Hess RA, Small C, Griswold MD (2008b). Expression of stimulated by retinoic acid gene 8 (Stra8) in spermatogenic cells induced by retinoic acid: an in vivo study in vitamin A-sufficient postnatal murine testes. Biol Reprod 79(1): 35-42. 


\section{DANKSAGUNG}

An dieser Stelle bedanke ich mich bei Herrn Prof. Dr. Dr. h.c. W. Engel für die Bereitschaft, diese Arbeit zu betreuen. Vielen Dank für die intensive Betreuung, die vielen Anregungen und die Unterstützung bei dieser Arbeit und bei der Fortführung meines Studiums.

Ein besonderer Dank gilt auch Frau Dr. J. Nolte für die Bereitstellung des Themas, für die vielen geduldigen Anregungen, ihre umfassende Unterstützung bei der Versuchsplanung und - durchführung und die gute Zusammenarbeit, die immer wieder zu meiner Motivation und zum Gelingen dieser Arbeit beigetragen hat.

Mein Dank gilt auch den Kollegen aus dem Labor 107 \& 105 für die gute Zusammenarbeit und die gute und ungezwungene Atmosphäre. Besonders bedanke ich mich bei den beiden TAs Frau Ullrich und Frau Fey die mir immer hilfsbereit zur Seite standen.

Ich bedanke mich natürlich auch bei allen anderen Mitarbeitern des Instituts für Humangenetik, besonders dem Team der AG Hahn und den Mitarbeitern des Tierstalls. 
